\title{
Getting past the gates: \\ the new economics of Canadian broadcasting
}

by

\author{
Jim Patrick
}

\author{
A thesis submitted to the \\ Faculty of Graduate Studies \\ in partial fulfillment of \\ the requirements for the degree of \\ Master of Arts, Mass Communication \\ Carleton University \\ Ottawa, Ontario \\ (C) 2006
}




$\begin{array}{ll}\begin{array}{l}\text { Library and } \\ \text { Archives Canada }\end{array} & \begin{array}{l}\text { Bibliothèque et } \\ \text { Archives Canada }\end{array} \\ \begin{array}{l}\text { Published Heritage } \\ \text { Branch }\end{array} & \begin{array}{l}\text { Direction du } \\ \text { Patrimoine de l'édition }\end{array} \\ \begin{array}{l}\text { 395 Wellington Street } \\ \text { Ottawa ON K1A 0N4 } \\ \text { Canada }\end{array} & \begin{array}{l}\text { 395, rue Wellington } \\ \text { Ottawa ON K1A ON4 } \\ \text { Canada }\end{array}\end{array}$

Your file Votre référence ISBN: 978-0-494-16437-2 Our file Notre référence ISBN: 978-0-494-16437-2

NOTICE:

The author has granted a nonexclusive license allowing Library and Archives Canada to reproduce, publish, archive, preserve, conserve, communicate to the public by telecommunication or on the Internet, loan, distribute and sell theses worldwide, for commercial or noncommercial purposes, in microform, paper, electronic and/or any other formats.

The author retains copyright ownership and moral rights in this thesis. Neither the thesis nor substantial extracts from it may be printed or otherwise reproduced without the author's permission.
AVIS:

L'auteur a accordé une licence non exclusive permettant à la Bibliothèque et Archives Canada de reproduire, publier, archiver, sauvegarder, conserver, transmettre au public par télécommunication ou par l'Internet, prêter, distribuer et vendre des thèses partout dans le monde, à des fins commerciales ou autres, sur support microforme, papier, électronique et/ou autres formats.

L'auteur conserve la propriété du droit d'auteur et des droits moraux qui protège cette thèse. $\mathrm{Ni}$ la thèse ni des extraits substantiels de celle-ci ne doivent être imprimés ou autrement reproduits sans son autorisation.
In compliance with the Canadian

Privacy Act some supporting forms may have been removed from this thesis.

While these forms may be included in the document page count, their removal does not represent any loss of content from the thesis.
Conformément à la loi canadienne sur la protection de la vie privée, quelques formulaires secondaires ont été enlevés de cette thèse.

Bien que ces formulaires aient inclus dans la pagination, il n'y aura aucun contenu manquant.

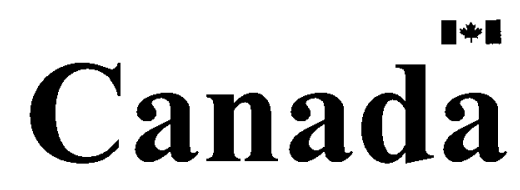




\begin{abstract}
This study tests conventional wisdom about why we regulate broadcasting in Canada. It is generally assumed that because economies of scale benefit American producers, content-based regulation is necessary, because Canadian content is beneficial in ways that American content is not. This assumption makes two unrelated claims: one economic, one cultural. Either could be true without the other being so. It is true that American producers enjoy natural economic advantages over Canadian producers, but that has no bearing on the 'national character' of the content. At the same time, it cannot be reasonably claimed that a producer's birthplace has any automatic bearing on the 'values' embodied in his or her work. Our current framework needs to be updated to separate the economic rationale from the cultural, and to reflect the open communications environment developing around it.
\end{abstract}




\section{Acknowledgements}

My thanks to Ross Eamon, Michael Dorland, Charlene Elliot, Allan Clarke and Andrew Cardozo, whose classes shaped the approach and subject matter of this thesis. And of course to Paul Attallah, who advised and challenged me every step of the way.

My thanks to Jason Bristow and Ken Goldstein, frequent and trusted sounding boards. Also to my friends and colleagues at the Canadian Association of Broadcasters, an endless supply of advice and expertise.

My thanks to friends and family for putting up with me while I researched this thesis, and especially to Natalie, who put up with me while I wrote it. 


\section{Table of contents}

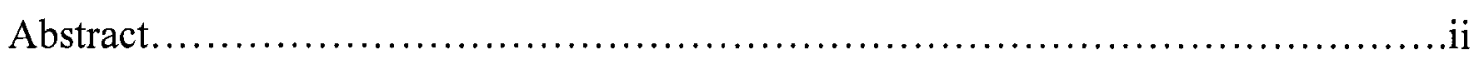

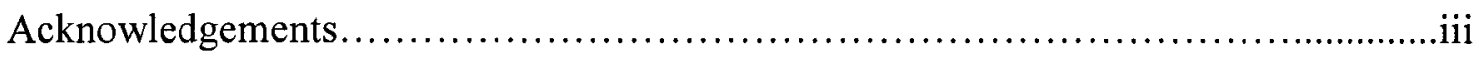

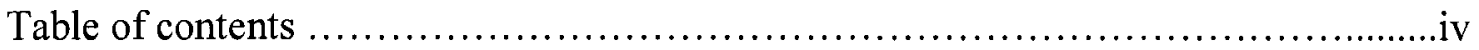

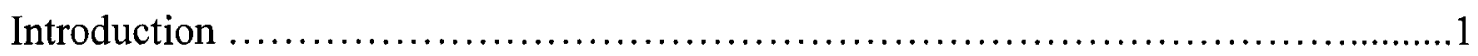

\section{PART ONE}

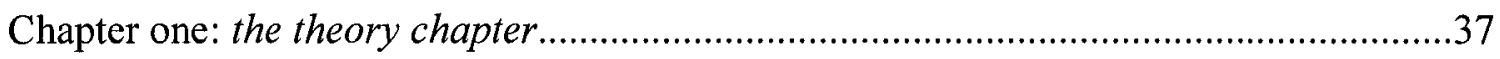

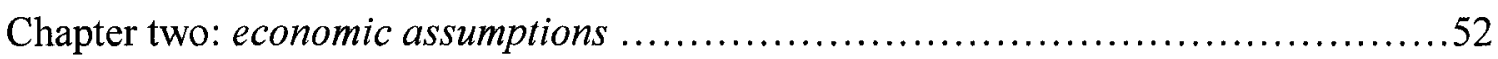

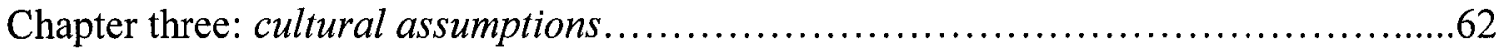

\section{PART TWO}

Chapter four: the history of policy chapter...................................... 81

Chapter five: the new economics of broadcasting ................................ 122

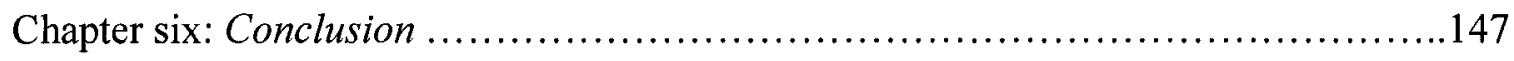

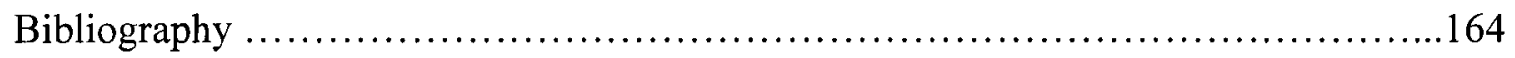




\section{Introduction}

"With our relatively small population thinly dispersed over a vast land mass, and with a globally dominant culture and economy located immediately south of the border, we look to broadcasting and telecommunications to help make Canada whole -in both a societal and economic sense."

\section{Charles Dalfen, Chair, CRTC 2004'}

We are dealing with an old story rather than a new one ... the talk of a communications revolution and exalted hopes and equally exaggerated fears of the media, are repetitions so predictable as to suggest undeviating corridors of thought.

$$
\text { James Carey }^{2}
$$

Imagine broadcasting in Canada as a wide open plain, dominated by a walled fortress. Broadcast programming is produced on one side of the plain, the audience lives on the other. In the early days of regulated broadcasting, there were very few roads the broadcaster could use to get to the audience, and they all ran straight through the fortress.

This made it easy to regulate the traffic between broadcasters and audiences: all goods moving through the policy gates were bought and sold at regulated prices, in regulated packages. Market access, advertising, and the nationality of content and its creators

\footnotetext{
${ }^{1}$ Chair of the CRTC, in a speech to the Canadian Association of Broadcasters annual convention, Ottawa, November 29, 2004.

${ }^{2}$ From Communication and Culture: Essays on Media and Society. New York: Routledge.
} 
were all strictly controlled. Because all broadcasting traffic was considered to use a public throughway, tolls were exacted in the form of fees and quotas.

Some traffic predated those walls, and simply bypassed them: over the air signals from border stations in the United States have always avoided our various customs and tariffs. Maintenance of the walls was made vastly easier by the invention of cable, which as a closed system, presented obvious places to install gates and tolls. Whenever a new technology has made it easier for programming to bypass our policy space, we have responded by attempting to push the walls outward, capturing as much of the new commerce as possible, directing the traffic along predetermined routes, in accordance with various political priorities.

Today, there are plenty of ways to move content from one side of the plain to the other without passing through those gates. Wireless technologies are making it increasingly difficult to limit the transmission of a signal to a particular user, device, timeframe, or location. Broadcasting is moving increasingly to private networks, and away from publicly-owned airwaves, at least in the sense we have always understood them. Programming used to be transmitted in bulk, passing through the fortress and its regulations, to large audiences who generally consumed it all at once, on the same device.

Arguably, the household VCR was the first time-shifting device. It allowed any programming to be stored, reused, shared, or rented, thereby removing its distribution and 
consumption from the standard channels which had previously existed. Audio-visual content was rarely portable however, as it was generally limited to the home, or in the case of radio, to the car stereo. The Sony Walkman was an early example of content beginning to become portable as it moved away from the home and towards the person. Audiences were beginning to be more active in their choices, although the commerce of the commercial communications industry was still largely concentrated on serving a passive consumer.

The new commerce of communications is video-on-demand (VOD), digital video recorders (DVRs), pocket satellite radio receivers, and episodes of hit prime-time drama on your iPod. It is the $3 \%$ of video-enabled mobile phones that were sold in 2005 , and the $90 \%$ that will be sold in 2008 . $^{3}$ We no longer have to call the house and talk to whoever happens to answer. Now we can call the person. We no longer have to radiate signals 'to whom it may concern'. We can send them directly to the pocket or the earphone, without ever passing through a regulated system. The audience is no longer restricted to mass consumption, and preaching to mass audiences is becoming a thing of the past. Audiovisual content is becoming increasingly customized. The audience is no longer passive, but active in the selection, arrangement and production of content. 'Commercial' communication is no longer 'mass' communication but 'private' or 'individualized' or 'personalized' communication. This is true not just at the level of consumption, but also at the level of control over distribution: content can be generally

\footnotetext{
${ }^{3}$ Mobile phone numbers from QuickPlay Media. Cited in Davidson, S. "Mobile biz gets moving," Playback, January 23, 2006, 1.
} 
consumed anytime, anywhere. Control over manufacturing is becoming the domain of the person, rather than the institution.

Because most of this is occurring on privately owned networks, less and less broadcasting traffic is passing through the public policy space. Soon, the volume of traffic that bypasses the gated space will outstrip the amount that passes through it. This means we need to take a serious look at our reasons for maintaining those walls - why do we do it? What benefit does it bring? Unfortunately, this type of first-principle question typically takes a back seat to how do we do it?

If our broadcasting policy is to have any relevancy in the modern communications marketplace, we have to pay serious attention to all the new ways content is moving across the plain, directly from producer to audience, and (within the audience) from person to person. Unfortunately, we continue to devote nearly all of our regulatory energy to what is happening inside the walls.

The more traffic that bypasses our gates, the weaker the rationale for maintaining them becomes. That rationale has long reflected the notion that a small of amount of broadcasting traffic travels on narrow, publicly-owned roads to a large audience. It further assumes that the audience consumes the same traffic at the same time, and especially, that they come to share the 'unique Canadian ideals and opinions' it embodies or conveys. 
That economic and cultural reasoning no longer applies - mainly because of engineering advances that have increased the capacity of private roads and the speed of the broadcasting traffic, but also because of advances in how audiences engage with audiovisual programming.

If the old economics of broadcasting were about abundant audiences and scarce spectrum, the new economics are about the reverse. Unfortunately, most of our rules and regulations, and the reasons we think we need to have them, are still predicated on the old economics.

Much of the tension between recent developments in the marketplace and the objectives of the Broadcasting Act can be understood by considering the distinction between the economic and political objectives at work in our broadcasting policy. Donald Ellis observes that "even if new technologies have liberating potential, they are dependent on access to significant resources and must develop without upsetting the established order or status quo ... (there are) two opposing perspectives on all modern forms of media ... the economic and the political." (1999, 63-64)

The political 'objectives' of Canadian broadcasting policy are usually expressed as a series of economic and cultural arguments: first, we need a highly regulated system because without it, the strength of the American market would squeeze our broadcasters out of business. Second, the corresponding decline in Canadian content would then weaken our 'cultural sovereignty' in the face of the powerful Hollywood content 
machine. As a political goal, 'cultural sovereignty' is more about protecting jurisdiction than identity: it is more about preserving our ability to protect our culture, than it is about actually protecting it. As a 'cultural' goal, it is more about protecting market share than distinct values. It is about maintaining, for as long as possible, regulations that supposedly counterbalance American economies of scale. However, the political and cultural goals of our broadcasting policy have little, if anything, to do with 'Canadian culture', which for all intents and purposes, remains vaguely defined, at best, in official circles.

This thesis examines the 'cultural sovereignty' argument, on both cultural and economic grounds. It examines the supposition that exposure to Canadian content is somehow beneficial, while exposure to foreign programming is somehow detrimental. It also examines the supposition that economies of scale would automatically drive Canadian broadcasting out of business. In current broadcasting policy, these two ideas are inextricably linked. I will argue that they need not be. The cultural argument behind our broadcasting policy could hold true independent of the economic argument: the benefits of domestic content bear no relation to the circumstances of their production.

It is true that economies of scale give American broadcasters a natural advantage over Canadian broadcasters. But that advantage would hold true even if Hollywood began, for some reason, to produce nothing but Canadian content. The economic argument is not tied to the type of content being produced. It is tied to who does the producing. 
The linchpin assumption is that the nationality of the creator and distributor has a cultural impact on the content, whatever the conditions in which it is produced. Little official effort has ever been made to verify that assumption, or even to provide specific examples of circumstances under which it might or might not be true.

We assume some types of foreign content, such as soap operas, are harmful to our national identity, while other types, such as opera, are not. We decide that certain foreign television stations, such as CNN and Fox News, should be allowed to compete in similar formats with their Canadian counterparts, while others, such as HBO and ESPN, should not. This is because our broadcasting policy is more about protecting a distinct market for Canadian programming rights than a distinctive Canadian culture. Little policy energy has ever been spent demonstrating the connection between the two.

The cultural and economic arguments that support our policy walls do not logically relate, but are frequently linked to buttress each other-economies of scale exacerbate the negative effects of American content, or so the argument goes. But if privileged American content is truly harmful, then why do not we have regulations in other content industries? American producers of magazines, newspapers, movies, board games and opera also benefit from the sheer size of their domestic marketplace, but we do not limit their access to our market. This is a glaring inconsistency that completely undermines our walled policy space - if we must have a restricted broadcasting market to compensate for American economic advantage, then why do not have a restricted 
publishing marketplace? A regulated performing arts marketplace? Our cultural policy supposes, without justification, that some content is more harmful than others.

So, while the economic argument is true, only in broadcasting does a cultural argument piggyback on it. As more and more content gets past our broadcasting policy walls, it is time for regulators to get past the notion of a gated space as necessary for 'preservation of our Canadian identity', to separate the cultural and economic arguments, and to determine which, if any, are relevant in a modern context.

At a physical level, there is nothing terribly complicated about broadcasting. A signal is translated into a set of electromagnetic waves, sent from a transmitter along a wire or to an antenna, and then reconverted by a decoder back into an audible or visible signal. At a symbolic level, we invest all sorts of responsibility in this transfer of signals, not the least of which is creating and maintaining Canada's national identity and 'cultural sovereignty'. It could be argued that other media have just as much symbolic power as television or radio, but only onto broadcasting have we grafted a set of official expectations that surpasses mere physics, and borders on faith.

Over the past eight decades we have developed a highly regulated broadcasting system whose main duty, we are often reminded, is to give us a distinctive Canadian identity. However, the way we regulate the system has essentially the opposite effect. It makes us more dependent on the United States-or more accurately, contributes to our interdependence. It also greatly underestimates the determination of audiences to freely 
choose the terms and timing of the content they consume, and to develop ideals and opinions for themselves.

Our current regulatory system is a collection of rules that privilege Canadian broadcasters over American broadcasters, by setting the terms and conditions by which producers, broadcasters, advertisers, distributors and audiences do business with each other. It determines what programming consumers can consume, in which quantities, in which combinations, at what price. It assumes that American content is not only cheaper than Canadian content, but more popular as well, and that it must therefore be handicapped in some way.

By restricting and channelling American broadcasters' access to Canadian audiences, these rules are designed to preserve a distinctive market for Canadian programming rights. The theory is that Canadian broadcasters have to sell advertising on popular, profitable American programs to help pay for the unpopular, unprofitable Canadian programs they are required to carry. It further assumes that when sold together, popular American networks will help sell packages of unpopular Canadian networks. In this sense, under our current framework, we rely on American programming to help pay for Canadian programming.

Because we use American content to subsidize Canadian content, each new Canadian television and radio station actually increases the supply of American content in Canada. So we create Canadian content quotas, on the assumption that Canadian audiences will 
naturally prefer American content -which is in itself difficult to rationalize, considering that American content is assumed to convey values that clash with our own distinct Canadian values. The cultural policy reasoning is that content reflects the national values of its creator. Why, then, are we, as Canadians, so drawn to American content?

The effect of Canadian content quotas is to increase the amount of programming that audiences least prefer. Like some type of cultural cod liver oil, we may not like Canadian content, but apparently it is good for us. But with more communications technology and programming at our disposal than ever before, the power of Canadian content to immunize us from American values is seriously in question. Nevertheless, we continue to invest our official hopes for a distinctive national character in sitcoms, soap operas and pop music that are generally most successful when they look and sound as American as possible.

Our current regulatory framework is anchored by the 1991 Broadcasting Act. This decrees that the broadcasting system shall be run by Canadians, and be primarily about producing Canadian content. It requires broadcasters to be "responsible," which is not surprising, since it entrusts them with the "cultural, political, social and economic" life of the nation (and, if they still have time, with "enlightening, informing and entertaining" Canadians).

All told, the 1991 Broadcasting Act has 34 separate legislative objectives, many of which could more properly be described as ideals. It is the latest draft of an ambitious and 
immeasurable agenda that has put up a stubborn resistance to technological and economic change over the past 80 years. These ideals provide the spiritual guidance for specific rules and regulations designed, in theory, to preserve a distinct Canadian culture, and in practice, to maintain a distinct Canadian market for programming rights. However, the open communications environment that makes it increasingly easy to circumvent the policy gates resists conventional wisdom about how and why we need to regulate the broadcasting system.

As our broadcasting policy grows increasingly removed from the ways in which we actually enlighten, inform and entertain ourselves, there needs to be a tightening of interest around the question of what exactly that policy is meant to achieve in the modern context, and whether or not it is actually achieving it. Most recent government studies on broadcasting conclude that our current way of regulation is under threat, before concluding that the government must therefore increase its capacity to regulate. The exercise of regulation within the gated policy environment has become and end unto itself, with little energy left over for deconstruction or circumspection. The CRTC issues hundreds of policy and regulatory decisions every year, but provides little insight into whether its objectives still make for good public policy.

If asked how rules that preserve a distinctive market for Canadian programming rights contribute to a distinctive Canadian culture, the official policy response would be that they preserve the ability of Canadian businesses to operate in the broadcasting market. But that answer merely restates the question: how does content produced and distributed 
by Canadians affect audiences differently, at a cultural level, from content produced and distributed by Americans? What is the cultural impact of programming produced and distributed in a regulated environment, as opposed to content produced and distributed in an unregulated environment? The regulatory framework we have developed in the absence of clear answers to these questions is so selective and inconsistent as to border on the absurd.

This thesis focuses on how we have arrived at the current juncture in Canadian broadcasting policy, and whether its economic and cultural assumptions are still valid in the face of modern communication practices. It examines the inconsistencies in our current approach to regulation, and questions whether its objectives are in fact achievable at all.

This thesis is structured in two main parts, the first largely theoretical, and the second largely historical. In this introduction I outline the main tools by which the broadcasting system is currently regulated, as these form the main terms of reference throughout the rest of the thesis. The introduction also outlines the basic propositions and questions that frame my analysis. The conclusion outlines several principles by which our broadcasting marketplace should be managed, consistent with this analysis. 
Part one has three chapters:

Chapter one is the theory chapter, providing a general framework for joining the issues discussed in subsequent sections. Like much of our current broadcasting policy, it uses Harold Innis's 'staple theory' to examine how we have inherited the broadcasting system we have today, and how that system has deepened our interdependence with the Untied States (or, at the very least, with American communications systems).

Chapter two focuses on the economic assumptions behind Canadian broadcasting policy. The conventional theory is that without government intervention, our domestic marketplace has too few resources, and too few consumers, to support a stable supply of Canadian content. I will examine the conditions in which we produce Canadian content, and how are supposed to respond to it as consumers.

Chapter three focuses on the cultural assumptions behind Canadian broadcasting policy. The conventional theory is that without a stable supply of Canadian content, we will lose some measure of our Canadian identity. I will examine the benefits of producing Canadian content, and how we are supposed to respond to it as citizens.

Part two has two chapters:

Chapter four focuses on the history of Canadian broadcasting policy to date, examining our official mistrust of each new technological advance in broadcasting. It interprets the 
major legislative, regulatory and policy milestones as stubborn attempts to keep our broadcasting system as closed as possible to American content, despite the fact that Canadian and American broadcasting systems have generally been moving towards more open and interdependent operations the whole time.

Chapter five focuses on the new economics of broadcasting, and the challenges they pose to a regulatory system largely predicated on the old economics of broadcasting.

The final chapter sketches the outlines of a more affirmative, forward-looking broadcasting policy, based on new economics of broadcasting, rather then the old.

Our current broadcasting regulations are so numerous, so dense, and multiply with such ferocity, that every two years a major law firm in Toronto publishes a freshly annotated edition of 'The Canadian Broadcasting Regulatory Handbook,' in two volumes, in 6 point type, on 2000 rice-paper pages. ${ }^{4}$ Accordingly, I deliberately maintain a high altitude with respect to the level of detail on any given rule or regulation, saving the technical explanations and annotations for footnotes.

Also, I generally try to avoid referencing specific companies or 'stakeholders' in the system, as it becomes hard to avoid being drawn into specific ownership structures and personalities involved. The idea is to focus on the various government reports, laws and regulations that make up our current framework, rather than the specific agendas of the

${ }^{4}$ Grant, P. Keenelyside, A., Buchanan, G. The 2004 Canadian Broadcasting Regulatory Handbook, and the Regulatory Guide to Canadian Television Services. (Toronto): McCarthy Tétrault, 2004. 
agencies, companies or individuals that operate within it. I am more concerned with implications than motivations.

The current broadcasting policy 'toolkit'

Since the early days of radio in Canada, there have been two general arguments in favour of state intervention in broadcasting - one economic or industrial, the other cultural or societal. Today there are several sets of rules by which the state maintains a regulated broadcasting system in Canada. These rules can be loosely grouped under the headings of ownership, access, advertising, and content.

\section{Ownership rules}

The colour of a broadcaster's passport is not a trivial matter to regulators. Current broadcasting policy strictly limits ownership of broadcasting businesses to Canadian citizens. Liza Frulla once remarked in a speech about her top priorities as Minister of Canadian Heritage "let me add a final note about something that will not change in broadcasting policy. We have made it clear that the ownership of Canada's broadcasting system will remain in Canadian hands. We will not compromise on this matter - it is fundamental." Ironically, the Auditor General criticised her department six months later for not doing enough to verify the nationality of owners and creators before qualifying them for grants and subsidies. This gap between the ambition of a policy and its actual application is a recurring theme in Canadian broadcasting regulation. ${ }^{6}$

\footnotetext{
${ }^{5}$ Frulla, L. "How Culture Defines Who we Are." Speaking notes for an address to the Canadian Club of Toronto, May 9, 2005: http://www.pch.gc.ca/pc-ch/min/discours-speech/2005-05-09 e.cfm

${ }^{6}$ Auditor General's report: http://www.oag-bvg.gc.ca/domino/reports.nsf/htm1/20051105ce.html
} 
On one hand, the ownership argument runs, only someone who has lived the Canadian experience can recreate it for others. On the other hand, as Acheson and Maule argue, the notion that only Canadians can tell Canadian stories is "an emotional wrapping for an industrial policy," ensuring only that stories are told by Canadians, not that Canadian stories are told. "There is no evidence," they counter, of "a systemic connection between ownership and content." $(2001,19)$

At a time when programming content is as likely to originate from an overseas server as a downtown transmitter, it is increasingly difficult to see the link between the 'national identity' of a television program, and the birthplace of the owner of the company that broadcasts it or runs the cable to your house.

Canadians currently own and operate television and radio stations in Australia, Ireland, and the United Kingdom. ${ }^{7}$ This does not mean, of course, that those stations broadcast $100 \%$ 'Canadian content' because their owners happen to be Canadian. Those outlets produce programming of interest to their respective audiences, in complete disregard to the colour of their owners' passports. In today's media marketplace some of that content

\footnotetext{
${ }^{7}$ Several Canadian broadcasters own and operate substantial overseas broadcasting and content distribution businesses. For example, CanWest is the majority owner of Australian television network TEN, as well as 6 Australian radio stations. In New Zealand, Can West has a minority stake in TV3, while in Ireland they hold $45 \%$ of a network with the same name. CHUM Television sells its programming in over 150 countries, and has licensed CityTV and MuchMusic-branded channels to operators in the US, Argentina, Finland, Colombia, Malaysia, Mexico and Spain. Alliance Atlantis maintains sales and distribution offices in Australia, Spain, Ireland and the UK.
} 
may be Canadian, but only because of its popularity with foreign audiences, not because of the birthplace of the station owners.

But if a Canadian owner can produce Australian and Irish content, can an Australian or Irish owner produce Canadian content? Not under our current regulatory framework. The fact they do not hold Canadian passports would mean, supposedly, that their work does not contain or reflect 'Canadian values,' whatever the setting or storyline. This presumption leads to absurd situations whereby content produced by Canadians, but that has nothing to do with Canada, supposedly makes a greater contribution to our national identity that content produced by a non-Canadian, set and filmed entirely in Canada. ${ }^{8}$

Moreover, most Canadian broadcasting companies are publicly traded on Canadian and international stock markets. Their millions of voting and non-voting shares trade hands and cross borders on a regular basis. Even if we accept some connection between the nationality of content and its creator, for the most part, regulators really have no idea who owns exactly how much of which company at any given moment anyhow.

\footnotetext{
${ }^{8}$ For example, Canadian David Cronenberg's critically acclaimed film History of Violence was shot in Ontario, by a Canadian director, and earned award nominations from Cannes to the Golden Globes. It is widely expected to earn a 2006 Oscar nomination. Nonetheless, because it does not make use of any Canadian lead actors, it does not meet official definitions of 'Canadian content', and is ineligible for a Genie award, which are only awarded to officially 'Canadian' films. See Proudfoot, S. "With a Canadian location, director and crew, acclaimed film still too 'foreign' for Genie nod." Ottawa Citizen, January 27, 2006. A1.
} 


\section{Access rules}

The CRTC controls market access for both Canadian and non-Canadian channels. It also manages those channels' access to audiences by regulating their business relationship with distributors. The corollary effect of these rules, never officially stated, of course, is to control audiences' access to the programming carried on those channels.

The government has always tried to restrict who gets to supply broadcasting content to Canadians. Historically, it has done so by requiring a licence to operate a broadcasting business in Canada, and, as noted, by limiting access by non-Canadians to the Canadian market. The effect of this, of course, is to restrict access by Canadians to non-Canadian content. Today the CRTC micromanages which Canadian channels must be carried by which distributors. It determines in which combinations they may be packaged with foreign channels. It sets the precise ratio of channels in which a distributor has an ownership stake, to channels in which a distributor has no ownership stake. These are generally referred to as "distribution and linkage" rules. ${ }^{9}$

The CRTC further manages audiences' demand for new foreign channels by requiring a Canadian broadcaster or distributor to sponsor them for inclusion on an official list of 'eligible satellite services.' Distributors are limited to carrying foreign services that appear on one of these lists. The lists also specify which foreign channels can be packaged with which Canadian channels. Some can be linked to Canadian specialty

\footnotetext{
${ }^{9}$ The most recent version of these rules, as amended, were issued in October 2005. See Broadcasting Public Notice CRTC 2005-98, Distribution and Linkage Rules for Class and Class 2 Licensees, October 27, 2005: http://www.crtc.gc.ca/archive/ENG/Notices/2005/pb2005-98.htm
} 
channels, while others can only be sold in packages containing Canadian pay channels.

The Broadcasting Distribution Regulations require distributors, in any event, to carry "a preponderance" of Canadian channels, and to ensure that all customers subscribe to more Canadian channels than non-Canadian channels. ${ }^{10}$

When assessing a request to add a foreign service to these lists, the CRTC considers the format of the service, and will refuse to put it on the lists if it is "wholly or partially competitive" with any existing Canadian service. ${ }^{11}$ The Commission also requires the

\footnotetext{
${ }^{10}$ For the most recent version of the CRTC's Eligible Satellite Services list see Public Notice CRTC 200615 Revised list of eligible satellite services, February 9, 2006: http://www.crtc.gc.ca/archive/ENG/Notices/2006/pb2006-15.htm
}

The increasing pace at which foreign services are being approved for carriage in Canada can be loosely measured by the how often the CRTC amends the lists. In 2002, once. In 2003, once. In 2004, three times. In the first 14 months since the Commission liberalized the inclusion criteria, six times. See Public Notice CRTC 2004-96 Improving the diversity of third-language television services $-A$ revised approach to assessing requests to add non-Canadian third-language television services to the lists of eligible satellite services for distribution on a digital basis, December 16, 2004: http://www.crtc.gc.ca/archive/ENG/Notices/2004/pb2004-96.htm

The current Broadcasting Distribution Regulations were issued in December 1997, and have been amended and updated frequently since that time. For the original version, see Public Notice CRTC 1997-150, Broadcasting Distribution Regulations, December 22, 1997: http://www.crtc.gc.ca/archive/ENG/Notices/1997/PB97-150.HTM

For the most recently amended version, see Public Notice CRTC 2004-18, Amendments to the Broadcasting Distribution Regulations-implementation of the policy framework for community based media, March 30, 2004: http://www.crtc.gc.ca/archive/ENG/Notices/2004/pb2004-18.htm

It should be noted that the CRTC signaled that it would amend the Broadcasting Distribution Regulations in October 2003, to reflect the carriage requirements for cable distributors set out in Public Notice 2003-61, The regulatory framework for the distribution of digital television signals, October 30, 2003:

http://www.crtc.gc.ca/archive/ENG/Notices/2003/pb2003-61.htm. 27 months later, it has yet to do so, nor has it held a proceeding to determine what the carriage rules for digital television signals will be for DTH distributors, a priority it first identified in the October 2003 policy framework.

${ }^{11}$ The Commission's policy is set out in Public Notice CRTC 1997-96, July 22 1997: http://www.crtc.gc.ca/archive/ENG/Notices/1997/PB97-96.HTM It states that the Commission will not authorize non-Canadian services that can be considered either totally or partially competitive with existing, licensed Canadian specialty and pay services. It further states that it will "consider the removal of existing non-Canadian services" from the lists if they undergo a change in format so as to become competitive with a Canadian pay or specialty service, but that "it will not be disposed to remove a non-Canadian service from the lists, even if it should license, in the future, a Canadian service in a competitive genre." At the 
foreign service to file a statement that it "does not hold, and will not obtain or exercise, exclusive programming rights with respect to the distribution of its programming in the Canadian market." 12

same time, it must be noted that the CRTC consistently undermined its own policy in licensing and approving Canadian and foreign services that obviously compete with existing Canadian services. The CRTC explains away this inconsistency by insisting, for example, that Sportsnet, a regional sports service, does not compete with TSN, a national sports service. While it may be true that professional sports leagues sell separate regional and national programming rights, the distinction in unperceivable to the subscriber. Moreover, the CRTC has all but dropped the pretense of exclusivity where news is concerned. For example, when originally licensed, Newsnet was limited to 15 minute programming "wheels", a restriction meant to distinguish it from CBC Newsworld, which could "clock" its programming segments any way it chose. Newsnet successfully applied to have that restriction removed in 2005, the same year the CRTC approved Fox News, which joined CNN, BBC International and Al Jazeera, among others, in competing directly with Newsworld, which still notionally enjoys "genre exclusivity." With the possible exception of the Weather Network, it cannot be demonstrated that any Canadian specialty service operates in an entirely distinct genre anymore.

The Commission also applies a 'competitiveness test' when considering requests to license new Canadian services. However, in the case of new Canadian services, the Commission only considers whether the new service would compete with certain existing Canadian services. The test for new foreign services is therefore stricter than the test for a new domestic service -a potential consideration for trade policy analysts.

${ }^{12}$ In 1994, the Commission licensed the New Country Network (NCN) a new Canadian service. As a result, as per its policy at the time, it removed the similar American service Country Music Television (CMT) from the lists. This move resulted in civil litigation, allegations by the United States Trade Representative that Canada was in breach of its obligations under the Free Trade Agreement, and threats of retaliatory sanctions. This case was resolved through negotiation and the launch of a joint-venture between the two services.

In 2003, the Canadian Association of Broadcasters requested that the Commission remove American service TNN from the lists, arguing that by changing its format and name to SpikeTV, the service was a de facto new service that had never been considered for inclusion to the lists. According to the CAB, the format change raised significant questions about the Commission's ability to manage satellite services once they have been added to the lists. In its submission to this proceeding, The Canadian Association of Film and Television Producers agreed, noting that in its view, allowing SpikeTV to remain on the lists would "undermine the entire genre protection policy." On the other hand, The Canadian Cable Television Association saw this case as "... a classic example of what is wrong with the current rules in a competitive world." According to the CCTA, removing SpikeTV from the lists would result in significant consumer disruption, and could "inflame unresolved international trade issues first raised in the CMT case." The Commission eventually concluded that, although SpikeTV has never been considered for inclusion to the Lists, if anyone had applied for its inclusion, it would have been granted, and declined to remove it. See Public Notice CRTC 2005-9 Distribution of Spike by Broadcasting Distribution Undertakings, January 27, 2005: http://www.crtc.gc.ca/archive/ENG/Notices/2005/pb2005-9.htm

The issue of which non-Canadian third-language services to add to the lists has been more controversial of late. In 2004, the Commission approved the addition of five Spanish, one German, one Romanian, and one Arabic service to the lists. At the same time, it denied a number of others-including, infamously, Italianlanguage service RAI International - on the grounds that they would be competitive with existing Canadian third-language services. See Public Notice CRTC 2004-50 Requests to add non-Canadian Third-language 
Once a foreign service is approved for distribution in Canada, a number of 'linkage' rules kick in, determining the exact ratio of Canadian to foreign channels that can be sold in any given package. Canadian channels also have certain distribution guarantees, depending on their licensing status. Some channels, for example, have to be carried on the basic service of a cable distributor and are granted a regulated wholesale rate for that carriage. Others have guaranteed access to discretionary packages, but no guaranteed rate. $^{13}$

Services to the lists of eligible satellite services for distribution on a digital basis, July 15, 2004: http://www.crtc.gc.ca/archive/ENG/Notices/2004/pb2004-50.htm

In its decision, the Commission noted that RAI had stated in a letter to Canadian service Telelatino that it would not discuss a renewal of their program supply agreement until RAI International was added to the lists. Accordingly, the Commission determined that it was not convinced that RAI would not withhold rights to its programming in the Canadian market, and denied the request to add it to the lists. This decision drew much public criticism, including demonstrations on Parliament Hill, and direct cabinet-level intervention by members of the Italian government. In the same decision, the Commission announced that it would hold Canadian distributors responsible for the content of Arabic-language news service Al Jazeera. This decision represented the first time that the Commission had held a distributor responsible for the content of a programming service. At the same time, the Commission announced a related policy proceeding to examine whether "the current (policy) approach strikes the appropriate balance between ensuring there is an adequate level of service to third-language communities and fostering Canadian thirdlanguage services."

A panel struck by the Department of Canadian Heritage to respond to this proceeding issued a report on access to third-language services in Canada. The report recommended a general loosening of current competition policy for foreign third-language services, contingent on the services' commitment not to exercise preferential programming rights in the Canadian market. The reports also called for the creation of a production fund for third-language programming, to be funded by $10 \%$ of foreign services' revenues generated in Canada. The Commission adopted the main recommendation, loosening the rules by allowing competitive foreign third-language to be added to the lists, but did not create a $10 \%$ production fund. They also introduced a new distribution rule, requiring a customer to subscribe to at least one Canadian channel operating in the same third-language before being able to subscribe to the foreign channel. See Public Notice CRTC 2004-96 Improving the diversity of third-language television services - A revised approach to assessing requests to add non-Canadian third-language television services to the lists of eligible satellite services for distribution on a digital basis, December 16, 2004:

http://www.crtc.gc.ca/archive/ENG/Notices/2004/pb2004-96.htm

13 For specialty channels licensed for analog distribution, there are two main categories of distribution status: Dual Status (meaning the channel has to be carried on basic unless the channel operator agrees to be carried on a discretionary tier) and Modified Dual Status (meaning the opposite). See Public Notice CRTC 
As per ownership regulations, this access regime is becoming increasingly permeable. It is based on the ability of broadcasters to limit the transmission of a signal to a specific territory or device. Today, viewers can download programming from anywhere in the world, on any number of devices, in complete disregard for geographic rights markets. Domestic distributors pluck 'local' signals and turn them into 'distant' signals by selling them in other provinces or regions. The current market access rules are simply not suited to a borderless rights environment in which any content provider can reach any Canadian, on any device, from anywhere.

Moreover, the access rules that are supposed to regulate industry behaviour also regulate audience behaviour. They are designed, in theory, to provide Canadian alternatives to American content, but their practical effect is to shift spending and consumption patterns away from any natural direction they might tend to follow: $\mathrm{NBC}$ has to agree not to withhold the rights to West Wing from CTV, in order that CTV can raise advertising revenue from the program -revenue necessary to produce 'distinctive Canadian content.' The value of that advertising is further insulated by the requirement that distributors replace the incoming NBC signal with the CTV signal, ensuring that $100 \%$ of the Canadian audience for West Wing sees CTV's commercials. But for CTV to take advantage of that regulatory protection, it must program West Wing in precisely the same time slot as NBC, abdicating, in effect, scheduling decisions to the American broadcaster.

2005-98, Distribution and Linkage Rules for Class and Class 2 Licensees, October 27, 2005: http://www.crtc.gc.ca/archive/ENG/Notices/2005/pb2005-98.htm 
To watch the program, the Canadian audience has the illusion of a choice between two 'competing' networks, while in reality, the decision is between two versions of the 'preferred' Canadian signal. In this sense micromanaging the relations between various links in the value chain, our broadcasting policy also micromanages individual tastes and preferences. At the same time, the communications marketplace is becoming increasingly personalized. Audiences expect to pay once for whatever content they want, in whatever format, from whatever source. For the most part, new technologies and business models make that possible. Still, our market access rules function as audience access rules, maintaining gates that are increasingly bypassed by creators and audiences.

\section{Advertising rules}

Broadcasting policy also determines who can earn revenue from the sale of broadcast advertising in Canada. Current policies limit access to the Canadian advertising market to Canadian television and radio operators, who are in turn limited to the number of minutes per hour they can use to run commercials (radio stations have no hourly limits). ${ }^{14}$

The rationale for these rules circles back to content: if there was too much foreign competition for advertising revenues, Canadian broadcasters would retain less of those revenues and not be able to spend as much on Canadian content, and our national identity would be weaker for it. Moreover, if foreign broadcasters could sell ads in Canada, they

14 Conventional television stations are limited under section 11(1) of the Television Broadcasting Regulations from broadcasting more than 12 minutes per hour of commercial messages. See: http://www.crtc.gc.ca/eng/LEGAL/TVREGS.HTM Specialty channels are each restricted by condition of their individual licences from exceeding 12 minutes per hour of advertising. 
would have little incentive to sell the rights to their programming to a Canadian broadcaster.

Since 1975, Canadian cable companies have been prevented from replacing advertising on American channels with Canadian advertising. ${ }^{15}$ They are also required to replace the signal from an American over-the-air channel with the signal from a Canadian over-theair channel, if both broadcasters are airing the same program at the same time - the socalled 'simultaneous substitution rules. ${ }^{16}$ Separately, Canadian cable companies are not permitted to sell the two minutes per hour of 'local avails' that come into Canada on American cable channels, such as CNN or A\&E (so called because those two minutes are 'available' for American cable companies to sell advertising in each 'local' market). As a further disincentive, since 1975, the Income Tax Act has not allowed Canadian companies to deduct the cost of advertising purchased from American broadcasters.

These advertising rules are widely viewed as key measures for maintaining a distinct Canadian market for programming rights. They assume that if a Canadian broadcaster were to lose a portion of its Canadian audience to an American broadcaster airing the same program, the value of the advertising on that program would be reduced. They also

\footnotetext{
${ }^{15}$ Cable companies cannot replace the advertising in American channels with Canadian advertising. See: Public Notice CRTC 1997-25, New regulatory framework for broadcasting distribution undertakings, March 11, 1997: http://www.crtc.gc.ca/archive/ENG/Notices/1997/PB97-25.HTM
}

In 1975, Bill C-58 amended the Income Tax Act to prevent Canadian companies from deducting from their taxable income the cost of advertising purchased from border stations. The restriction also applies to ads purchased in American magazines and newspapers. See section 19(1) of the Income Tax Act for the exact wording of the legislation, still in effect: http://laws.justice.gc.ca/en/i-3.3/65846.html

16 See section 30(2)(a)(i) of the Broadcasting Distribution Regulations: http://www.crtc.gc.ca/eng/LEGAL/BDU.HTM 
assume that if an American broadcaster could reach Canadian audiences directly with its advertising, there would be little incentive to sell the rights to its programming to a Canadian broadcaster (who would then, so goes the theory, not be able to use the American program to earn money to meet its Canadian content requirements).

Yet some American broadcasters do earn money directly in Canada. PBS stations in border cities solicit and accept donations from Canadian audiences. American radio stations in some border cities keep sales offices in nearby Canadian cities -in 1975, KVOS in Bellingham, Washington claimed that the Income Tax restriction would cost a dozen jobs from its sales force in Vancouver. YES-FM in Malone, New York, advertises itself as "Ontario and Upstate New York's radio station", carrying ads from Canadian businesses in Cornwall and Montreal. ${ }^{17}$ Moreover, in attempting to protect the value of advertising on Canadian broadcasters, the regulations can have a deflationary impact on the advertising market in general: since Canadian businesses cannot claim American advertising as a business expense, American broadcasters in border cities often reduce or discount the cost of their ads for Canadian buyers to compensate for the tax restriction. This causes Canadian broadcasters to lower the cost of their ads to compete. The restriction on the sale of local avails reportedly prevents up to $\$ 70$ million in advertising inventory on American cable channel from being sold in Canada, ${ }^{18}$ inflating the value of

\footnotetext{
${ }^{17}$ Cited in Appendices to the Proceedings of the Senate Standing Committee on Banking, Trade and Commerce, Senate of Canada, Issue No. 93, June 16, 1976. See also: YES-FM's website: http://www.yesfm.com/
}

\footnotetext{
${ }^{18}$ See Appendix A, page 32, of the Canadian Association of Broadcasters' reply to Public Notice CRTC 2004-47 (PN 2004-47) and Public Notice CRTC 2004-48 (PN 2004-48): Proposal by the Canadian Cable Television Association and Application No. 2003-1177-0 by Vidéotron ltée, respecting the use of the local
} 
the rest of the Canadian inventory, while at the same time, the Income Tax restriction puts downward pressure on Canadian ad rates in some markets. The effect of the former probably outweighs the effect of the latter, but there is nonetheless a gap between the stated objective of advertising policy and its practical impact.

As noted, the simultaneous substitution rules also encourage Canadian broadcasters to duplicate the primetime schedules of American broadcasters, in order to maximize the value of the advertising on hit shows. This of course gives programming control over the most watched portions of the television schedule to precisely the American networks whose influence the regulations are meant to limit. It presumes centralized control over who watches what, and when they watch it, despite rapid deployment and adoption of ondemand business models that make programming available anytime, anywhere.

Advertising regulations are predicated on the old economics of broadcasting, in which a signal could be controlled within a specific territory, timeframe, or device. Today, wireless broadband communication does not respect national borders, on-demand programming does not reflect prime-time scheduling, cross-platform content is not limited to one format or device, digital video recorders allow viewers to skip commercials, and the sheer number of unregulated advertising practices and platforms is increasing rapidly. These factors are making the current advertising restrictions increasingly difficult to apply or defend. If audiences cannot be channelled to certain media at certain times, advertisers on those channels will find those audiences elsewhere 
-in 2005, for example, brewing giant Heineken announced it was ceasing all television advertising in the United Kingdom, and was shifting to outdoor and internet advertising instead. $^{19}$

Despite these mounting pressures, the regulator has expressed only a mild concern with updating the existing rules and regulations. "At some point in time," a CRTC official recently remarked, somewhat indifferently, "the commission may have to adapt to the new advertising model out there. $" 20$ This is a telling statement: the regulator recognizes that the existing rules no longer reflect how the market operates, but apparently is in no immediate hurry to update them. The difference between how regulations assume the market operates and the way it actually works is another theme we see repeated throughout the history of Canadian broadcasting policy.

\section{Content rules}

Canadian content regulations refer to specific spending and exhibition quotas for Canadian programming on radio and television, and the various official tests by which the 'Canadianess' of that programming is established.

Generally speaking, each conventional television broadcaster is required to program a certain percentage of Canadian content at certain times of the day. Each specialty

\footnotetext{
${ }^{19}$ Walsh, D. "Heineken calls last orders on TV ads after 30 years." London Times, October 21, 2005: http://business.timesonline.co.uk/article/0,9071-1836183,00.html

${ }^{20} \mathrm{McArthur}, \mathrm{K}$, and Robertson, G. "CRTC ponders impact of product placement." Globe and Mail, November 21, 2005, B1.
} 
broadcaster is required as a condition of its license to invest a certain percentage of its revenues in Canadian content, and to air certain amounts of it at certain times of the day. $^{21}$ Each over-the-air radio station is required to dedicate a certain percentage of musical selections to officially Canadian music. ${ }^{22}$ As noted, Canadian cable and satellite companies are required to carry certain Canadian channels in certain packaging arrangements with non-Canadian channels, while ensuring that their customers buy a preponderance of Canadian channels within each package and overall. In a recent and controversial development that will be discussed in greater detail in chapter five, subscription radio broadcasters are required to offer a certain number of Canadian channels alongside American channels, and to ensure those Canadian channels carry no less than $85 \%$ Canadian content (combining, in essence, content and packaging rules, which is appropriate, considering that satellite radio operators are both programmers and distributors). ${ }^{23}$

21 The Television Broadcasting Regulations require all private conventional stations to "devote not less than 50 per cent of the evening broadcast period to the broadcasting of Canadian programs," and all public stations to "devote not less than 60 per cent of the evening broadcast period to the broadcasting of Canadian programs." See section 7 (a) and (b) of http://www.crtc.gc.ca/eng/LEGAL/TVREGS.HTM Specialty channels are each required by condition of their individual licence to spend a certain percentage of the previous year's revenues on Canadian content, and to devote certain percentages of their programming schedules to Canadian content at certain times of each day, week, month or year. The precise requirements vary from service to service.

${ }^{22}$ Section 9 of the Radio Broadcasting Regulations requires all commercial radio stations to broadcastat least 35\% Canadian musical selections between 6:00am and 6:00pm, Monday to Friday. Section 2 (a)(i) through (iv) of the Radio Broadcasting Regulations sets out the MAPL test (Music, Artist, Production, Lyrics) for determining which musical selections count as Canadian ( 2 of the 4 categories must be scored, performed, recorded or written by a Canadian). Section 2(b) through (d) then capture any number of possible exceptions to that rule. See http://www.crtc.gc.ca/eng/LEGAL/Radioreg.htm

${ }^{23}$ In June 2005, the CRTC approved three subscription radio services for operation in Canada: Canadian Satellite Radio (affiliated with American satellite radio company XM. Decision:

http://www.crtc.gc.ca/archive/ENG/Decisions/2005/db2005-246.htm ), Sirius Canada (affiliated with American satellite radio company Sirius. Decision: http://www.crtc.gc.ca/archive/ENG/Decisions/2005/db2005-247.htm), and a proposed terrestrial-based service to be operated by CHUM and Astral Ltd (Decision: http://www.crtc.gc.ca/archive/ENG/Decisions/2005/db2005-248.htm) 
Numerous federal agencies are involved in the application of various tests to determine if a program is officially Canadian. Most of these tests hinge on the nationality of the creators, while some focus on the 'Canadianess' of the storyline or other cultural references. The nationality issue is problematic in and of itself, as is the way the tests weigh the importance of each job in any given production. The 'cultural reference' tests are falling out of favour with most agencies, but still carry a great deal of symbolic weight when programs are being considered for funding.

This thesis will focus chiefly on how Canadian content rules apply to English-language broadcasters. ${ }^{24}$ Canadian content regulations also apply to French-language and socalled 'third-language' broadcasters, and to public and non-commercial broadcasters in all languages. However, the underwriting concern that Canada will weaken its cultural identity without state intervention in broadcasting has historically been rooted in English-

\footnotetext{
The subscription radio policy requires licensees to carry a minimum $10 \%$ Canadian channels. $85 \%$ of these channels' musical and spoken word programming must be Canadian. This caused no shortage of controversy, primarily from commentators mixing apples and oranges, comparing the programming requirements of subscription radio directly to the programming requirements for commercial radio. The former combines a distribution service with a programming service, while the latter is a straight programming service. The programming requirement for subscription radio is two dimensional (number of channels, and the percentage of airtime on them) while commercial radio is one dimensional (amount of airtime only). See Chapter 5 for further discussion of the subscription radio issue.

${ }^{24}$ I do not distinguish between CBC television and 'commercial' broadcasters in this thesis, given the historical dependence of $\mathrm{CBC}$ television on its commercial inventory, and the similarity in regulatory obligations of public and private broadcasters. Although the $\mathrm{CBC}$ is alone among Canadian broadcasters in having its operations and administration legislated in micro detail under its own section of the 1991 Broadcasting Act, it operates, for all intents and purposes, under the same rules and regulations as CTV, Global or any other private broadcaster (albeit with higher Canadian content quotas during some parts of the broadcast day).
} 
language broadcasting, on the basis that English-language content undergoes the lowest 'cultural discount' when crossing the border from the United States. ${ }^{25}$

For example, despite the prevalence of French in many parts of Canada, the federal government has never expressed an official concern that French-speaking Canadians will lose their cultural identity in the absence of Canadian alternatives to programming from France. Nor is Canadian broadcasting policy predicated on offsetting the economic advantages of producing content in France over Quebec, despite the fact that France has a much larger population who speak the same language. To the contrary, the Department of Canadian Heritage provides direct financial support to TV5, an international Frenchlanguage network that brings international French-language programming to Canadian audiences. $^{26}$

On the other hand, concern over the fate of Canada's national identity in the face of American programming has felled forests in support of specific policies, regulations, legislation, codes, studies, reports, profiles and speeches emanating from 80 years worth of Royal Commissions, Standing Committees, Special Ministerial Advisory Panels, regulatory bodies, and advocacy groups.

\footnotetext{
${ }^{25}$ McFayden, Hoskins and Finn: "(a cultural discount) arises because viewers in importing markets generally find it difficult to identify with the way of life, values, history, institutions, myths, and physical environment depicted. Language differences are also an important reason for a cultural discount as the appeal of the viewing is reduced by the need to dub or subtitle, and by the difficulty in understanding unfamiliar accents." $(2000,3)$ Clearly, under this definition, American programming undergoes a negligible cultural discount when imported to the Canadian market.

${ }^{26}$ See: http://www.canadianheritage.gc.ca/progs/ac-ca/progs/tv5/index_e.cfm
} 
As the then-Minister of Canadian Heritage remarked in horror recently, "think of it $89 \%$ of the time Canadians are watching drama, they are watching foreign - mostly American - programs." 27 The current Chair of the CRTC agrees that this is an EnglishCanadian problem, noting that

when it comes to French-language Canadian drama, domestic productions do very well, attracting over half of all viewers of drama on French-language services. But American programming predominates in English-language drama. Homegrown productions attract only a small minority of Canadians watching drama on Canadian English-language television. ${ }^{28}$

It is not surprising, given their views, that most federal Canadian content energy is spent on English-language television and radio (and to a lesser extent, film).

Despite the unpopularity of Canadian drama, relative to American drama, there persists a concerted lobby in favour of increasing the amount of Canadian drama in the system. In 1999, the CRTC removed the requirement that conventional broadcasters program certain percentages of drama. ${ }^{29}$ The Canadian Coalition of Audiovisual Unions (a collection of guilds and unions primarily representing Canadian writers, directors and actors) has long called for a return to the pre-1999 policy, blaming it for causing a "crisis in Canadian drama." When the CRTC announced that it would allow Canadian broadcasters to sell more advertising in exchange for increased spending on Canadian drama, the CCAU said

\footnotetext{
${ }^{27}$ Ibid.

${ }^{28}$ Charles Dalfen, in a speech to the Broadcast Executives Society, Toronto, April 12, 2005.

${ }^{29}$ See Public Notice CRTC 1999-97, Building on Success, a policy framework for Canadian television, June 11, 1999.
} 
this was not enough (before, of course, anyone had time to see if it would work), calling again for a return to the policy days of $1998 .^{30}$

Their position makes several faulty claims. It either assumes that the audience will simply go where you channel them ('produce it and they will come'), or it is not concerned with audiences at all. The CCAU argues that broadcasters should not respond to audience tastes, rather, that they should dictate them. This is a highly paternalistic view of audiences. It also says quite clearly that these unions and guilds have no interest in how the 2006 marketplace operates, advocating instead for a return to a 1998 policy, as if the same market conditions still applied—-they demonstrably do not.

Together, these ownership, access, advertising and content rules form the framework for state intervention in the Canadian broadcasting system. This thesis covers how these rules have evolved over time in response to technological advancements - or, more to the point, how new technologies have consistently made it easier for Canadians to access American content, as the rules have tried to keep up.

A number of propositions and questions inform this approach: ${ }^{31}$

\footnotetext{
${ }^{30}$ See Public Notice CRTC 2004-93, Incentives for English-language Canadian Television Drama, November 29, 2004: http://www.crtc.gc.ca/archive/ENG/Notices/2004/pb2004-93.htm For CCAU press release in reply, see: http://www.wgc.ca/policy/mediaroom/ccau_response.html

${ }^{31}$ Informed in large measure by Winter and Goldman: "Do Canadian and American cultures differ and, if so, in what manner? To what extent is "Canadian" media content Americanized? Does media content influence culture generally, and, more specifically, is US content acculturating Canadians? Finally, is it possible that Canadians themselves are jeopardizing Canadian culture? In the academic realm, these questions date back at least to the late 1940s and political economist Harold Innis, who is said to have founded the modern study of media imperialism." $(1995,202-203)$
} 
First, despite 80 years of rules and regulations governing all aspects of broadcasting in Canada, there is little evidence that Canadians are any more or less 'distinct' from Americans as a result, nor that domestic content delivers external benefits to Canadians that foreign content does not. Moreover, the harder we try to define 'Canadian' content, the more problematic it becomes.

Second, if Canadian culture is so similar to American culture that American content crosses the border with little or no cultural discount, then precisely what are the distinct cultural elements of Canadian society we are trying to protect? On the other hand, if Canadian culture is so distinct from American culture as to warrant state intervention to preserve that distinctiveness, then surely our national identity is strong enough to withstand American sitcoms and pop music.

Third, if market forces work against the efficient production and supply of Canadian content, such that corrective state intervention is warranted, then why do we only have detailed rules and regulations for broadcasting? If our national identity hinges on access to Canadian content delivered by Canadian-owned media, then surely that is important enough to warrant state intervention in the content of Canadian newspapers, books, or the internet? If exhibition quotas are crucial for TV and radio, then why not require bookstores to dedicate a percentage of shelf space to Canadian authors, record stores a percentage of rack space to Canadian musicians, movie theatres a percentage of screen time to Canadian movies, and newspapers a percentage of column inches to Canadian 
news? We do have foreign ownership regulations for Canadian publishing houses, newspapers and film distributors, and some advertising rules for magazines, but only in broadcasting do we find official content quotas and rules dictating the business relationships in the marketplace. Does this suggest that broadcast media have a greater impact than other media in the formation and maintenance of Canada's national identity? Does Canadian Idol "safeguard, enhance and enrich" our cultural sovereignty better than Canadian Press?

Fourth, technology increasingly mitigates the ability of the state to intervene in broadcasting at all, such that soon, only the most conventional forms of content will be 'regulatable' at all. If we cannot limit the distribution or reproduction of broadcasting signals, then many of the existing rules and regulations will become increasingly ineffective and irrelevant.

Finally, our broadcasting policy hinges on a parochial and unsupported notion of Canadian identity. There is no attempt made anywhere in our broadcasting policy to explain how someone with a Canadian passport injects a song or program with Canadian ideas, or how they are subsequently passed on to Canadian audiences. Is it automatic or deliberate? Is the change it effects incremental, or does it happen all at once, by some sort of cultural osmosis? These questions have never been addressed, as they obviously cannot be answered. This is a fundamentally insular and unsatisfying policy, turning more on vague notions of national difference than on any sense of individual creativity. Being Canadian means little more in our broadcasting policy than being not-American. 
The elaborate weights and measures that test the Canadianess of content are entirely blunt instruments: any Canadian will do, provided you have the paperwork to prove it. ${ }^{32}$ The fact someone is not American matters more than their level of talent or experience.

Like most blunt instruments, these tests are also imprecise: some programming that contains Canadian references, or is the product of Canadian labour, counts as officially Canadian, while some does not, depending on who does what in the production team any Canadian will do, but not in any job.

This is hardly an affirmative picture of a distinctive Canadian culture. On the one hand, our reliance on popular, profitable American programming to subsidize unpopular, unprofitable Canadian programming suggests that our national identity is in fact dependent on the products of a foreign culture, and hardly 'culturally sovereign' at all. On the other hand, much of that officially suspect American content is either the product of Canadian labour, and/or indistinguishable in form and substance from much Canadian content, and vice versa, suggesting that we in fact operate within an interdependent system.

Simply put, the current regulatory framework for broadcasting does not ensure that 'Canadian stories' get told, only that stories get told by Canadians. Even then, there has

\footnotetext{
${ }^{32}$ Author Pierre Berton was once challenged by the Department of Canadian Heritage to provide proof of his Canadian citizenship when a documentary to which his name was attached was being measured for official Canadian content status. See "Prove you're Canadian: Feds to Berton." Montreal Gazette, December 21, 2001.
} 
never been a concerted effort to explain why this is good for us, or how it makes us different from Americans.

In our gated policy space, it just is, and just does. 


\section{PART ONE}

\section{Chapter 1: the theory chapter}

"In creating and satisfying the huge national appetite for cultural product, the industries engaged in its manufacture exhibit the same economic trends as did the industries in the preceding industrial era."

Herbert Schiller, $1989^{33}$

Our current regulatory framework was conceived in an era of scarce broadcasting spectrum, and of large audiences who shared the same limited menu of programming at the same time. Our regulatory understanding of these factors descends in large measure from the political economy orientation of Harold Innis, but has largely been overtaken by events.

Discourses of scarcity: leveraging resources to control communications The history of regulated mass media is the history of controlled access to the scarce resources necessary for communication. Typically, that access has been leveraged to ensure that media resources are used to support political objectives. This is as true in the digital age as it was at the dawn of the printing age in Western society.

Harold Innis portrays the eighteenth-century English practice of licensing printing presses as early mass-media regulation, rooted in notions of scarcity. He describes the limited

\footnotetext{
${ }^{33}$ From Culture Inc, The Corporate Takeover of Public Expression, New York: Oxford University Press, 1989,35 .
} 
availability of paper, and the need to ensure it was not being wasted on the printing of seditious materials. At that time, "public opinion was determined in part by the availability of paper and the cost of printing." $(1951,142)$

By requiring official state sanction to operate a printing press, the Crown tried to ensure that a limited resource was used to support the state - not unlike the rationale behind current Canadian broadcasting regulation. As the availability of paper increased, so did instances of its use for unlicensed, unregulated printing - not unlike the current increase in unregulated sources of television and music programming, as digital technology increases the capacity of the broadcasting spectrum to accommodate a growing range of new services.

Siebert describes in detail the various sixteenth and seventeenth century interventions of the English state in the operation of printing presses. In 1529, when Dutch tracts that questioned the notion of divine right began turning up in England, King Henry VIII decreed that all English printers had to be licensed and imposed trade regulations on the import of raw paper and any printed materials - not unlike current rules that prevent foreign broadcasters from operating directly in Canada, and that require Canadian broadcasters to use 'domestic' spectrum to reach the Canadian audience. ${ }^{34}$

In 1557 Queen Mary gave a charter to the Stationers Company that handed them sole jurisdiction over the publishing of official communications, and the right to approve or

\footnotetext{
${ }^{34}$ See Satellite-Use Policy to accommodate Broadcasting Services to the Canadian Public: http://strategis.ic.gc.ca/epic/internet/insmt-gst.nsf/en/sf08453e.html
} 
deny any new entrants to the marketplace - not unlike the early incarnations of the CBC that functioned as both official state broadcaster and regulator, determining who got broadcasting licenses, and for what purpose. Only those printers whose loyalties lay with the Crown were granted permits to import paper and operate a press, just as only those broadcasters who agreed to broadcast specific amounts of state-produced CBC programming were granted the use of spectrum in the early days of Canadian broadcasting.

Under Elizabeth I control over the press reverted to the religious authority, driven by a Royal Injunction of 1559 that handed control over pre-publication licensing to the Archbishop of Canterbury and the Bishop of London. These controls were further enshrined in law by the first Star Chamber decree of 1586. In 1637, the second Star Chamber decree was passed, backed up by the Law of Seditious Slander. With the abolition of the Star Chamber at the outset of the English civil war, laws pertaining to control of the press were essentially abandoned.

During this period of looser regulation, unlicensed printing was rampant in London. The number of pamphlets advancing controversial political arguments and viewpoints multiplied exponentially within the first year after the Star Chamber was abolished. (Siebert, 1952, 52) So, in 1643 Parliament, as target of much of the pamphlets' criticism, re-enshrined a licensing regime again centralized under the London Stationers. These orders were grounded in the Regulation of Printing Act in 1643. 
Regulation of the press gradually weakened under Charles II, until the Regulation of Printing Act finally lapsed in 1694. A great deal of printed material began to spill into England from the continent. Piracy became an issue for authors and publishers. (Williams, 1966, 47) Legislation in 1739 imposed a heavy tax on paper imported from Europe, and imposed severe penalties on unauthorized importers of printed books. (Innis, 1951, 143) However, at the same time, "with the expansion of paper production in England, following the establishment of paper factories . . . restrictions on printing were relaxed." (Innis, 1951, 154)

So, as paper become less scarce, people came to expect easier access to unregulated material. As the volume of unsanctioned printing spread, the regulator tried to find new ways to control it, before ultimately giving up altogether. The increased availability of paper stimulated a change in attitude toward regulation, just as that new demand for printed material was an incentive to develop better and cheaper ways to deliver it. In this sense, changes in ideology and technology had a compounding effect on each other.

A similar trend is discernable today. As new technologies make better use of the broadcasting spectrum, we are seeing an unparalleled increase in unregulated broadcasting activity, unprecedented changes in how people consume broadcasting content, accompanied by efforts to push the domestic policy walls outward, and/or to impose heavier penalties for unlicensed access to foreign signals. ${ }^{35}$ This trend poses significant questions about the continued relevance of our current broadcasting policy.

\footnotetext{
${ }^{35}$ In 2004 the Liberal government introduced Bill C-2 that would have seen increased penalties for anyone caught accessing unlicensed satellite signals from $\$ 1000$ to $\$ 25,000$. Also, for the first time, broadcasters
} 


\section{Metropole-hinterland thesis}

If Innis was sensitive to how media resources can be leveraged to control the messages they carry, he was also sensitive "to the means by which the hinterland was in a continual struggle to both escape and accept metropolitan dominance." (Carey, 1988, 155) His metropolitan-hinterland thesis is a prominent aspect of his work on early Canadian staple economies, and also has direct application to a discussion of modern media practices.

Innis argued that understanding the give and take between metropolitan centres and satellite regions was key to understanding how communications shape cultures. The centre controls access to the necessary resources for communications, the margin challenges that control by developing new means of communications, the metropolis asserts its control over the new medium, in turn shaping the culture of the hinterland, and the cycle continues. This will be a familiar concept to students of Canadian broadcasting policy, which is usually taught as a "too-little-too-late response to the culturally imperialist designs of the United States." (Beale, 1993, online)

But the relationship has never been one of unrelenting dominance and dependence. Rather, as Carey puts it, it is "a complicated interplay of resistance and acceptance." $(1988,83)$ In the context of modern North American media markets, I would argue, the interplay between the United States and Canada has produced an interdependent 
relationship - a healthy Canadian market for American programming, and an equally healthy American market for Canadian talent and creativity.

However, the suggestion that Canadians might somehow identify with American programming (and not just consume it because it is being foisted on us by an insensitive neighbour who does not appreciate our 'unique cultural values') rarely factors into cultural policy debates. Instead, it has been assumed that Canadian identification with American content is itself evidence of ideological alienation which is the very thing that even more Canadian content is supposed to cure. Hence, poor ratings for Canadian programming has never been considered as evidence that the content itself may be unappealing, for whatever reason, to Canadian audiences; to the contrary, it has generally been seen as evidence that we need to produce more of it.

Ian Jarvie observes that:
(A) derived theory of economic or media imperialism . . . could be readily adapted in a left-nationalist reading of Canadian political economy from the perspectives of dependency theory ... In the Canadian context, dependency theory has been ... not just as economistic doctrine, but an ongoing political reflection on the unequal exchange of power between the centre and the margin. (cited in Raboy, 1996, 10)

This notion plays heavily into Marc Raboy's work on how Canadian authorities have historically reacted to new and potentially unsettling communications technologies. He charts a pattern of Canadian resistance and acceptance to new communications technology that emerges from the United States. He calls it "the way in which broadcasting and communications policy comes about in Canada:" 
1. a new technology is developed and placed on the commercial market in the United States. 2. Canadian industry pressures for rapid introduction of a Canadian model on the Canadian market. 3. The Canadian public authorities inquire into the possible impact of the new technology. 4. An operational model is proposed, reflecting the historic compromise between socio-cultural and economic-industrial objectives. $(1990,318)$

Of course, this model runs somewhat against the grain of the usual picture of Canada as existing on the margins of the American metropolis. In Raboy's model - which I adopt in chapter four to examine how Canadian broadcasting regulators have historically responded to the introduction of various new media - Canada reacts as both the centre and the margin: from out of the dominant and untamed economy to the south comes a new technology, spilling into our painstakingly balanced sphere of influence, threatening to upset our carefully considered political and cultural objectives . . a least until we can regulate it into supporting those objectives, at which time we issue the usual proclamations about its potential to help liberate us from American influence.

The metropole-hinterland thesis can also be used to understand how centralized content distributors handle innovations that threaten their established business models. Recent trends in the media environment have seen unlicensed producers and distributors challenging international market leaders, to the point where the bigger company simply absorbs the upstart, altering its original business models in the process, but reasserting effective control over the medium.

For instance, major record labels now offer services that allow people to download music, either for a fee or for free. These services arose largely in response to Napster, 
which pioneered the software that eventually enabled 15 billion unlicensed music downloads, ${ }^{36}$ and as a result, found itself the target of massive lawsuits by those same labels ${ }^{37}$ Or, as Innis might have seen it, "(the) capacity of the new technology ... enhanced the capacity of imperial powers to bring satellite areas within the orbit of their control." (Carey, 1988, 135)

Allison Beale notes that "Innis is blamed for posthumously influencing the so-called dependency orientation of the cultural elite and supporters of public broadcasting in Canada." Michael Dorland (1991) also locates Innis, Donald Creighton, Wallace Clement and Dallas Smyth in this 'dependency' tradition, holding them responsible for the current dependent orientation of Canadian cultural policy.

Under this dependency posture, the assumption is that Canada (hinterland) is forever a subservient broadcasting marketplace to the United States (metropole), and that only by way of corrective state intervention can that cycle of dominance be broken, and our cultural sovereignty preserved. Consider the following quotation from Dallas Smythe, emblematic of this view:

Anglophone Canadians have been substantially assimilated to American cultural values of all kinds, after their dependency on Britain weakened. Several centuries of dependence on Britain and later the United States has given most Canadian people a feeling that the country is inferior in most ways to the imperial way of life. It must be remembered that Canadian views of American life are those of the

\footnotetext{
${ }^{36}$ Rosenberg, S. "As you kiss your tired old CDs goodbye, imagine a broadband future that is not like the Broadcast Past." salon.com, February 4, 2000: http://www.salon.com/tech/col/rose/2000/02/04/napster_swap/

${ }^{37}$ See "Record Labels Sue Napster": http://news.com.com/2100-1027-997860.html At is peak, Napster had 80 million users who traded over 15 billion songs. Source: Grimes, C. "Play it again -Napster proved there was a demand for online music." The Financial Times. August 29, 2001.
} 
colonial. More specifically, the economies of scale make possible and necessary in the United States Consciousness Industry the production of media material with a degree of technical virtuosity, glitter, and glamour which indigenous Canadian productions can imitate only weakly. $(1981,182)$

This "colonial" view of domestic broadcasting is not particular to Canada. Writing about the popularity of American programming in Britain, Raymond Williams complains that "at certain levels, we are culturally an American colony." (1981, 109) I would argue, however, that Canada's relationship with the United States, at least where broadcasting markets are concerned, is not one of perpetual dependence, but one of highly developed interdependence.

We create ownership, access, advertising and content rules that under-privilege or challenge the dominance of American broadcasters operating in our market. In some cases we require them to sell the rights to their programming to a Canadian intermediary, rather than accessing our market directly (e.g. HBO, ESPN). In other cases, where we cannot prevent their over-the-air signals from reaching Canadian audiences, we take steps to ensure that they cannot capitalize on that viewing in the form of advertising revenue (e.g. NBC, ABC, CBS). We do this out of an official fear that our culture will otherwise be subjugated by American culture. These controls have helped stimulate the expansion of the Canadian broadcasting system. Of course, most Canadian television and radio stations populate their schedules with predominantly American programming, undermining, it could be argued, the official efforts to distinguish ourselves by way of a distinct broadcasting system. 
At the same time, the Canadian broadcasting system has not been subsumed by the American system, despite the fact that most production and consumption is of American (or American-style) programming. Far from being absorbed into American programming markets, we spend $\$ 3$ billion a year on Canadian programming, ${ }^{38}$ and we supply a large portion of the creative talent and labour upon which that American television and music programming relies. ${ }^{39}$ American production companies shoot many of their television programs in Canada. ${ }^{40}$ This suggests that the relationship between the centre and the margin in this case is one of interdependence, rather than mere dependence. This further suggests that much of the theoretical underpinnings of the current regulatory framework which I would argue descend directly from Innis's dependency posture - are skewed in the wrong direction.

By persisting in the official belief that Canada is somehow a vassal to American broadcasting markets, our broadcasting policy returns an impoverished picture of Canadian culture, one in which we are forever subservient to trends and decisions made south of the border, and in which the talents and creativity of our producers are only

\footnotetext{
${ }^{38}$ Canadian Film and Television Producers Association Profile 20054.

${ }^{39}$ The Canadian Consulate in Los Angeles maintains an online directory of Canadian actors, directors, writers and designers working in Hollywood. It is updated every two weeks, and currently features some 2200 names. Since October 2001 it has generated more than a million 'hits' or unique visits. See http://www.canadiantalentla.com/. According to this website, Canadians received 50 Emmy nominations for work on primetime American television series in 2005, 49 in 2003, and 62 in 2002.

${ }^{40}$ According to the Canadian Film and Television Producers' Association (CFTPA) there was $\$ 1.95$ billion in foreign-financed film and television production in Canada in 2004, above and beyond official coproduction work. As Canada has co-production treaties with virtually every industrialized country but the United States, it stands to reason that the bulk of that 'foreign location shooting' was by American producers -presumably, anyone else would have hired a few Canadians in minor roles (enough to earn 6 out of 10 points on the Cancon scale), qualified as an official co-production, and gained access to lucrative CAVCO production and service tax credits. CFTPA Profile 2005, 13: http://www.cftpa.ca/newsroom/pdf profile/profile2005-english.pdf
} 
deemed to make a contribution to 'our national identity' if they fit a narrow, politicallydefined policy mould.

The space (transmission) and time (ritual) bias

James Carey finds similar impulses in the American communications experience to those that resulted in the micro-regulation of broadcasting in Canada. Faced with a large landmass and dispersed population from a multitude of backgrounds, Americans turned to the "transmission or transportation solution":

How were we, to use a phrase of that day, 'to cement the union?' To make it all too simple, the answer was sought in the word and the wheel, in transportation and transmission, in the power of printing and civil engineering to bind a vast distance and a large population into cultural unity or, as the less optimistic would have it, into cultural hegemony. (Carey, 1988, 5-7)

In his most famous construction, Innis developed a theory of the ways in which communications and transportation systems structure (or "bias") relations of time and space. Space-binding media are those that extend the reach of messages across distances, such as print and broadcasting across wavelengths. Time-binding media are those that extend the reach of messages across the ages, such as sculpture and story-telling. Innis associated space-binding media with messages that permitted the expansion of control over territory, and time-binding media with the survival of the stories and myths that form our collective memory and that give legitimacy to our institutions.

Carey interprets Innis as allowing us to see communication on one hand "as a process of transmitting messages at a distance for the purpose of control," and on the other, as a process of "persuasion; attitudinal change; behaviour modification; socialization through 
the transmission of information, influence or conditioning, or alternatively, as a case of individual choice over what to read or view." (1988, 42-43) He refers to these as the transmission and ritual views of communication.

A transmission view of communication is directed toward the extension of messages in space, while a ritual view is directed towards "the maintenance of society in time ... the creation, representation, and celebration of shared even illusory beliefs . . the sacred ceremony that draws persons together in fellowship and community." (Carey, 1988, 43)

Building on Raboy's model of how we historically respond to new technological advances, two camps tend to emerge on most questions of communications policy - the industrial (economic) and the cultural (political). I equate the industrial camp with the transmission view of communications, and the cultural camp with the ritual. The industrial camp looks to the open market to maximize the business potential of each new gadget, while the cultural camp looks to the regulator to make sure it does not undermine our cultural policy objectives (or, cynics might charge, to make sure that the business potential is channelled in favour of their particular constituencies).

Broadly speaking, business looks to the new technology and sees a new way to make money transmitting messages across space, while cultural nationalists look at it and see a new way to enhance our 'cultural sovereignty' by 'telling stories that reflect unique Canadian values'. The regulator then tries to strike a balance by grafting rules and 
regulations onto the operations of the new gadget, generally dressed up in ritualistic rhetoric about the power of sound and images to preserve our unique Canadian values.

The 'transmission' advocates believe that resources will be allocated to their highest valued use, ultimately increasing their capacity to transmit more messages even faster across space. The 'ritual' advocates believe communications to be too important to be left to the open market, and that we need regulatory oversight to ensure that 'our culture' survives across time, and is not drowned out by the increasing volume and frequency of messages. Their argument is an enactment of an old stimulus-response notion: prolonged exposure to American content somehow Americanizes us, unless otherwise diluted by regular doses of Canadian values in TV and radio form.

In summary, much of our current regulatory framework is predicated on Innis's political economy: we manage the message by limiting access to the resources necessary to communicate it across space and time; we respond to new technologies that threaten our ability to manage those resources by assimilating them to our overall cultural project; in so doing, we try to strike a balance between the economic and political potential of the new technology.

But is Innis's political economy still the right foundation for our broadcasting policy? He wrote of ancient cultures whose development unfolded over thousands of years. The changes Innis relates to developments in communications media took millennia to resonate. It is only on a metaphorical basis that his work can be applied to our current 
communications marketplace, in which cultural phenomena unfold overnight, in which cultural artefacts reach millions of people instantaneously, and vanish the moment they are consumed. Moreover, the civilizations that interest Innis expanded their empires by force. As satisfying an appeal to anti-Americanism as it may be, it would difficult to sustain the view that sitcoms and pop music are a precursor to armed invasion by the United States.

At the heart of our cultural policy is an overdramatic declaration of dependence, an assumption of cultural subservience. Our broadcasting policy assumes that without carefully maintained walls and gates, we would be powerless to stand up to the imperialist impulses of our bullish American neighbours. This is turn paints Canadian audiences in the worst kind of light: passive, overexposed to outside influence, unable to make correct cultural choices without a restricted menu.

By relegating Canada to the periphery of American influence, our broadcasting policy ignores how permeable the supposed centre is to outside persuasion. The thousands of Canadians working in Hollywood are only one example. The American audiovisual market is nothing if not diverse, reacting to international influence and styles almost effortlessly - consider the popularity not only of Canadian stars, but of foreign films, books, and art.

The following chapter discusses the notion of cultural diversity in greater detail, but it is worth noting that even if we did accept the current series of policy propositions (i.e. that 
American cultural artefacts are substantially different from Canadian cultural artefacts, that economies of scale privilege American producers to the degree that their content would invariably drown out Canadian content, assimilating us to American values in the process, and that we therefore need policy bulwarks against that assimilation), then why should regulated access to the Canadian market be limited to broadcasting?

In the following two chapters, I examine the economic and cultural perspectives behind our current approach to broadcast regulation, testing their relevance in light of current conditions. 


\section{Chapter 2: economic assumptions}

"Whatever problems plague the Canadian market for popular Canadian culture, they have little to do with the products of that culture or their producers. They are not even particularly Canadian. They have everything to do with the unique economic behaviour of cultural products in general."

Peter Grant and Chris Wood, 2004

"The argument has come to rely, almost exclusively, on ... economies of scale.

Canadians are different, the argument runs, and would naturally choose works of art that spoke to these differences, in preference to the alien art that comes to us from south of the border. But they are not presented with such a choice, or not on equal terms, because of the immense scale economies available to producers of American art, by dint of the huge national market, who may thus undercut Canadian producers in their own."

Andrew Coyne, 1996

As noted in chapter one, the theoretical underpinning of state intervention in broadcasting is rooted in notions of scarcity: we need to maintain a closed-access broadcasting system because we need to make the best use of a scarce resource, the broadcasting spectrum. Notions about the ways in which we produce, consume and interact with content are also inherent to the economics of broadcasting regulation.

McFayden, Hoskins and Finn state that "the belief that indigenous programming and film possessing desirable attributes can make viewers better citizens is at the heart of both the economic and cultural arguments" for state intervention in the cultural industries. (2000,

3) If the objectives behind cultural regulations have not been clearly met, they 
conclude, it is "because of an inadequate understanding of the economic motivations of the participants and the effect on their conduct." $(2000,10)$

Ken Goldstein similarly links economic, industrial and cultural motivations, citing four "framing propositions" for state intervention in broadcasting:

a radio frequency spectrum with interference characteristics, assumption that the spectrum and/or the market would allow only a very limited number of players, or even just a monopoly; a concern about the size of the Canadian market in relation to the adjacent US market, and the fear that Canada would be overrun with US content. $^{41}$

Raboy makes a similar point, citing "the institutionalization of discourses of scarcity (whether of the spectrum, of channels, or of programming)" that characterize Canadian cultural policy debates. $(1996,3)$ These "discourses of scarcity" are reflected in several economic assumptions about the behaviour of broadcasting content in the Canadian marketplace.

To ensure Canadians benefit from the 'externalities' (or, "desirable attributes") of Canadian TV and radio, we are told, state intervention is necessary to offset the natural competitive advantage that American broadcasters enjoy by virtue of their vastly larger domestic market: if it were not for market access rules, the theory runs, there would be a scarcity of Canadian broadcasters as American broadcasters swept in and bought them up or otherwise ran them out of business. Americans' competitive advantage is multiplied by the low cultural discount to American content as it crosses the border heading north:

\footnotetext{
${ }^{41}$ From "What works: Some practical considerations for the role of the state in broadcasting." Paper presented to the International Seminar on the Role of the State in Broadcasting. McGill University, Montreal, January 25, 2005.
} 
if it were not for content quotas, the theory runs, there would be a scarcity of Canadian content as it was swamped by cheaper American content.

To come at this from a theoretical angle, conventional economic wisdom is that access rules and content quotas are necessary to counter the 'public good' attributes of broadcasting content: because consumers of conventional television or radio cannot be excluded from accessing the signals, it is impossible to charge them for the content directly. Because it is impossible to charge them directly, it is impossible to know how badly they want to watch any given program - i.e. how much they are willing to pay for it. Accordingly, programming decisions are based on serving the largest common denominator. In catering to the largest possible market, broadcasters overlook or underserve whatever natural niche market for Canadian content exists. As a result, the market fails to provide the 'externalities' that flow from Canadian programming.

Fellows, Flanagan and Shedd refer to 'externalities' as "social spillover benefits or costs that flow from the private consumption or production of a product." $(1997,555)$ McFayden, Hoskins and Finn define "external benefits" or "positive externalities" as the "positive side-effects from viewing" television programs. $(2000,3)$ Currie, Hooper and Carter cite "the presence of externalities" as one of the arguments in favour of public broadcasting: "an individual's viewing can have additional benefits for society as a whole, for instance, through his or her engagement in the democratic process as a more educated citizen." (2004, 72) 
Without agreeing, Grant and Wood acknowledge the common criticism that because external benefits cannot be measured, they should not be used to justify state intervention. $(2004,59)$ For example, Andrew Coyne argues that "though many have been claimed, it is not all clear what real benefits those who do not go to the theatre, for example, get from those who do, or why we should take it on faith that these 'externalities' are worth more than those of other putative public goods, each with its own case for subsidy." $(1996,2)$

So, when the 1929 Report of the Royal Commission on Broadcasting (the Aird Report) frets that Canadian youth were being exposed to "ideals and opinions that are not Canadian" (cited in Bird, 1988 42) it was, in other words, worried that American externalities were displacing Canadian externalities. In this sense, the notion of "external benefits' is another way of understanding both the cultural and economic imperative for state intervention in broadcasting.

A related economic concern is whether Canadian broadcasters can compete with their better capitalized American counterparts in the absence of market access rules. The commonly cited concern is that 'economies of scale' enjoyed by American broadcasters are realized in the 'sunk' and 'discriminatory' costs of broadcasting content, and that this hands Americans a competitive advantage over Canadian producers, begging corrective state intervention to 'level the playing field'. 
Baker notes that "communications can often be cheaply provided for everyone after being originally produced." $(2002,19)$ Grant and Wood cite the "near-zero marginal costs" of providing additional copies of content, after the initial investment is "sunk" into the first copy, as the key element in "discriminatory pricing." (2004, 131)

They note that as result of "sunk" or "discriminatory" pricing, producers can resell a cultural good in foreign markets at a price that bears no relation to the original cost of its production: "no matter how cheaply a local broadcaster can buy or make an indigenous drama, distributors of U.S. shows can undercut that cost." (2004, 131). Liss Jeffrey agrees, arguing that "the problem is structural. U.S. producers enjoy competitive advantages because they can recover most of their production costs in a market ten times the size of Canada's." $(1996,205)$ Linda McQuaig figures that since "Canadian networks can buy these U.S. programs for a fraction of what it would cost to generate original Canadian programming," they "would run virtually nothing but American shows if Ottawa did not require them to make some room for Canadian content."42

This is the main economic argument for the need to carve out an official space in the domestic market for Canadian broadcasters, and an official space within their schedules for Canadian programming: faced with cheaper imported competition, Canadian broadcasters would otherwise be constrained in their ability to provide Canadian programming. That constraint stems not only from the advantages of scale enjoyed by

\footnotetext{
${ }^{42}$ McQuiag, L. "Will we benefit from U.N. pact on cultural diversity?" Toronto Star, October 30, 2005. A16
} 
American broadcasters, but also from the 'public good' and 'non rivalrous' nature of broadcasting content

Fellows, Flanagan and Shedd define 'public goods' as commodities in which "no one person can identify the specific part of the benefit he or she receives and benefits cannot be excluded from any member of the group." $(1997,112)$. Grant and Wood adopt a similar definition, finding that "public goods have two distinct aspects: "nonexcludability' ... and 'non-rivalrous consumption'." (2004, 56) McFayden, Hoskins and Finn note the 'joint consumption' characteristic of television content, "meaning that viewing by one person does not detract from the viewing experience enjoyed by others," and that "it is impossible or too costly to exclude any person from consuming" broadcast content. (2000, 3) Harold Vogel finds 'public good' attributes in cultural content where the "cost of production is independent of the number of people who enjoy the benefits and (where) one person's consumption does not reduce the quantity available to others." (2001, 189) Currie, Hooper and Carter note the problems caused for the market because "programmes, once made and broadcast, can be consumed by additional viewers at little or no additional cost to the broadcaster." $(2004,71)$

The 'non excludability' of broadcasting content is often used to justify Canadian content quotas: if we cannot keep someone from accessing the signals, then we cannot charge them directly for them. If we cannot charge them directly, we cannot tell how much they would be willing to pay for them, which is another way of saying that we cannot tell precisely how much they want them. 
The result, as Andrew Coyne has noted:

is to reduce decisions on which programs were produced to one dimension: size of audience. Even if a minority of viewers were greatly interested in a program, and hence, willing to pay a premium for it, the minority would always be outvoted by the larger number of viewers another program might attract, no matter how indifferently they might feel about it. ${ }^{43}$

In other words, the 'public good' nature of broadcasting content means that the market cannot always ensure a diversity of choices, reflective of every taste. In the absence of Canadian content quotas, the argument goes, there is no guarantee that the market would provide Canadian content, or the positive externalities that flow from it.

Coyne also cites the 'non-excludability' of broadcasting content as one of the main reasons why advertising is sold the way it is, and one of the main arguments for funding a public broadcaster (perhaps the most overt form of state intervention in the marketplace). He notes that "people tend to think of public funding and ad finance as opposed. But in fact they have much in common. Both evolved as solutions to a problem of television's infancy: namely, the impossibility of charging viewers directly for the programs they watched." ${ }^{44}$ He argues that in an advertising-funded marketplace programming is not produced and sold to viewers: rather, viewers themselves are the product, to be packaged and sold to advertisers. The effect is to focus programmers on quantity, as opposed to quality. What counts is how many eyeballs happen to be watching, regardless of how intensely they may be watching. Hence the familiar evils of private broadcasting: the tendency to the

\footnotetext{
${ }^{43}$ Editorial, "Beyond the network mindset." Globe and Mail. April 13, 1995. C1.

${ }^{44}$ Coyne, A. "Let the viewers decide." National Post. September 24, 2005. A15.
} 
lowest common denominator, the indifference to specialized tastes, the monotonous sameness, all in pursuit of the broadest possible audience. ${ }^{45}$

Of course, as the three channel universe became a 30 channel universe, then a 300 channel universe, the number of people watching any given channel at the same time got smaller and smaller. The connection between this audience fragmentation and a general lowering of the 'quality' of programming (a frequent complaint about the 300 channel universe) has also been explained by Innis's staple theory.

For example, Ken Goldstein uses Innis to explain the current trend toward low-budget television productions. He concludes that "fragmentation puts downward pressure on unit costs"-i.e. as the cost of transporting goods becomes cheaper, the goods become more ubiquitous, and the individual value of the each separate good being transported declines. For example, Innis writes that "as the costs of navigation declined, less valuable commodities emerged as staples-precious metals, timber, and finally wheat." $(1951,6)$ Goldstein translates this into "as the costs of channels declined (because of digital distribution), less costly programs emerged as staples-long-form drama, variety programs, and finally reality-based shows." $(2005,5)$

To summarize, the economic reasoning behind much of our broadcasting policy hinges on scarce broadcasting spectrum, large audiences that are hard to measure precisely, and better-capitalized foreign competition. Chapter 5 focuses on challenges to these old economics posed by recent developments in technology. The old economics were about scarcity and large audiences; the new economics are about the reverse. Accordingly,

${ }^{45}$ Ibid. 
much of the traditional economic understanding of Canadian broadcasting policy has been overtaken by events.

The notion of broadcasting as a strict 'public good' is challenged by encryption technologies that have made it progressively easier to ensure the customer pays -at least the first time they download it to their set-top box or iPod. Consumption is becoming more personalized at the audience level, meaning that it is less centralized at the policy level. This challenges assumptions about the external benefits that flow from a large audience consuming the same content at the same time. Of course broadcasters have an incentive to program for as large an audience as possible, and to adjust costs to the size of that audience. But as content becomes increasing personalized, reproducible and portable, It is becoming increasingly feasible to program (and advertise) to increasingly narrow audiences. ${ }^{46}$

The old economics also embody assumptions about of the external benefits of Canadian content that are every bit as subjective and selective as the cultural arguments outlined in the following chapter. If the economics of the Canadian broadcasting market are such that it cannot support the efficient production of Canadian content, this is only a problem if Canadian content is preferable to American content (i.e. if the values and ideals

\footnotetext{
${ }^{46}$ Some of the newest American 'broadcasters' do not broadcast at all. Rather, they make a library of content available, under a brand, to cable companies to licence for inclusions in their on-demand inventory. For example, Sportskool provides a range of sports instruction videos to American cable companies, who list Sportskool as a separate category on their VOD menus. The company has no linear television presence, and exists only in an on-demand space, where viewers to any given program at any given time can be counted in the hundreds, not millions. (See: www.sportskool.com) This of course has a particular appeal to advertisers who can target specific customers based on specific viewing preferences. Chapter 5 examines on-demand advertising in more detail.
} 
conveyed by Canadian content are preferable to the values and ideals conveyed in American content). 


\section{Chapter 3: cultural assumptions}

"Canada has a vital need for a broadcasting system that .. . harnesses the contributions of all Canadians to strengthen the country's cultural, political, social and economic fabric."

Canadian Radio-television and Telecommunications Commission, $2005^{47}$

"No other communications medium has had this charge laid upon it by Act of Parliament: 'to safeguard, enrich and strengthen the cultural, political, social and economic fabric of Canada.' We rely for this on the same medium that is the principal advertising mainstay for the soap industry."

Report of the Special Senate Committee on Mass Media, $1970^{48}$

Certain social and cultural benefits of a Canadian-owned and operated broadcasting system have long been assumed. A through-line runs from the earliest government studies on broadcasting to the most recent: from the Aird Report in 1929 to the Lincoln Report in 2003, government studies have long linked Canada's cultural sovereignty to the 'Canadianess' of its broadcasting content.

This theme hinges on some basic assumptions. The first is that broadcasting makes a direct, if imprecise, contribution to citizenship, cultural identity, and political stability. The second is that if we are exposed to too much American content, we will lose some

\footnotetext{
${ }^{47}$ See Public Notice CRTC 2005-24 (21 March 2005) Commission's response to the report of Task Force for Cultural Diversity on Television: http:/www.crtc.gc.ca/archive/ENG/Notices/2005/pb2005-24.htm

48 "The Uncertain Mirror: Report of the Special Senate Committee on Mass Media." (1970) Queen's Printer for Canada.
} 
measure of our distinctiveness vis-à-vis the United States, and become a weaker, less distinct culture as a result. This in turn assumes that if we are constantly primed with Canadian cultural references via Canadian television and radio, we will somehow develop a distinctive and intuitive patriotism.

Under this assumption, as Andrew Coyne observes, American content is not necessarily inferior-indeed it is frequently acknowledged to be superior but rather is simply foreign. For the cultural nationalist, a nation's culture is not an organic necessity, the product of its citizens' natural human urge to create: it is a thing forever threatened with extinction, imperilled not so much by the ignorance or indifference of the art-going public, but by their cosmopolitanism. ${ }^{49}$

In our readiness to accept the content of another culture, the theory goes, we dilute our own. The government trades heavily on Canada's multicultural character, but at the same time, warns us to consume American culture in moderation.

Liss Jeffrey notes that the "the cultural sovereignty position highlights three key points: the linkage between identity formation and exposure over time to television; the linkage between television and cultural diversity; ... and the linkage between political unity and a broadcasting system that is predominantly Canadian." $(1996,215)$ These points can be thought of as the main cultural assumptions behind Canadian broadcasting policy-if we watch enough American television, or listen to enough American music, we will become more American in our identity.

\footnotetext{
${ }^{49}$ Coyne, A. "Against Art Subsidies." Next City Magazine, Fall 1996.
} 
For this to be true, we must somehow be able to distinguish what is and what is not Canadian content. But the current policy framework is not concerned with the content itself -it is concerned with the passport a creator happens to hold. In this sense, the government approved picture of 'Canadian culture' is not something organic, but rather something synthetic, existing only within a narrow range of official criteria, definable only by means of standardized testing.

As this chapter will demonstrate, the regulatory framework reduces 'Canadian culture' to a fundamentally self-defeating set of equations: to protect our inclusive culture we reduce it to an exclusive question of citizenship; to preserve our cultural diversity, we limit access to as diverse a range of cultural products as possible; to ensure our cultural independence from the United States, we administer a system of rules that furthers our interdependence with the American broadcasting system.

\section{Cultural identity and national citizenship}

Canadian broadcasting policy treats audiences as essentially passive receptors of television and radio. Exposure to any television program or piece of radio content produced by a Canadian is assumed to automatically invest the listener with some indefinable sense of 'Canadianess.' Exactly how that happens is not at issue in our broadcasting policy. The impact of content on its audience is simply assumed, as is the linkage between the nationality of the producer and the "expression of the country's identity," as it resides in the soap opera or pop song in question. 
In their recent defence of nationalist cultural policies, Grant and Wood allow that national identity is a "fuzzy concept" in that there is no test that can capture it "with perfect precision." However, they maintain that public policy "is capable of devising a test" to measure "the 'national' and indeed 'cultural' values embedded in commercial creative goods." (2004, 4 and 149) The tests they go on to describe, however, do not measure values at all, they measure citizenship.

No fewer than five federal bodies (CRTC, Telefilm, CAVCO, CTF, CMF) are currently engaged in the implementation of tests to determine the nationality of broadcasting content. For the most part, the test is straightforward: if you have a Canadian passport or social insurance number, you qualify as a Canadian for the purposes of Canadian content rules. The assumption that flows from this test is murkier: once you qualify as officially Canadian, any programming to which you contribute money or creativity will somehow embody and reflect your Canadian identity.

The CRTC sets specific Canadian spending and exhibition quotas for Canadian radio and television broadcasters. It relies on a points scale administered by the Canadian Audiovisual Certification Office (CAVCO), which determines which programs meet those quotas. That scale assigns a certain number of points to each proposed production, based on how many "key creative" positions are held by Canadian citizens. Any production with six or more points (out of a possible ten) counts as Canadian for the purposes of meeting CRTC Canadian content quotas. ${ }^{50}$

\footnotetext{
${ }^{50}$ See CAVCO guidelines: http://www.pch.gc.ca/progs/ac-ca/progs/bcpac-cavco/index_e.cfm
} 
Telefilm Canada applies the same CAVCO 10-point scale to international co-productions in order to assess whether a co-production counts as officially Canadian for the purposes of meeting CRTC quotas, whether it qualifies for public financial support, and if so, how much. The Canadian Television Fund subjectively measures Canadian "themes, subject matter and points of view," in order to determine if a proposed production is Canadian enough for public support. ${ }^{51}$

The CRTC and the CMF (Canadian Music Fund) apply the so-called MAPL test -Music, Artist, Production, Lyrics - for the purposes of determining whether a proposed album qualifies for public financial support, and whether particular songs count toward regulatory quotas for radio. If any two of the four criteria are Canadian, so is the song. ${ }^{52}$

These agencies and their various practices respond to the 1929 Aird Report's concern that " ... the majority of programs heard are from sources outside of Canada ..." and that "the continued reception of these has a tendency to mould the minds of young people in the home to ideals and opinions that are not Canadian."

The underlying assumption behind the cultural nationalist's position is that only Canadians can produce programming that reflects Canadian themes, or that contains

\footnotetext{
${ }^{51}$ See Canadian Television Fund Guidelines: http://www.pch.gc.ca/progs/ac-ca/progs/fct-ctf/index e.cfm

${ }^{52}$ See section 9 of the Radio Broadcasting Regulations for a description of how MAPL is applied in a radio context: http://www.crtc.gc.ca/eng/LEGAL/Radioreg.htm . See http://www.pch.gc.ca/progs/acca/progs/fmusc-cmusf/music_fund_e.cfm for CMF guidelines. At least one agent who represents new recording artists has cleverly suggested that bonus points should be awarded if the song is by a new or 'Emerging' artist, adding the E to MAPLE, as it were.
} 
recognizable Canadian elements, and that in the absence of these themes and elements, we will begin to think and act more like Americans. Left unsaid is that thinking and acting like Canadians is preferable to thinking and acting like Americans.

This concern, and the elaborate regulatory framework that responds to it, assumes a direct correlation between ownership and content -i.e. that only Canadians can produce content that reflects Canadian "ideals and opinions." It also assumes that prolonged exposure to American ideals and opinions will "mould minds" in ways that are not Canadian, undermining our national and cultural identity, and threatening our cultural sovereignty, and ultimately, endangering cultural diversity.

The assumption that Canadian television and radio content can ensure or preserve Canadian identity presupposes that it contains some characteristics or markers with which Canadians instinctually identify, and that we must be able to recognize the presence or absence of those markers in any given program or song. It follows that any program or song that displays those markers will be recognized by Canadians as 'Canadian', and will subsequently go to work moulding our minds to Canadian ideals and opinions.

But this is hardly the case: 'official' Canadian content is not necessarily content that contains Canadian themes and references, but content produced by Canadians. To CAVCO, the CRTC, Telefilm and FACTOR, the ideals and opinions contained within the content are irrelevant; it is the citizenship of the creator(s) that determines, supposedly, how Canadians will respond to the final product. If the creators are 
Canadian, then the final product is presumed automatically to reflect Canadian ideals and opinions, and hence, make a direct contribution to Canada's cultural identity.

A television program produced and financed by an American-born producer, holding a Canadian passport, shot in the U.K., set in Rome, featuring German characters, eating Japanese food, would count as official Canadian content on the CAVCO scale. The same program, shot in the same studio, with the same script, same actors and same setting, produced and financed by an American without a Canadian passport, would not.

A country song written, scored and recorded by a Canadian, living in Nashville, about an Australian living in China counts as Canadian on the MAPL scale. A song written, scored and recorded by an American, living in Toronto, about a Canadian living in Winnipeg, does not.

The current policy framework accommodates financing and talent from some foreign sources, but not others. Telefilm administers over 50 co-production treaties between Canada and other countries. These agreements "enable Canadian producers and their foreign counterparts to pool their creative, artistic, technical and financial resources to coproduce films and television programs that enjoy the status of national productions in each of the countries concerned." 53

${ }^{53}$ See Telefilm Canada website: http://www.telefilm.gc.ca/04/41.asp 
For example, under the terms of our co-production treaty with Bulgaria, a program produced by a Bulgarian production company, featuring a Canadian lead actor, music composer, and director could be considered $100 \%$ Canadian content for the purposes of qualifying for federal funding, or for meeting the CRTC's Canadian content quotas. At the same time, it could count as 100\% Bulgarian content for any Bulgarian regulatory purposes. If this undermines any official cultural assumptions about the influence of a producer's nationality and the 'nationality' of the content, the government is ready to live with that discrepancy, on the grounds that co-productions "promote quality and demonstrate remarkable energy and understanding of markets, making Canadian producers valued, sought-after partners. ${ }^{.54}$

Of course, this is not true if it is an American production company paying half the bills. Canada has co-production treaties with Senegal, Malta, and Uruguay (not widely known as centres of film production), but not with the United States. The assumption, apparently, is that Canadian identity is strong enough to withstand the foreign influence of financing from some countries, but not others. In fact, each year since 2002, Telefilm has approved three or four 'quadripartite' co-productions featuring some combination of Canadian, German, British, Italian, Czech, Luxembourgeois, French and Swiss financing and talent. ${ }^{55}$ These productions qualified as $100 \%$ Canadian content, meaning that viewing it will, according to our current policy, invest Canadian audiences with Canadian ideals and opinions. However, had the, say, Czech or Italian or German partner been

\footnotetext{
${ }^{54}$ Ibid.

${ }^{55}$ See Telefilm Statistics on Co-Production 2002-2005: http://www.telefilm.gc.ca/04/42.asp
} 
American, the production would not have qualified as Canadian content, and it follows, would not have communicated Canadian ideals and opinions.

If this seems inherently subjective and inconsistent, it is hardly surprising, given the highly selective notions of 'Canadianness' at work in our various cultural policy institutions. For example, the test for Canadian "themes, subject matter and points of view" applied by the CTF is so narrow that a proposed documentary about a nun in Quebec City who treated the wounded at the battle of the Plains of Abraham was rejected because it "is about history before there was a Canada," and hence, not Canadian. ${ }^{56}$ Apparently, the CTF is subject to its own time bias.

At the same time, the supposedly objective labour-input tests employed by the CRTC, CAVCO, Telefilm and FACTOR are actually just as subjective as the CTF's thematic tests. The test awards two points if the director or screenwriter is Canadian, but only one point if the highest-paid actor is Canadian. Bizarrely, the second-highest paid actor must always be Canadian. The assumptions here are as clear as they are speculative: that the input of directors and screenwriters leaves twice the cultural residue on the final program as the lead actor (who, it follows, must not inject as many cultural markers as the supporting actor, who must in all circumstances be Canadian). This bears out Tyler Cowen's observation that it is unclear why "individuals latch on to some cultural elements as comprising distinct markers of identity and meaning, while attaching little significance to other markers." $(2002,136)$

\footnotetext{
${ }^{56}$ See Posner, M. "TV producers blast fund's 'parochial' Canadian-content rules." Globe and Mail, February 14, 2005, R7
} 
Citizenship criteria for a particular program or song are also as selective in conception as they are in application. If Canadian television and radio programming contributes to the formation of Canadian ideals and opinions, surely the same can be said of Canadian books and newspapers -yet apparently, distribution and exhibition quotas in publishing are not necessary to ensure our cultural identity, as they are in broadcasting.

There are restrictions on foreign music on radio, but not on foreign wire copy in newspapers. The CRTC permits some American channels direct access to the Canadian market, while restricting others - reflecting Cowen's further observation that when it comes to cultural nationalism, it is usually unclear "which external influences will be accepted and which will continue to be classified as harmful intrusions." $(2002,139)$

The assumptions about ownership, labour, and content that lie just below the surface of Canadian broadcasting policy are so selective and inconsistent as to be essentially meaningless. Officially 'Canadian' programs and songs are often indistinguishable, for all intents and purposes, from American programs and songs. Yet because it was financed or produced by someone with a Canadian passport (or by someone with a passport from a country with which we have a co-production treaty) the official assumption is that it contains and conveys Canadian values, and by its very presence, contributes to a 'diverse' cultural marketplace. 


\section{Broadcasting and cultural diversity}

In Canadian broadcasting policy circles, ensuring cultural diversity in Canada does not mean ensuring access to as wide a range of content as possible. Rather, it means ensuring access to as wide a range of narrowly-defined content as possible. Only those television and radio programs that meet a narrow set of official citizenship criteria constitute Canadian content, and are therefore assumed to make a contribution to our official cultural diversity.

In this construction, anything that does not meet those criteria not only fails to reflect that identity, but threatens to overwhelm it. This concern is not uniform, however, as American content is often assumed to pose a greater threat to cultural diversity than, for example, British content: the recent lockout of employees at the $\mathrm{CBC}$ led to the replacement of the usual $\mathrm{CBC}$ National news with news from the $\mathrm{BBC}$. In the current policy climate, it is inconceivable that the $\mathrm{CBC}$ would have replaced its nightly newscast with one from, say, PBS, let alone CNN or Fox News. This lends further strength to Cowen's argument about some external influences being seen as threats while others are deemed to be acceptable: outside British influences are acceptable, outside American influences are harmful.

Grant and Wood acknowledge that "the world of cultural expression is vastly enriched by the free flow of ideas across borders," $(2004,3)$ but fret that "the distribution of cultural products is often in the hands of gatekeepers who reduce choice rather than expand it." $(2004,1)$ Of course, they are referring here to business gatekeepers, whose practices, 
they argue, must be mitigated by government gatekeepers. Accordingly, they find in favour of regulations that discourage or limit the distribution of foreign content, arguing that

unrestrained free trade in the cultural sector, far from yielding higher real income for all participants, would simply institutionalize the dominance of a few advantaged producers and prevent governments from taking effective measures to ensure shelf space and choice for diversity of cultural expression. $(2004,357)$

Cowen writes that this type of concern over a loss of cultural diversity in the face of foreign cultural products

makes two separate and partially contradictory charges. On one hand, there are critics of the American ethos of 'commercialism and individualism.' On the other hand, there are critics who are more generally concerned with the spread of homogenized, mass market culture, and the perceived threat it poses to national, or regional cultures." $(2002,93)$

He finds that cultural nationalists inevitably try to increase diversity within their society by limiting the amount of diversity across societies. He would agree that Canadian broadcasting policy makers are prepared to "... tolerate a less extensive menu of choice, if in return, they can maintain their special status to a greater degree. It is identity they seek, not choice, per se." $(2002,131)$. To be sure, the current Chair of the CRTC once remarked that "support for Canadian programming may require restricting the choices of services available to (the viewer), ${ }^{, 57}$ which is another way of saying that it is sometimes in the public interest to prevent the public from viewing what it is interested in: we will ensure domestic diversity by limiting international diversity; we will ensure domestic choice by restricting international choice.

\footnotetext{
${ }^{57}$ Charles Dalfen, quoted in Galloway, G. "Broadcasters offered ads for home-grown drama." Globe and Mail, November 30, 2004, B7.
} 
These "partially contradictory charges" are also realized in the partially contradictory mandate of the Department of Canadian Heritage: it supports policies that restrict the flow of cultural products into Canada, but, at the same time, operates programs that support the flow of Canadian cultural products out of Canada, and into other countries. The departmental website states that: "The Department of Canadian Heritage seeks to ensure that the Canadian cultural sector not only maintains, but expands its position as a world content provider and as a leading force in the global information society and knowledge-based economy." ${ }^{.58}$ In other words, we are not just content with our current share of other countries' markets for cultural expression, we want more of them.

At the same time, Canadian Heritage has long advocated cultural exemptions to Canada's international trade agreements. These exemptions make it possible for Canada to limit access to cultural exports from other countries. Moreover, successive ministers of Canadian Heritage have been leading advocates of the recently ratified UNESCO convention that preserves the right of countries to set cultural policies favouring domestic cultural products over imported cultural products - up to and including barring their access to home markets (in theory, if not in practice). ${ }^{59}$

\footnotetext{
${ }^{58}$ See Canadian Heritage Trade and Investment Development Directorate website: http://www.pch.gc.ca/progs/ac-ca/progs/rc-tr/progs/ddci-tidd/index_e.cfm

${ }^{59}$ For a thorough discussion and analysis of Canada's treatment of cultural products within international trade systems, see Jason Bristow's doctoral dissertation "Canada and the Cultural Trade Quandary: Rethinking National Identity, Economic Liberalization and Policy Capacity." Carleton University 2003.
} 
So, while the Department believes on the one hand that we need to increase our exports of Canadian cultural products, it also believes, on the other hand, that imports of foreign cultural products threaten domestic cultures. In this sense, 'protecting our culture' means protecting it from foreign competition. As Adamson notes, by enshrining our right to limit imports of cultural products, "the (UNESCO) convention gets in the way of the very cultural diversity it purports to support, all in the name of something impossible to define or quantify.", 60

\section{Broadcasting and cultural sovereignty}

Marc Raboy writes that

Canadian cultural nationalists want to preserve, or develop, a set of social or cultural values that will guarantee Canadian distinctiveness from the United States. Once that is understood, it is not difficult to comprehend the cultural nationalist's position that state intervention, direction, and even ownership (of broadcasting) must be seen as fundamental to the whole process of differentiating Canada from the United States." $(1997,4)$

The way these cultural assumptions play out on a Canada-United States level can be illustrated by comparing them to a Quebec-Canada level. "In Quebec," Raboy notes, "the attempts to use state power for the promotion of cultural sovereignty was an ironic replication on a smaller scale of Canadian policy with respect to the States." $(1990,12)$

Raboy's 1990 history of Canadian broadcasting policy treats the tension between Ottawa and Quebec over which level of government should have jurisdiction over communications as one of the formative elements in the evolution of our current

${ }^{60}$ Adamson, R. "Will we benefit from UN pact on cultural diversity?" Toronto Star, October 30, 2005. A16. 
framework. For instance, he credits Quebec premier Robert Bourassa with an early use of the phrase 'cultural sovereignty' in connection to communications policy: in September 1970, Bourassa indicated that the Quebec government would seek to negotiate a stronger role for Quebec in the development of communications policy in order to ensure the province's "cultural sovereignty" vis-à-vis English Canada. (cited in Raboy $1990,208)$

More recently, the Bloc Québécois issued a complementary opinion to Our Cultural Sovereignty: the second century of Canadian broadcasting, a 2003 report by the House of Commons Standing Committee on Canadian Heritage (commonly referred to as "the Lincoln Report', after then committee chair Clifford Lincoln). In its appendix to the report, the BQ argues that "if the federal government acknowledges that urgent action is required to safeguard Canadian culture vis-à-vis the United States, it must also recognize that Quebecers' battle to protect and develop their own culture is legitimate."61

Further, in June 2004, the CRTC decided not to renew the licence of popular Quebec City radio station CHOI-FM, citing its repeated warnings to the station concerning its use of "offensive comments, personal attacks and harassment." 62 This decision prompted Mario Dumont, leader of the provincial opposition party l'Action démocratique, to propose that

\footnotetext{
${ }^{61}$ Lincoln Report (Our Cultural Sovereignty: the second century of Canadian broadcasting. Report of the Standing Committee on Canadian Heritage) 857. http://www.parl.gc.ca/InfoComDoc/37/2/HERI/Studies/Reports/herirp02-e.htm

${ }^{62}$ See Broadcasting Decision CRTC 2004-271 CHOI-FM: non-renewal of licence, July 14, 2004 : http://www.crtc.gc.ca/archive/ENG/Decisions/2004/db2004-271.htm
} 
l'Assemblée nationale be immediately recalled in order to pass a law 'nationalizing' (i.e. at a provincial level) all communications currently under federal control. ${ }^{63}$

These recent expressions of Quebec's desire to protect its 'cultural sovereignty' from a dominant Canadian cultural establishment illustrate Raboy's 1990 observation that "Quebec's position on broadcasting was based on the same type of sentiment that had led successive Canadian governments to seek ways to assert Canadian cultural autonomy from external threat." (Raboy, 1990 191)

If we accept, on a national level, that Canadian culture is under threat of being overpowered by the ubiquitous 'other' that surrounds it, and if we further accept that the media are a useful tool for countering that assimilation, then it is not too far a stretch to Quebec's Bill 101, restricting the use of English in outdoor media. Either policy could be defended on similar grounds -ensuring a distinctive cultural presence in the media space in which we live, work and shop, by limiting the visibility of a threatening cultural influence.

I believe a better explanation for nationalist cultural policies, however, is Innis's observation that "each civilization believes in its uniqueness and superiority to other civilizations. Indeed, this may be the meaning of culture-something we have that others do not." $(1951,21)$ In this sense, when the Minister of Heritage remarks that "we have to protect Canadian identity and we have to start talking about cultural sovereignty also,

${ }^{63}$ See "Mario Dumont veut que le Québec émette ses propres licences" http://lcn.canoe.com/infos/national/archives/2004/08/20040806-105503.html 
because ... we are not American," ${ }^{64}$ it is possible to see Canadian cultural policy as an expressions of fear, not of assimilation by another culture, but of assimilation by an inferior culture.

There is a healthy measure of chauvinism and cynicism in the cultural assumptions that support and are supported by our current broadcasting policy. In this sense, I agree with Andrew Coyne that "cultural nationalism is not about culture, it is about nationalism."65

Moreover, there is a lack of simple logic at work in these constructions. Pierre Trudeau once remarked that "a society cannot be distinct in relation to another, in fact, without that other being distinct in relation to the first." Quebec could be constitutionally 'distinct' from the rest of Canada. But the same logic applies as to whether Canada can be culturally sovereign from the United States. Quebec cannot be distinct from Saskatchewan without Saskatchewan being distinct from Quebec; likewise, if the United States is culturally sovereign from Canada, then it stands to reason that Canada must be culturally sovereign from the United States.

Andrew Coyne picks up on this theme when he notes that "either we are different from the Americans, or we are not. If we are, then price comparisons are irrelevant. Canadian

\footnotetext{
${ }^{64}$ Hampson, S. "Good at the talking part." Globe and Mail, February 19, 2005. R3

${ }^{65}$ Coyne, A. “Against Art Subsidies.” Next City Magazine, Fall 1996.

${ }^{66}$ Trudeau, "Trudeau Speaks Out" Maclean's, September 28, 1992. Vol. 105, No. 39, p 22-26.
} 
culture and American culture are not, under this assumption, substitutable, interchangeable with each other, but wholly unrelated articles.",67

In other words, if Canada is inherently distinctive from the United States, then there should be a natural market for distinctive content that reflects our unique character or values, regardless of the relative size of the American market to our own. On the other hand, the fact that American content undergoes such a low cultural discount when crossing into Canada suggests that we are not that different from Americans, inasmuch as the 'symbolic content' of American programming resonates to a comparable degree with both American and Canadian audiences. Taken together, the main cultural and economic arguments of cultural nationalists cancel each other out: Canadians are so like Americans that the open market will not reflect how different we are.

It stands to reason that Canada cannot be, at one and the same time, independent of and dependent on the United States. As noted, our regulatory framework is dependent on American programming to help pay for and promote Canadian programming. This means the system we have erected in the name of preserving our cultural independence is in large measure reliant on American cultural products to pay the bills. Dorland argues that 'cultural interdependence' is " . . . discernable along a theoretical axis bounded at one extreme by "cultural sovereignty" and at the other by the "cultural pervasiveness" of American influences that some people claim to see in Canadian cultural life." $(1991,38)$ If we respond to American influences to the extent that we need to limit our exposure to them to preserve our cultural distinctiveness, does that not mean we are not that culturally

${ }^{67} \mathrm{Ibid}$. 
different to begin with? Of course, what we watch on television or listen to on the radio is only one reflection of which cultural markers we respond to, but it is the central marker under our current broadcasting policy.

Canada is demonstrably interdependent with the United States in many spheres: communications, economic, military, and environmental. Yet where television and radio are concerned, we go to great lengths to preserve a myth of complete independence "preserving" something that has never really existed. The popularity of American television programs and pop music in Canada is both an endorsement and indictment of Canadian broadcast policy. On one hand, the argument goes, we need rules to limit direct access to our market to counteract their popularity; at the same time, Canadian enthusiasm for American content is still strong after 80 years under those rules.

Canadians' historic taste for American content has always been a motivating factor for those charged with establishing specific rules and regulations to curb our cultural appetite. At the same time, the number of Canadians working in the United States to create that content, and the amount of American content that is actually produced in Canada, is, ironically, often held up as a national success story.

These two factors - our undeniable fondness for American television and radio content and our notable influence over its production-suggest that we are in fact interdependent where broadcasting tastes and markets are concerned. The reality of this fact has yet, however, to catch up with the way in which we regulate the broadcasting system. 


\section{PART TWO}

\section{Chapter 4: the history of policy chapter}

In 1850 , it would have taken 84 years to transmit a 90 minute, full colour video along telegraph wires. In 1950, it would have taken 2 years and 9 months to transmit the same video along analog telephone wires. By 1970, those analog wires could deliver it in 255 days. In 1990, it would have taken 10 days to send it over a digital telephone line. In 2002 , it would have taken 8 hours to download it using a dial-up internet connection. In 2003, you could download it in 44 minutes over a cable internet connection, and in 2006, it takes less than 10 seconds to transfer an MPEG4 compressed 90 minute, full colour video using wireless broadband 'ethernet'. 68

In 2005 , it costs about $\$ 2200$ a year to store 10,000 hours of video content. By 2015 , it will cost $\$ 2$. In 2005 , it costs about 40 cents to stream an hour of MPEG4 video. By 2015 , in will cost less than a penny. ${ }^{69}$

As technology has steadily increased transmission capacity and reduced transmission cost, the amount of programming traffic passing through and around our policy gates has increased exponentially. The expanding volume of foreign programming in particular

\footnotetext{
${ }^{68}$ Transmission numbers, from Lincoln Report, 59.

${ }^{69}$ Storage and transmission cost numbers from Sanford C. Berstein Research, "Media time is running out," February 25, 2005. Cited in The end of Television as we know it, report from IBM Business Consulting Services, January 27, 2006: http://www-

1.ibm.com/services/us/index.wss/ibvstudy/imc/a1023172?cntxt=a1000062
} 
has been a preoccupation of broadcasting regulators, ever since the first cross-border radio signals spilled into Canada. Each technological development in Canadian broadcasting has been perceived in official circles as a cultural threat first, and a business opportunity second.

This chapter is not a detailed constitutional history of Canadian broadcasting policy. Instead, it focuses on some major legislative, regulatory and commercial developments, examining them as responses to technological developments. The examples cited are selected because they illustrate how, over time, the economic and cultural assumptions described in the previous two chapters became the conventional thinking about how and why the broadcasting system should be regulated.

This is not to suggest that each technological advancement in broadcasting has been evenly matched with a neatly corresponding regulatory response. To the contrary, the regulations often appear determined to ignore the technological environment. Nor is to suggest that dealing with new sources of foreign content has been the sole regulatory motivation over the years. Debates about public vs. private ownership, English vs. French content, national vs. regional coverage, and federal vs. provincial jurisdiction, were all dominant issues at one time or another. Each, in its own way, still is.

But the debate about Canadian vs. American content has historically produced the most profound expressions of nationalist faith in our broadcasting policy. As each advancement increases the tide of American programming flowing into Canada, the 
reaction from regulators since the 1920 s has been essentially the same: react to the advancement as a threat to public policy goals, undergo a period of official consternation about its consequences to our cultural identity, then license it in some form that placates (in theory) both commercial and nationalist interests.

Marc Raboy charts this pattern of Canadian resistance and acceptance to new communications technologies after they appear in the United States: first, a new technology is developed and launched commercially in the United States. Second, Canadian businesses seek to introduce the new technology in Canada. Third, there is some sort of official inquiry into the potential of this new technology to undermine Canadians' identity and to make some of them rich. Finally, the authorities approve a business model that tries to maximize the revenue potential of the new technology, while restricting its ability to deliver American content directly to the Canadian market. (1990, 318)

He elsewhere describes the "implementation of the various legal, institutional, administrative, economic and cultural measures" that constitute our regulatory framework as "... the institutionalization of discourses of scarcity (whether of the spectrum, of channels, or of programming)." (1996, 13-14, emphasis added) But as technology makes spectrum less scarce and programming more abundant, it is becoming harder to see the logic behind our current regulatory assumptions. 
It is worth noting again Ken Goldstein's four "framing propositions" for state intervention in Canadian broadcasting:

a radio frequency spectrum with interference characteristics; an assumption that the spectrum and/or the market would allow only a very limited number of players, or even just a monopoly; a concern about the size of the Canadian market in relation to the adjacent US market, and the fear that Canada would be overrun with US content. ${ }^{70}$

Licensing and ownership rules were established to address the first and second propositions, advertising rules to address the third, and content rules to address the fourth. Today, however, the first two propositions have been largely surpassed by steady advances in broadcasting and communications technology. The third and fourth should not be an issue if Canada truly is 'culturally sovereign' from the United States-either we are distinct or we are not. If we are, there would be a natural market for content that reflects that distinctiveness. If we are not, then policies predicted on 'cultural sovereignty' are trying to preserve a distinctiveness that does not exist in the first place.

Notwithstanding the current market conditions that challenge our conventional economic and cultural assumptions, these framing propositions, and the assumptions they reflect, continue to form the basis for state intervention in Canadian broadcasting, 80 years after they were first embodied in regulation. The result is a system in real danger of worrying itself to death while the world passes it by.

${ }^{70}$ Ibid. 


\section{Before radio, there was snow and ice}

In the earliest strains of Canadian broadcasting we hear echoes of familiar themes. On December 23, 1900 Canadian Reginald Fessenden sent a message between two 50-foot towers on Cobb Island in Virginia. The message was "Is it snowing where you are Mr. Thiessen? If so, telegraph back and let me know." 71

This was a notable transmission for a number of reasons: first, it was the first voice message transmitted by radio waves; second, it was by a Canadian working in the United States; and, third, as a subtle variation on "is it cold enough for you?", it qualifies for CTF support for its uniquely Canadian theme and subject matter.

This is not, however, Mr. Fessenden's only entry in the annals of Canadian broadcasting history. On Christmas Eve 1906, he broadcast his wife singing O Holy Night to sailors on the Chesapeake Bay, as he accompanied her on the violin. ${ }^{72}$ However, despite the fact the artist was Canadian, the music and lyrics to O Holy Night were European, and the production took place in the United States. This earns the broadcast only one out of a possible four points on the MAPL scale, meaning that the Fessendens narrowly missed the added distinction of being the first official Canadian content on radio.

71 Lincoln Report, 48

72 Ibid. 
We can also detect familiar themes in the opening notes of government concern about the ability of Canadian broadcasting to withstand foreign influences. The day after Mr. Fessenden's inaugural broadcast on Cobb Island, a report was tabled in Ottawa by the Deputy Minister of Public Works. It noted "one danger to be feared, in connection with the constancy of the telegraphic service." Specifically, the report was worried about the ability of Canadian broadcasting to resist an "immense weight, (which) when set in motion, creates such a force that no human power is able to resist it." ${ }^{, 73}$ The Deputy Minister was actually referring to icebergs acting upon underwater telegraph cables, but in his rhetoric, accurately foreshadowed future expressions of official concern over "tidal waves" and "oceans" of American content, steadily, if unconsciously, eroding Canada's cultural identity.

\section{Early radio and the Aird Commission}

In the first two decades of radio, the Canadian broadcasting system developed along the same lines as in the United States, where private interests had a monopoly on broadcasting services. (Peers, 1979, 417) Smythe describes the relationship between Canadian and American broadcasting as "tributary," focussing on the American networks and their tendency to see Canada as an extension of their domestic market. $(1981,158)$

The classical point of reference for historians of Canadian broadcasting policy is the 1929 report of the Aird Commission. Its mandate was to "determine how radio broadcasting in

73 Report of the Deputy Minister of Public Works, Sessional Papers No. 19 (1st session, 9th Parliament), December 24, 1900. Cited in Bird, Roger ed. (1988) Documents of Canadian Broadcasting. Ottawa: Carleton University Press. 8. 
Canada could be most effectively carried on in the interest of Canadian listeners and the national interests of Canada." By that time, the four leading Canadian radio stations in Montreal and Toronto were affiliated with American networks, and the President of NBC is said to have bragged to the horrified Commissioners of his plan to extend his coverage across Canada. (Smythe, 1981, 164)

As noted, the Commission's response to this early American influence was to worry that "the majority of the programs heard (in Canada) are from sources outside of Canada." It fretted that "continued reception of these has a tendency to mould the minds of young people in the home to ideals and opinions that are not Canadian." (cited in Bird, 1988, 43) Implicit in this concern, of course, is that Canadian ideals and opinions are preferable to American ideals and opinions. To ensure the presence of Canadian ideals and opinions on the airwaves, the Aird Report recommended that Canada adopt the British model of broadcasting, with a publicly owned and financed national broadcaster.

Raboy observes that "the late 1920 s was a time of strong nationalist sentiment in English Canada and the Aird Report confirmed what most thoughtful Canadians apparently felt: that the only viable alternative to American domination of Canadian airwaves was a national public enterprise." $(1990,29)$ As the Ottawa Citizen cautioned at the time, "the Canadian people have to decide whether Canada is to have an independent Canadian broadcasting system worthy of Canada, or to become dependent on US sources for radio service." (cited in Raboy, 1990, 30) 
Paul Audley characterizes the report's recommendations as "implicitly reject(ing) the premise that the economic factors which had resulted in the dominance of both American signals and U.S. programming should be allowed to determine the future of Canadian broadcasting." Instead, he submits, the Aird Report recommended a policy framework which stressed the social, political, and cultural significance of broadcasting. (1994, 65)

In this sense, the Aird Commission gets the credit (and the blame) for the pattern of successive inquiries over the next 80 years: it was a response to perceived threats, stemming from economies of scale enjoyed by American radio broadcasters; it sought to mitigate that inherent advantage by limiting Americans' access to the Canadian market; and, it did so under the guise of protecting young Canadians from extended exposure to American cultural influences.

Radio and the 1932 and 1936 Broadcasting Acts

Despite Aird's prescriptions, by the 1930s American radio stations were increasing their coverage in Canada, and CBS and NBC were lobbying the Canadian government to withdraw from broadcasting regulation altogether, so they could run radio in Canada as a "concession." (Raboy, 1990, 56) Despite (or perhaps because of) their lobbying, the federal government was moving in the other direction, towards tighter regulations.

In 1932 the Supreme Court of Canada and the Judicial Committee of the Privy Council in London confirmed federal jurisdiction over Canadian broadcasting. Ottawa introduced 
the first Broadcasting Act later that year. The national aspirations of the proposed legislation were evident from the time of its first reading in the House of Commons. On May 18, 1932, Prime Minister Bennett introduced it as follows:

First of all, this country must be assured of complete Canadian control of broadcasting from Canadian sources, free from foreign interference or influence. Without such control radio broadcasting can never become a great agency for the communication of matters of national concern and for the diffusion of national thought and ideals and without such control it can never be the agency by which national consciousness may be fostered and sustained and national unity still further strengthened." (cited in Raboy, 1990, 46)

The Parliamentary hearings that followed produced one of the most often-quoted lines in the history of Canadian broadcasting. Appearing before the committee hearing comments on the proposed act, Graham Spry framed the question as “... whether Canada is to establish a chain that is owned and operated and controlled by Canadians, or whether it is to be owned and operated by commercial organizations, associated or controlled by, American interests. The question is, the State or the United States?" (cited in Bird, 1988, 65)

Spry would later write in the Canadian Forum that "there is no agency of human communication which could so effectively unite Canadian to Canadian and realize the aspirations of Confederation as radio broadcasting. It is the greatest Canadianizing instrument in our hands ..." (cited in Bird, 1988, 64) Spry's arguments would be adopted and repeated by successive generations of regulatory advocates: we need a regulated Canadian broadcasting system to keep us sufficiently Canadian, so as to resist being slowly 'Americanized'. 
The 1932 Broadcasting Act created the Canadian Radio Broadcasting Corporation (CRBC). Similar to the Stationers Company 400 years earlier, its charter was to be the sole source of all broadcasting content in Canada, and the sole licensor of all new privately-owned radio stations. By Autumn 1933, the extent of official Canadian broadcasting content was two and a half hours of national and regional network programs each evening and on Sunday afternoons. (Smythe, 1981, 169)

At the same time, hours of American radio were still freely available, on a daily basis, to anyone living within receiving range of the border. Peers notes that even if CRBC had the budget and authority of the BBC, " . . it could not have won the majority of listeners to Canadian programs. American advertisers were not only appealing to popular tastes but creating a popular culture which was continental in scope." $(1969,157)$

Fear that a creeping continental culture might undermine national objectives spurred tighter regulatory controls, as it had four centuries earlier in England. In 1936 a second Broadcasting Act was passed. It created the $\mathrm{CBC}$ as a replacement to $\mathrm{CRBC}$, and brought within its ambit those private stations it did not already control. The 1936 Broadcasting Act was an attempt to both counter and accommodate the presence and popularity of American radio. Peers notes that Ottawa was aware " . . . that Canadian listeners had been affected by American programs, the pattern of broadcasting in the United States, and the availability of programs at seemingly no cost to listeners." (1969, 421) 
Accordingly, the 1936 Act sanctioned a system of private stations in the American commercial model, with regulatory content obligations levied in the name of national interest. In this sense, the 1936 Act supports Raboy's observation about the reflexive tendency of regulators to seek compromises between economic and cultural concerns when faced with new sources of foreign content. Moreover, radio's contribution to Canada's growing interdependence with the United States was becoming evident. Peers argues that "the fact Canadian sponsors often sold or manufactured goods under the same brand names as in the United States, indeed were often branch plants of American firms, only increased the inducement not to cut all ties with the American radio networks and the system in operation in that country." $(1969,421)$ In other words, the growing North Americanization of Canadian broadcasting was beginning to be recognized as something inescapable, and at the same time, something to be corrected by regulation.

\section{Early television and the Massey-Lévesque commission}

By the late 1940s-early 1950s, the first American television signals were spilling into Canada. Ottawa had to decide whether to fold television into the operations of the $\mathrm{CBC}$, and/or to what extent it should allow private ownership.

Peers describes pressure from the $\mathrm{CBC}$ and the private sector for as rapid an introduction of television as possible, given the Americans had several years' head-start. $(1969,422)$ The first Canadian television stations were owned and operated by the $\mathrm{CBC}$. In cities where the $\mathrm{CBC}$ did not own television stations, it licensed privately-owned stations, but required them to air primarily $\mathrm{CBC}$-produced programming. 
In this way, the introduction of television to Canada followed the same pattern as the introduction of radio: prompted by its introduction and popularity in the United States and subsequent spill into Canada, the government created a partly public, partly private framework as an attempt to accommodate both commercial and cultural interests.

Peers notes that by this time "another problem was for the $\mathrm{CBC}$ to keep pace with the increasingly professional, and costly, programs turned out by American networks and film suppliers; if this were not done, Canadian audiences would be drawn in increasing proportions to United States stations which were now accessible to more Canadian viewers." $(1969,425)$ To address the dearth of popular Canadian content, the government struck another Royal Commission, co-chaired by Vincent Massey and Georges-Henri Lévesque.

Their report noted the "new and even disturbing possibilities of television broadcasting" to influence public opinion, calling the new technology a "new and unpredictable force in our society." It characterized American television as "essentially a commercial enterprise, an advertising industry," that would not serve Canada's "national needs." (Raboy, 1990, 104) At the same time, it conceded that "it seems desirable to use appropriate American television programs" to draw audiences to the Canadian broadcasting system. (cited in Bird, 1988, 220-235) 
In this way, Massey-Lévesque struck a familiar posture in Canadian broadcasting policy: official concern over the presence and popularity of American programming, matched by efforts to harness it in support of Canadian content. As Raboy notes, while "the Massey Commission ... articulated the traditional public rhetoric behind Canadian broadcast policy, it contributed to widening the gap between the rhetoric and the actual reality of the system." $(1990,108)$ I would add that the gap between rhetoric and reality was inevitable so long as the regulatory framework treated American programming as an unstoppable threat to Canadian culture, and as a valuable resource to be tapped in support of Canadian cultural objectives.

Regulators in the 1950s were not only concerned with content issues, but technical matters as well. There was some question as to whether Canada would adopt the American technical specifications for television, or those of other systems being developed in Europe. Raboy argues:

the implications of this would be momentous for the development of television, particularly in English Canada. A different pattern of 'lines and frames' would have technically protected the Canadian market for Canadian signals right from the start. $(1990,104)$

Similarly, Smythe laments:

If Canada had seriously intended to protect its culture from total domination by the United States ... (it) would have adopted different and superior standards ... Through prohibition of the importation or production of television sets designed on the United States standards, the viewing of United States television programs received directly from United States stations would have been prevented. When the technique of cable television developed in the United States, Canada would have restricted cable television operations to those employed by CBC to improve reception in big cities." $(1981,177)$ 
The fact that Canada chose American technical standards is treated as a missed opportunity by Raboy and Smythe. This is, however, wistful and wishful thinking: had we not adopted the American standard for conventional television in the 1950s, we would have spent the next 50 years fighting the import of 'illegal' American televisions into Canada. Adopting European standards would simply have given birth to broadcasting 'pirates' a generation earlier, and would not have been successful in insulating Canadian audiences from 'harmful' American programming. It would, however, have insulated us from the explosive choice of the American market, by giving the regulator firmer authority over what we watch, and when.

\section{Television, the first Fowler Commission, and the 1958 Broadcasting Act}

In 1952, when the Massey-Lévesque report was still being digested by regulators, there were already 146,000 television sets in Canada. Two years later, there were over a million. ${ }^{74}$ As most of Canada's population is clustered within receiving range of the American border, most of these new television sets were picking up clear signals from American border cities.

By 1957, the government was (again) sufficiently concerned with the growing amount of American programming in Canada that it (again) struck a royal commission to figure out what to do about it. The Fowler commission heard from over 100 witnesses, many of whom explained (again) their economic and cultural assumptions about the effect of American television on Canadian markets and audiences.

74 Source: Canadian Cable and Telecommunications Association: http://www.ccta.com/english/View.asp?t=\&x=141\&mp=13 
The Association of Canadian Advertisers wrote in its brief to the Fowler Commission: "the primary purpose of 'Canadian broadcasting' is the maintenance of Canada as a distinct and independent country ... that is, to preserve the integrity of Confederation and keep Canada Canadian." But at the same time it argued that "we must recognize the influence of American broadcasting and ways of life in the lives of Canadians." (cited in Raboy, 1990, 124)

Not that everyone perceived this American influence as an intentional threat. A professor R.M. Lower told the Commission that "while he sees 'no nefarious or conscious' attempts on the part of Americans to dominate Canadian television ... American interests are so powerful that they could take over our Canadian airwaves hardly knowing they were doing it." ${ }^{, 75}$ The professor's statement reflects the now familiar notion that economies of scale are an irresistible cultural force that, like an iceberg on a telegraph cable, cannot help but grind Canadian identity down.

In his final report, Fowler cited these same irrepressible economies of scale as a danger to Canada's cultural survival, and ultimately, its survival as a distinct nation. He submitted that:

The central, unique fact about Canadian broadcasting is that we are here in North America, a nation of 16 million people living beside a nation of 168 million which speaks the language of our majority and is rich, inventive, with a highly developed broadcasting system of its own. No other country is similarly helped and embarrassed by the close proximity of the United States. . . Can we resist the

75 Quoted in the Globe and Mail, September 18, 1956. 
tidal wave of American cultural activity? Can we retain a Canadian identity, art and culture -a Canadian nationhood?" (cited in Bird, 1988, 252)

This report is also noteworthy for containing the first official recommendation that the regulatory functions of the $\mathrm{CBC}$ be hived off from its broadcasting operations. This separation of powers became the key feature of the 1958 Broadcasting Act. It took away the CBC's regulatory power, and gave it instead to a new Board of Broadcast Governors (BBG). The BBG's mandate was to ensure the "provision of a broadcasting service of a high standard that is basically Canadian in content and character." To help it realize this mandate, the Act established two major regulatory requirements, both of which survive in some form today: $80 \%$ of the equity in any privately-owned radio or television station had to be held by Canadians, and $45 \%$ of all television programming was required to be "Canadian in nature."

Cable television, the second Fowler Committee, and the 1968 Broadcasting Act In 1964 the Secretary of State for Communications (again) turned to Fowler to (again) study the availability and popularity of American programming on Canadian airwaves.

In 1957, the first Fowler report declared that the purpose of the Canadian broadcasting system was "to inform, enlighten, entertain and sell goods." By 1964 and the second Fowler report, patriotism trumped commercialism as it declared that the purpose of the Canadian broadcasting system was now "to inform, enlighten and entertain the Canadian people and promote their national unity." ${ }^{, 76}$ (Cited in Bird, 1988, 355)

\footnotetext{
${ }^{76}$ Michael Dorland observes that " . . . the organizing language of Canadian policy, reflected in a long series and steady stream of Royal Commissions, white papers, public and parliamentary inquiries and
} 
Fowler also provided a definition of 'Canadian culture' that was to have a rhetorical resonance in decades of future government reports:

When we declare that broadcasting should be a major instrument for the development of a distinctive Canadian culture, we use that most abused word "culture" in its broadest and original meaning. It is the reflection of life itself, in all its variety - its beauty and ugliness; its significant artistic achievements and its unimportant daily occurrences; its big people and its little people: its important and often inscrutable messages, and its light insignificant interests; its great opinions and its amusing anecdotes; tragedy and comedy, laughter and tears, criticism, irony, satire and sheer fun and amusement - are all essential. ${ }^{77}$

The second Fowler report led to a government White Paper on broadcasting, which in turn led to a subsequent report by the Standing Committee on Broadcasting, Film and Assistance to the Arts. In its report on the report about the report, the Standing Committee found that "a distinctively Canadian broadcasting system is essential to our national identity, unity and vitality in our second century." (cited in Foster, 1974, 229)

The committee was to recommend a new broadcasting regulator and a new broadcasting act. This new act received Royal Assent in 1968. The CRTC was subsequently created as a replacement to the BBG in 1969.

Peers writes that the 1968 Broadcasting Act "refined and clarified the intent of the 1958 act, gave the regulatory board more scope and a new name, but it did not represent any

legislative and regulatory modifications, effected a slow and difficult transition from the discourses of culture to the discourses of economy." $(1996, \mathrm{xi})$ In the case of the two Fowler reports, the transition worked the other way - the organizing language moved from a commercial posture to a more nationalist one.

${ }^{77}$ Fowler Committee Report, Cited in Bird, Roger ed. (1988) Documents of Canadian Broadcasting. Ottawa: Carleton University Press, 355. 
fundamental policy departure from that introduced by the previous conservative government." $(1969,416)$ I would disagree with his assessment, in that the 1968 Broadcasting Act, for the first time, officially committed the regulator to manage the system in a way that is "responsive to new technologies."

This was a highly significant development, as it brought cable into the purview of the broadcasting regulator. Until this point, we had only regulated the channels; now we were regulating channel distributors. Peers notes that Canadian broadcasters had long been recommending regulatory oversight of what were then called 'community antennae systems', and which were seen at that time as "merely another means of importing American programs." $(1969,436)$ The regulatory balance between broadcasters and distributors was to become another running debate in policy circles.

Raboy blames the proliferation of cable television for "undermining" the "basic logic of the system" by enabling "the unlimited penetration of Canadian television space by cable-imported U.S. stations." He notes that cable was seen to be "fracturing the economic basis of private broadcasting" and disrupting the cultural "imperatives" of broadcasting policy. $(1990,211)$

Similarly, under the heading of 'responding to new technologies', the CRTC fretted in 1969 that microwave technology would boost the transmission strength of American television stations, increasing their availability in Canada. It worried that this "would 
represent the most serious threat to Canadian broadcasting since 1932. . . it could disrupt the Canadian broadcasting system within a few years." (cited in Raboy, 1990, 197)

Later that same year, after much lobbying from the cable companies, the CRTC permitted them to use microwave technology to collect distant American television signals, and to distribute them in Canada. By 1975, the Commission had come full circle, declaring microwave and cable distribution to be "a chosen instrument of public policy." 78

So, by the late 1960 s, the framing proposition for state intervention in broadcasting was no longer about responding to American domination of scare spectrum. To the contrary, it was about responding to Americans' use of spectrum-enhancing technologies. As Raboy observes, " ... the rhetoric of cultural nationalism was to prove capable, when push came to shove, of effecting a relatively smooth transition from the pre-1960s regulation of media scarcity to the post-1960s management of media abundance." (1996, $14)^{79}$

Put another way, broadcasting regulation was beginning to turn from the old economics of broadcasting (which were about large audiences and scarce spectrum), to the new economics of broadcasting, (which are about fragmented audiences and abundant

\footnotetext{
${ }^{78}$ Source: Museum of Broadcast Communications website: http://www.museum.tv/archives/etv/C/htmlC/canadiancabl/canadiancabl.htm

${ }^{79}$ Under the heading of 'familiar themes', it is worth noting that in its 1971 coverage of CRTC cable regulation hearings, the Globe and Mail reported that broadcasters were seeking direct compensation for the use of their signals by cable companies. 33 years later, the National Post reported the broadcasters were still arguing about how they should be paid by cable companies. See Smith, M. "Miles of Tape, Reams of Paper." Globe and Mail, May 1, 1971, and Viera, "CanWest seeks to reform cable fee 'imbalance'." National Post, December 1, 2004.
} 
spectrum). At the same time, the cultural assumptions about the 'external' benefits of Canadian programming delivered on a Canadian-owned broadcasting system were coming under strain on several fronts. The main selling point of cable was its ability to deliver signals that originated too far away for normal antennas to pick up. Given that most of the Canadian audience was accustomed to tuning into American stations with rooftop antennas, it stands to reason that the distant signals they were looking for on their cable systems would be, at least in part, American. So just as each new television and radio station in Canada increases the amount of American content in the system, each new cable system increased the supply of American channels. This reflected the usual willingness of our broadcasting policy to tolerate a high degree of inconsistency. It also suggests that despite cultural assumptions to the contrary, Canadians instinctively identify with American programming, and policies designed to curb that appetite have in fact had the opposite effect.

\section{Pay Television}

The next major technological challenge to Canada's cultural policy objectives was the introduction of pay television. Again, the introduction of subscription-based channels in the United States prompted Canadian inquiries into their potential as both a new business line for broadcasters, and as a threat to cultural policy goals. 
In 1972, the CRTC invited comments on how pay television might be introduced to Canada. After two and half years of deliberation, it decided that pay television would be too disruptive to the system, and decided against licensing it for the Canadian market. ${ }^{80}$ As Raboy describes it, "the context was reminiscent of the situation at the time of the introduction of television in the late 1940s. Public policy was resisting the pressure of Canadian entrepreneurs for rapid introduction of a new technology along the lines of a communication model developed in the US, in the absence of either clear public demand or clear Canadian policy goals." $(1990,273)$

In 1976, Cabinet directed the CRTC to reconsider its decision. In its revised opinion, the CRTC had a change of heart, finding that pay television actually gave it the opportunity "to convert technical systems to national purpose." As Raboy interprets it, "neither the government nor its regulatory agency was willing to resist a new American commercial model. Incredibly, American-style pay-television was adopted amid waves of rhetoric about serving Canadian national objectives." (1990, 279) Further illustrating this point, the $\mathrm{CBC}$ declared in 1978 that "as a nation, we can still make sure that new technological innovations in broadcasting, such as pay-television and fibre-optics, are introduced only if they are likely to lead to an increase in the viewing of Canadian programming." (cited in Raboy, 1990, 255)

This is not to suggest that the CRTC had changed its way of thinking about the benefits of distinctively Canadian content. To the contrary, despite (or, because of) increasing

${ }^{80}$ CRTC: Policies Respecting Broadcasting Receiving Undertakings (Cable Television) December 16, 1975. 
foreign competition at the hands of microwave and cable-delivered American television stations, Canadian broadcasters were still charged with keeping the country intact. In fact, the more competition they faced, the higher the stakes became. In a speech to the Canadian Association of Broadcasters in 1977, CRTC Chair Harry Boyle warned them to "spend more time and money explaining Canada to Canadians or risk contributing to the break-up of confederation." ${ }^{81}$

But by the end of the decade, technological developments that increased channel capacity were already challenging conventional regulatory wisdom. In 1979, the Toronto Star characterized the CRTC's cable policy as a futile attempt to under-privilege American programming in Canada:

They could talk about jamming television signals, they could delete foreign commercials, they could give tax advantages to advertisers using Canadian stations, but they could not stop Canadians from looking. . . Canadian private broadcasters will find that new technologies fracture audiences ... People will watch what they want to watch, and will do, (for new technology also makes them participants) what they want to do.",82

Similarly, in August 1980 the final report of the Federal Cultural Policy Review Committee stated that the CRTC could not and should not "prevent the public from obtaining access to the foreign programs or services it wants." (cited in Raboy, 1990, 280) How much direct access Canadians should have to foreign television channels, and on what terms, was to become an enduring question for regulators.

\footnotetext{
${ }^{81}$ Globe and Mail "Explain Canada, Boyle tells broadcasters." April 19, 1977.

82 Toronto Star "Your show of shows" March 23, 1979.
} 
Early Direct Broadcasting Satellites, and the Caplan-Savegeau Report

In the early 1980s, the gate-keeping power of the CRTC was further challenged by American direct broadcasting satellites (DBS), which were beginning to deliver television programming in the United States, with coverage areas that extended into Canada. Smythe saw in this development a new threat to the Canadian broadcasting system, and to the ability of the CRTC to do anything about it:

... the efforts of CRTC to protect the Canadian stations and cable systems .. have been problematic enough. With the recent American use of communications satellites to relay program material between American cable systems and terrestrial broadcast stations for distribution domestically, however, a new serious threat faces the Canadian stations and cable systems. $(1988,188)$

Not surprisingly, as Raboy notes, "the Government promised to protect (Canadian) cable from (American) satellites." $(1990,288)$ By the mid-1980s, the nature of the technological threat had changed, but our protective reflexes remained essentially unchanged from the 1920s. So too did our framing economic and cultural assumptions, as evidenced by a major broadcasting policy review undertaken between 1984 and 1986 by Gerald Caplan and Florian Sauvageau. Their mandate was to examine "audience fragmentation, changes in technology and their effect over Canada's cultural sovereignty."

Their final report questioned the main propositions for state intervention in broadcasting: "how can Canadians be offered a serious choice of Canadian programming, in a system in which a) American influences are inescapable, b) market forces dictate American programming through both production costs and advertising benefits, and c) Canadians

${ }^{83}$ Lincon Report, 34 
themselves want access to Canadian as well as American programming." (cited in Jeffrey, 1996, 249) Predictably, the report's main recommendation were revisions to the Broadcasting Act, and new powers for the regulator.

If the report's terms of reference and recommendations sounded familiar, so did the government's reaction. In its 1987 report "A Broadcasting Policy for Canada" (the last of fully fifteen reports Parliament issued in reply to the Caplan-Sauvageau report), the Standing Committee on Communications and Culture found that "economic and geographic forces have prevented our culture/communications markets from functioning efficiently, on their own, to provide a variety of identifiably Canadian products and services to Canadians." (cited in Audley, 1994, 81)

Another government policy statement the next year also found new broadcasting technologies to be problematic to the achievement of cultural policy goals, but again did not question the assumed benefits of the goals themselves. The 1988 policy statement "Canadian Voices: Canadian Choices" that accompanied the tabling of the proposed Broadcasting Act stated that:

... broadcasting goes well beyond the traditional over-the-air technologies of 'radiocommunications,' and will increasingly overlap and converge with telecommunications. Within this broadened scope, broadcasting jurisdiction is defined not so much by the technologies which carry and disseminate the signals, as by the content of the signals. The Bill is, therefore, technology-neutral and will be better able to adapt to changing technologies without risking erosion of federal regulatory jurisdiction.' (cited in Audley, 1994, 9)

When passed in 1991, the new Broadcasting Act (still in effect today) expanded the definition of broadcasting to include "any transmission of programs, whether or not 
encrypted, by radio waves or other means of telecommunication for reception by the public.." In this way, the legislation achieved its "technology-neutral" orientation: its objectives would apply equally, no matter what the platform.

Put another way, there would henceforth be no need to re-examine the central assumptions about why we regulate broadcasting every time a new technology challenges how we regulate broadcasting. The 1991 Act addresses the gap between 'rhetoric and reality' by declaring that whatever the reality, the regulator would take its cues from the rhetoric.

\section{'Death Stars' and the 1991 Broadcasting Act}

The 1991 Broadcasting Act's objectives are essentially unchanged from those of its predecessors. Ensuring Fowler's legacy, section 3(1)(i) of the current Act declares that the Canadian broadcasting system should "serve to safeguard, enrich and strengthen the cultural, political, social and economic fabric of Canada," while section 3(1)(iv) carries forward the tradition of the 1968 Act in decreeing that the system should be regulated in a way that is "readily adaptable to scientific and technological change."

In other words, our current regulatory framework is both neutral and responsive to technology. The effect of this paradox was evident in the CRTC's reaction several years later to so-called American 'Death Star' satellites. ${ }^{85}$

\footnotetext{
${ }^{84} 1991$ Broadcasting Act sec 2 (1)

${ }^{85}$ See Fraser 1990, 33 for a discussion of the origins and implications of the 'death star' label.
} 
DBS satellites were first introduced in the United States, enticing Canadian entrepreneurs to seek regulatory approval to introduce a Canadian version. The CRTC wrestled with the economic and cultural implications of this new platform, before licensing a model that treated the new technology as both a threat, and an opportunity.

Matthew Fraser notes that DBS satellites

brought a familiar experience to the Canadian broadcasting industry. Satellite television reproduced the early pre-cable days of television in the 1950s. When CBC television was created in 1952, many Canadians were already watching cross-border American channels with bunny-ears and roof-top antennas. Forty years later, the arrival of satellite broadcasting was no different: satellite TV signals, like off-air Hertzian signals, crossed the border via the airwaves." (1999, 29-30)

He describes the new technology as a "threat not only to the commercial interests of its most powerful client -the cable industry - but also to (the CRTC's) own institutional legitimacy." (1999, 30) In fact, like the president of NBC in 1928, a senior executive from American DBS company DirecTV appeared before the CRTC in 1993 to announce that it planned to increase its coverage in Canada in 1994, and that there was nothing the CRTC could do about it. He recognized that its operating in Canada was technically illegal, but argued that since its signals originated outside the CRTC's jurisdiction, the commission would be powerless to enforce its rules and regulations over it. (cited in Fraser, 1999, 36)

The CRTC responded to this direct challenge to its legitimacy by holding a series of 'structural' hearings to examine how it regulated the entire system. In the public notice 
that announced these proceedings, the CRTC fired a shot across DirecTV's bow, warning that it "will apply the appropriate enforcement tools to assert its jurisdiction over (American) undertakings should they enter the Canadian market without making contributions to the Canadian system as required of all broadcasting undertakings under the Act." " Those "contributions," of course, refer directly to Canadian content obligations.

In 1994, the government asked Gordon Ritchie, Roger Tassé and Robert Rabinovitch to review its satellite distribution policy. As Fraser notes, this review received over 300 briefs from "virtually all the major players in the Canadian broadcasting system," including some that "compared Power DirecTV to a 'Trojan Horse' whose arsenal of American channels and Hollywood movies threatened to undermine Canadian cultural sovereignty." $(1999,47)$

The CRTC ultimately issued licences for five Canadian DBS companies between 1995 and $1997^{87}$ although to distinguish them from their American counterparts, it began

\footnotetext{
${ }^{86}$ See Public Notice CRTC 1993-74, Structural Public Hearing, June 3, 1993: http://www.crtc.gc.ca/archive/ENG/Notices/1993/PB93-74.HTM

${ }^{87}$ Express Vu and Power DirecTv in 1995 (Public Notice CRTC 1995-217 Introductory Statementlicensing of new direct-to-home (DTH) satellite distribution undertakings, and new DTH pay-per-view (PPV) television programming undertakings, December 20, 1995: http://www.crtc.gc.ca/archive/ENG/Notices/1995/PB95-217.htm)
}

Star Choice in 1996 (Decision CRTC 96-259 StarChoice Television Network Inc: August 27, 1996: http://www.crtc.gc.ca/archive/eng/Decisions/1996/DB96-529.htm)

Alphastar and Homestar in 1997 (See Decision CRTC 97-87 Application for a new direct-to-home satellite distribution undertaking - approved, February 27, 1997: http://www.crtc.gc.ca/archive/ENG/Decisions/1997/DB97-87.HTM ; and Decision CRTC 97-38 Shaw Communications, on behalf of an company to be incorporated (Homestar), January 31,1997 : http://www.crtc.gc.ca/archive/eng/Decisions/1997/DB97-38.htm 
referring to them as direct-to-home, or 'DTH'. In its usual compromise between industrial and cultural objectives, the CRTC required these DTH companies to contribute $5 \%$ of their revenues to funds that subsidize the production of Canadian programming. Of these new licensees, only ExpressVu and Starchoice were ever to develop into legitimate, viable distributors.

The tensions and rationales raised in the DBS/DTH saga had always been present in Canadian broadcasting policy, but rarely were they as evident. Obviously, American satellite distributors were a direct threat to cable's revenues. More importantly, they exposed how quickly the regulator could be overtaken by technological change. It threatened to eat into cable's regulated bottom line, and at the same time, to delegitimize the regulator.

Cable, with its closed systems and geographic monopolies, conferred legitimacy on the regulator by making it easy to control the strength, location, and contents of broadcasting signals. In exchange for protection from competition in a distinct area, cable accepted the distribution and linkage rules that were supposed to privilege Canadian content over American content. Like over-the-air signals, DBS signals could not be limited to narrow geographic contours, and hence, threatened the central bargain between cable and the CRTC. DBS companies also offered American channels that cable was not permitted to carry, upping the ante by exposing the regulator's preference for managed choice over free choice. DBS also threatened to transfer control over many of distribution and linkage decisions from the regulator to the customer, undermining any reason for having 
them in the cable world. Not surprisingly, cable and the CRTC quickly turned DBS into a cultural problem ('Death Stars' were cast as a cultural threat, not a business threat) to delay its introduction until "Canadian alternatives" could be developed.

Digital broadcasting, the internet and the 2003 Lincoln Report In early 1999, when internet-based distributors started making Canadian television signals freely available anywhere in the world over the internet, the CRTC held public consultations to determine whether internet broadcasting could and should be regulated. ${ }^{88}$ In late 1999, the CRTC issued its usual compromise solution, announcing that under the expanded definitions of the $1991 \mathrm{Act}$, much of what happened on the internet was indeed a form of broadcasting, but that it would not try to license it. This decision is generally referred to as the New Media Exemption Order. ${ }^{89}$

Of course, issuing an exemption order is not the same thing as if the CRTC had simply said it will not regulate the internet. Technically, it means that internet broadcasting is regulated by way of exemption order: if a company meets certain conditions, it does not require a broadcasting licence. If it ventures outside of a narrow range of definitions, it does.

\footnotetext{
${ }^{88}$ See Public Notice CRTC 1999-84, New Media May 17, 1999: http://www.crtc.gc.ca/archive/ENG/Notices/1999/PB99-84.htm

${ }^{89}$ See Public Notice CRTC 1999-197, exemption Order for New Media Undertakings, 17 December 1999: http://www.crtc.gc.ca/archive/ENG/Notices/1999/PB99-197.HTM This prevented internet 'rebroadcasters' from claiming legitimacy under section 31 of the Copyright Act, which provides for the unauthorized retransmission of television signals by licensed distributors.
} 
The CRTC reasoned that by exempting internet broadcasters from any need to hold a licence, it would still be "contributing to the achievement of the broadcasting policy objectives." As noted above, these objectives were apparently so elastic as to be achievable under virtually any technological scenario, licensed or otherwise. This, of course, has had the side-effect of forestalling any serious examination of the economic and cultural logic behind these objectives.

The Commission did not define the internet when it issued the New Media Exemption

Order. It did, however, append a glossary that provided the following description:

The Internet is a distribution system that is capable of handling a wide variety of data (text, pictures and sound) in any number of formats. ... The Internet is a distributed, inter-operable, packet-switched network .... A distributed network has no one central repository of information or control, but is comprised of an interconnected web of "host" computers, each of which can be accessed from virtually any point on the network .... An interoperable network uses "open protocols" ..., and allows multiple services to be provided to different users over the same network. ${ }^{90}$

This definition has allowed for various forms of 'broadcasting over the internet' to be channelled through the policy gates. The key is the openness of the specific network with respect to the services it offers to consumers.

For example, 'IPTV' (Internet Protocol Television) distributors offer services that approximate, in quality and range of service, those of cable and DTH operators. They require a licence from the CRTC to operate, and are subject to the Broadcasting Distribution Regulations, and all related distribution and linkage rules. The set-top-box

\footnotetext{
${ }^{90}$ See PN CRTC 1999-98, cited at note 84.
} 
provided by IPTV companies to their customers is technically a point of contact with the internet, and the programming it provides is transferred in the form of internet packets. However, an IPTV system is not open - the distributor is at one end, the customer at the other. There is no way for anyone else to plug into that network and transmit programming. Nor can customers connect at their end by any range of devices -only by way of the equipment provided by the distributor. This means IPTV, in the form of service currently offered by telephone companies, does not qualify as 'broadcasting over the internet' - 'broadcasting using the internet' maybe, but that is not enough to fall under the terms of the New Media Exemption Order.

Similarly, the CRTC signalled its readiness to regulate broadcasting to mobile phones, at least by way of exemption order. ${ }^{91}$ In the Public Notice that called for comments on how to deal with broadcasting to mobile phones, the CRTC asked if it should regulate them by way of the existing New Media Exemption Order, or by way of a new type of exemption order. In other words, should we use an existing path through the gates, or create another one? These services, like IPTV, are closed, not open: the connection to the internet via the handset is not a connection to the full internet, rather to a closed channel into which only the distributor can insert programming. At the time of writing, the CRTC has yet to issue a decision in this proceeding.

\footnotetext{
91 See Public Notice CRTC 2005-82, Call for comments on a regulatory framework for mobile broadcasting services, September 12, 2005: http:/www.crtc.gc.ca/archive/ENG/Notices/2005/pb200582.htm
} 
In 2001 the CRTC issued its proposed policy for a new 'digital licensing framework' for conventional analog television broadcasters. Reverting to the traditional industrial/cultural compromise, it stated that throughout the period of the digital transition, "the continued strength and growth of our broadcasting industry should be fostered, and its cultural objectives maintained." 92 When it released its final digital licensing framework a year later, the CRTC specifically noted its concern that Canada was falling behind the United States in the pace of its digital television rollout. Unlike the United States, which had imposed an analog switch-off date to motivate broadcasters to make the transition to digital broadcasting, the CRTC instead announced a "voluntary, market-driven transition model, without mandated guidelines (as) the most appropriate approach for Canada." 93 To ensure Canada did not fall too far behind the United States, though, the CRTC said it would fast-track applications for new digital licences, but added that it would maintain the same Canadian content requirements as were applicable under the existing analog licences.

The traditional regulatory compromise was also reflected in the CRTC's licensing framework for digital specialty and pay channels, ${ }^{94}$ which created two classes of digital channel: Category 1 channels would be 'public interest' oriented, so would have high

\footnotetext{
${ }^{92}$ See Public Notice CRTC 2001-62, Call for comments on a proposed policy to oversee the transition from analog to digital over-the-air television broadcasting, 5 June 2001: http://www.crtc.gc.ca/archive/ENG/Notices/2001/PB2001-62.htm

93 See Public Notice CRTC 2002-31, A licensing policy to oversee the transition from analog to digital, over-the-air television broadcasting, 12 June 2002: http:/www.crtc.gc.ca/archive/ENG/Notices/2002/pb2002-31.htm

94 See Public Notice CRTC 2000-6, Licensing framework policy for new digital pay and specialty services, January 13, 2000: http://www.crtc.gc.ca/archive/ENG/Notices/2000/PB2000-6.htm
} 
Canadian content requirements, offset by high levels of market protection. Category 2 channels would have lower Canadian content requirements, but virtually no market protections. $^{95}$

The CRTC's approach to the digital transition reflects a regulatory vision of a digital broadcasting system that is virtually the same as an analog system, but with better pictures and sound. The CRTC assumed that the digital market would generally operate as the analog market had, and that audiences would respond to digital broadcasting much in the same way as they had to analog broadcasting.

Of course, the main difference between digital and analog broadcasting is that 10 to 12 digital channels can fit into the same amount of spectrum previously allocated to one analog channel. As a result, the number of channels available to audiences has been growing rapidly as the broadcasting system moves increasingly from analog to digital operations. This proliferation of programming options is having profound impacts on how the market operates and on how audiences respond to content, but these factors have yet to be fully appreciated or accommodated in our current regulatory framework. The following chapter addresses these changes and their effects in more detail.

\footnotetext{
${ }^{95}$ The track record of these digital channels would make an interesting side study, as recent viewing and financial data indicate that Category 2 channels generally outperform Category 1 channels in attracting audiences, subscriptions and revenues, indicating that what the CRTC considers to be in the "public interest' is not necessarily what the public is interested in. See Individual financial date for specialty and pay services 1999-2003, available online via: http://www.crtc.gc.ca/eng/publications/reports/BrAnalysis/p\&sp2003/individual/Cover.htm
} 
The most significant government report to have been issued during the digital transition was a mammoth, 900 page affair issued in June 2003 by the Standing Committee on Canadian Heritage, chaired by Clifford Lincoln. Its formal title Our Cultural Sovereignty: The Second Century of Canadian Broadcasting, leaves little question about its nationalist leanings.

Among the report's 87 separate recommendations are classic examples of the regulatory compromise between market forces and cultural benefits. For example, the report's recommendation for curbing the 'grey market' of Canadians who subscribe to foreign satellite services is "that the CRTC permit Canadian broadcasting distribution undertakings to offer a wider range of international programming, while being respectful of Canadian content regulations." This recommendation manages to assume, at the same time, that the regulatory framework is not supplying enough foreign programming, but that the reason for this -Canadian content regulations-must be preserved. ${ }^{96}$

\footnotetext{
${ }^{96}$ This recommendation was to have broad implications. It spawned a wave of requests to the CRTC for additions to the lists of foreign channels authorized for distribution in Canada. One of these requests was filed by the Canadian Cable Television Association, who requested that HBO, ESPN and several other popular American cable channels be added to the lists. The CCTA cited the need to fight signal theft as its reason for the request. In the words of the then-President of the CCTA, dissatisfied consumers turn to grey-market satellite providers "like an honest but hungry person stealing a loaf of bread . . it is time to cut the legs off this argument."
}

Notwithstanding the unfortunate image of a legless person, weak from hunger, installing a DirecTV satellite receiver on their roof, this argument remains at the forefront of the CCTA's campaign for more consumer choice as a remedy for the grey market (quotation taken from Canadian Press wire story Companies bid to import top US channels to boost revenues, June 23, 2003).

The CRTC ultimately rejected the CCTA's request on procedural grounds (see 'CRTC Letter to CCTA', November 7, 2003: http://www.crtc.gc.ca/archive/ENG/Letters/2003/lb031107.htm).

The CCTA made another request in 2004 for a number of foreign channels, this time in Italian, Arabic and other so-called 'third-languages'. The CRTC approved the addition of five Spanish, one German, one Romanian, and one Arabic service to the lists. At the same time, it denied a number of others-including, infamously, Italian-language service RAI International - on the grounds that they would be competitive with existing Canadian third-language services (see Public Notice CRTC 2004-50 Requests to add non- 


\author{
The 2003 Lincoln Report touches on a number of classic themes in Canadian \\ broadcasting regulation. Its introduction reflects an understanding of economic and \\ cultural factors at work in the system that would have been familiar to Aird, Massey or
}

Fowler:

English-speaking Canada shares a border, and a language, with the world's largest and most dominant producer of audio-visual programming. Canadians are constantly exposed to a mass media that endlessly promotes American shows and stars. American producers can sell programs at a price that is far below what it would cost to make similar shows in Canada. Canadian network programmers argue that American hits provide the revenue that allows the networks to invest in Canadian programs. This knot is not an easy one to untie and the Committee is not suggesting that the knot be untied so much as loosened. The goal must be to create more opportunities and more spaces, to strive for programs that are not only made-in-Canada but also made-for-Canada. $(2003,8)$

In addressing digital technology, it cites the need to keep up with the Americans, as a motivating factor:

Canadian third-language services to the list of satellite services eligible for distribution on a digital basis, July 15, 2004.: http://www.crtc.gc.ca/archive/ENG/Notices/2004/pb2004-50.htm). This decision drew much public criticism, including demonstrations on Parliament Hill, and direct cabinet-level intervention by members of the Italian government.

At the same time, the Commission announced a related policy proceeding to examine whether "the current (policy) approach strikes the appropriate balance between ensuring there is an adequate level of service to third-language communities and fostering Canadian third-language services." It recognized that the issue of access by Canadians from multiethnic communities to programming in their own language(s) was becoming conflated in many respects with the broader issue of grey-market satellite distribution in Canada.

In 2004 a consortium of broadcasters and cable and satellite companies was lobbying for stiffer penalties under the Radiocommunication Act for anyone caught selling or using illegal satellite receivers. When the proposed Bill to increase the fines for the 'grey market' was examined by the Standing Committee on Science and Technology, some MPs expressed concern that it would target consumers who were simply trying to access programming not currently authorized for the Canadian market.

The CRTC loosened its market access rules for third-language services in 2004, announcing that it would henceforth authorize third-language services that operate in the same language as existing Canadian channels. But to 'be respectful of Canadian content regulations' as Lincoln had recommended, it introduced a number of new market protections for the Canadian channels, such as the requirement that subscribers purchase the Canadian channel before being able to subscribe to the foreign channel (see Public Notice CRTC 2004-96, December 16, 2004). 
Most Canadians living in border cities can still receive over-the-air signals from United States, just as they did in the late 1940s and early 1950s before Canadian television was officially launched. Beginning in the late 1990s, many American broadcasters started to deliver high-definition television signals over the air . . . this reality means that Canadian broadcasters must follow suit. $(2003,433)$

At the same time it recognizes that the digital transition is undermining traditional regulatory authority. It quotes Richard Schultz, who told the committee:

The significance of the changing environmental conditions for the operations and effectiveness of the CRTC in fulfilling its fundamental responsibilities should not be underestimated for they may challenge the basic efficacy of existing regulatory powers and ultimately the ability of the CRTC to exercise any effective power to "command and control." (2003, 441)

Ultimately, the report reiterates the traditional view that "one of the primary purposes of the Broadcasting Act is to maintain and enhance national identity and cultural sovereignty through encouraging the development of Canadian expression and displaying Canadian talent." (2003, 472)

This is one of 45 times the report mentions "cultural sovereignty." Only once, however, does it define the phrase: "the right of a state to legislate in the cultural sector." (2003, 528) This is a telling interpretation, in that it implies that the 'sovereignty' that extends from our broadcasting system is based in administration, rather than identity.

It also implies that 'one of the primary purposes of the Broadcasting Act is to maintain and enhance national identity and the right of the state to legislate in the cultural sector' -i.e., that cultural legislation is important because it enhances our ability to legislate. It serves a self-reinforcing function, if not a cultural one. 
At the end of the day, the report speaks volumes, not only by virtue of its length or the number of its recommendations, but in suggesting that the administration of the broadcasting system is as important as the content of the broadcasting system. It reflects the age old response when regulatory authority comes under pressure from new technology: make tougher regulations. If traffic is getting around your walls, move them out to capture as much of it as possible.

\section{Satellite/subscription Radio:}

When the CRTC licensed two Canadian subsidiaries (XM and Sirius) of American satellite radio companies, and one all-Canadian terrestrial digital radio proposal (CHUM/Astral), in June 2005, it set the stage for a thorough rehashing of the historic Canadian response to new broadcasting technology.

In the Public Notice that prefaced the licensing decisions, the CRTC notes that the two Canadian subsidiaries were concerned that without speedy regulatory approval for their applications, American firms would corner the market and shut Canadians out of this new technological opportunity. It also notes that groups representing the interests of Canadian 'creators' were concerned that this new platform would simply be a pipeline for more American content and its attendant influence on Canadian culture. True to form, the CRTC issued a compromise decision, approving the business plans of the two companies, 
but requiring them to increase the amount of Canadian channels carried on each satellite before they could launch their services. ${ }^{97}$

This decision prompted a great deal of public reaction, as did a subsequent request to cabinet to have the licenses overturned, filed by CHUM/Astral, the two Canadian companies that own numerous conventional radio stations, and that had just received regulatory approval to launch a ground-based subscription radio service.

This Magazine framed the issue in familiar terms:

Are we about to enter a new age of radio with an endless variety of programming, easier access and more freedom of choice than ever before? Yes. Are our cultural institutions jeopardized by the onslaught of American entertainment? Yes. Does the CRTC have any power against such developments? Less and less. When sound quality is not sacrificed to distance and national borders are ignored by satellites and websites, the sheriffs of yore have limited power." 98

Similarly, the Ottawa Citizen's Don Martin saw the decision less as a compromise, and more as "the CRTC's white flag of surrender to a technology that knows no borders, and arguably signals the government-run authority's increasing irrelevance in a digital world." 99

Michael Geist, on the other hand, interpreted the licenses as "a text-book example of how (the CRTC) can still use its limited policy levers to promote Canadian content." $\mathrm{He}$

\footnotetext{
${ }^{97}$ Public Notice CRTC 2005-61, Introduction to Broadcasting Decisions CRTC 2005-246 to 2005-248: Licensing of new satellite and terrestrial subscription radio undertakings, June 16 2005: http://www.crtc.gc.ca/archive/ENG/Notices/2005/pb2005-61.htm

${ }^{98}$ Dick, T. "What is the Frequency Cancon?" This Magazine, September-October 2005, 13

${ }^{99}$ Martin, D. "2005: A space odyssey for a nation of music lovers." Ottawa Citizen, June 17, 2005. E4
} 
argued that by grafting Canadian content onto an American distribution platform, the CRTC was recognizing continental realities, while creating opportunity for Canadian artists. $^{100}$

However, the Commission's compromise incensed Member of Parliament Denis Coderre, who fumed that "le CRTC vient de définir le contenu canadien dans un contexte nordaméricain, et c'est totalement inacceptable,“ Displaying in one sentence a thin grasp of Canadian broadcasting history, an ardent nationalist's fear of American cultural influence, and a total indifference to everything that has changed in the broadcasting marketplace over the past 60 years, Coderre stated that "nous avons créé le CRTC après la Deuxième Guerre mondiale pour ne pas se laisser envahir par les ondes américaines. Quel est le changement en 2005?"101

The best line of the satellite radio debate goes to Andrew Coyne. He noted that one of the CRTC's motivations in licensing Canadian versions of an American distributor was to dissuade Canadians from accessing the American service directly, a practice that only required them to purchase an American decoder and provide an American billing address. Coyne noted wryly that "while until now Canadian listeners have long been faking American addresses to receive American satellite signals, henceforth American stations will be faking Canadian addresses to deliver it to them."102

\footnotetext{
${ }^{100}$ Geist, M. "Cancon in the internet age: CRTC's pay-radio decision benefits both musicians and listeners." Ottawa Citizen, June 23, 2005. F6

${ }^{101}$ Giroux, R. "Coderre sonne la charge contre le CRTC." Le Soleil, September 16, 2005. A10.

${ }^{102}$ Coyne, A. "The con we call Cancon." National Post, June 18, 2005. A16.
} 
The latest technological 'threat' to Canadian broadcasting prompted essentially the same response as the earliest. The introduction of radio, television, cable, microwave, satellite television, the internet and satellite radio all led the government to essentially the same economic and cultural conclusions: that because of the relative size of the American market to our own, only a regulatory framework predicated on citizenship and content can prevent American signals, and their American cultural references, from washing away our distinctive Canadian identity.

While it could be argued that this reflects a commendable degree of policy consistency, I would argue that it displays a telling disregard for how technology has changed the economics of broadcasting, and a stubborn resistance to any examination of the key cultural questions, such as: 'is there such as a thing as a distinctive Canadian identity? If so, how does Canadian television and radio programming "preserve and enhance" it? And why, if our "ideals and opinions" are so distinctive as to warrant a highly interventionist regulatory framework, are Canadian audiences persistently drawn to American programs, and the American values they supposedly reflect? Economies of scale cannot account for taste.

In the past, regulators and government inquiries have had the luxury of examining each technological advancement in isolation, sometimes taking years to study its supposed impact. Even then, many of these studies focussed on the impact of the new platform on the administration of broadcasting, rather than on the operation or consumption of 
broadcasting. Steady advances in Internet-Protocol (IP) delivered content (both to living rooms and back pockets) are placing the audience increasingly at the centre of the decision-making chain. Audiences have more control than ever before over what they consume, where, when, and how much they are willing to pay for it. Our approach to regulation, however, still treats the audience as essentially passive, downstream of where any important decisions are made. It reflects an enduring mistrust in the choices the audience might make, despite the fact that the rhetoric of 'choice' is still front and centre in the relationships between regulator, producer, broadcaster, distributor and consumer. 


\section{Chapter 5. the new economics of broadcasting}

And the winner, for Biggest Threat to the Broadcasting Industry That Might-Over Time and on Closer Inspection -Turn out to be Really Good Thing After All, is . . (Dramatic pause ... rustling of envelope) . . something like an 18-way tie between nearly every new product or service that has gone to market in the past few years, starting with new arrivals such as Google Video and video iPods, and on down the line to podcasting, the PlayStation Portable, PVRs, and TiVo (again), video cell phones, satellite radio, WiFi, Blu-Ray DVDs, blogs, HDTV (again), and so on.

Sean Davidson, Playback Magazine, $2005^{103}$

The entire concept of limited spectrum, on which the old economics of broadcasting are based, is obsolete. New technologies are emerging on a regular basis that permit a greater amount of audiovisual programming to reach audiences on a greater number of devices, using privately-owned networks, as opposed to publicly-owned airwaves. Digital compression technologies that permit distributors to wring greater amounts of bandwidth out of their spectrum allotments now represent a challenge to many of the fundamental economic and cultural assumptions about how and why we regulate the broadcasting system.

Leslie Ellis writes that: "spectrum is what you are born with . . bandwidth is what you do with it." $(2005,15)$ She uses a bookshelf to illustrate how bandwidth is allocated within the total amount of spectrum available to a typical urban cable system.

${ }^{103}$ Davidson, S. "They have seen the future. Or not. No easy answers as CAB looks at new technologies." Playback Magazine, November 7, 2005. 7. 
Imagine a single-row bookshelf with 750 individual slots for books, corresponding to the total amount of spectrum on a typical 750 megahertz cable system. On the far left of the shelf are 18 thin pamphlets, each taking up 2 slots $(2 \mathrm{MHz})$. These represent the amount of bandwidth that cable companies generally dedicate to 'upstream' data-the path that runs from the subscriber's house back to the cable plant. The return path carries requests for additional information from an electronic programming guide, pay-per-view and video-on-demand orders, or anything else that requires a signal to be sent back to the cable company from the subscriber. These pamphlets take up roughly $5 \%$ of the total shelfspace/bandwidth.

To the immediate right of these pamphlets are 83 bulky hardcover novels. These are the analog conventional and specialty channels. They occupy roughly $65 \%$ of the total shelfspace. To the right of these fat novels is a variety of books. Some are slim paperbacks, others are glossy, oversized art books. The paperbacks correspond to standard-definition channels that have been digitized and compressed, plus all the videoon-demand content. The big, glossy books are the high-definition digital channels, nice to look at, but profligate users of shelfspace: 330 standard-definition paperbacks take up the same amount of shelfspace as 99 high-definition art books. Each fat analog hardcover book removed from the shelf makes room for 10 to 12 new digital paperbacks.

The remaining $5 \%$ of slots are empty, buffers to signal interference between different types of channels, or are dedicated to various internet applications. 
In this cable model, readers do not control the contents of a book, but they can select the one they want, for as long as they want, in the format they want. The slots dedicated to return-paths and internet bandwidth allow the reader to order other books, from other shelves, in other libraries. This is where the concept of a linear, limited-choice media environment starts to break down.

Now compare this bookshelf model to a conventional over-the-air broadcasting model, in which the shelf is replaced by a loudspeaker, blaring the contents of one book at a time, for whomever happens to be listening. John Durham Peters states that "electromagnetic signals radiate 'to whom it may concern'" $(1999,206)$ like the Fessendens broadcasting O Holy Night to helpless sailors on the Chesapeake, a loudspeaker broadcasts its message to anyone who drifts into earshot. Similarly, Andrew Lippmann, argues that conventional broadcasting is "spam, sending out signals nobody asked for."104

This is the key conceptual difference in broadcasting today versus broadcasting before the 1990s. As Lippmann explains, the old model "was the province of the household, (whereas) 'broadbanding' is the province of the person." Broadcasters used to radiate their signals into the air, to be picked up by rooftop antennas, and beamed at whomever happened to be in front of the television or radio. We used to use the telephone to call the house, speaking with whomever happened to pick up the receiver. Today, we call the person. We used to radiate television and radio signals in the general direction of the

\footnotetext{
${ }^{104}$ Andrew Lippman, Associate Director of the Media Lab at MIT, Keynote Address to the Canadian Association of Broadcasters' annual convention, November 7, 2005, Winnipeg, MB.
} 
neighbourhood. Today, increasingly, we send them directly to someone's handheld device.

"Technology is gravitating to the person" in Lippmann's view. The audience is no longer bound to listen to whatever comes out of the loudspeaker. In theory, we can go to the shelf, select whatever book we want (or, connect to an endless chain of shelves in an endless series of libraries until we find one we want), turn to a specific page, copy it, send it to someone else, bookmark it for later, read it backwards or skip past the parts we do not like.

We are no longer sailors on the Chesapeake, captive audiences to the Fessendens's seasonal carolling, on the lookout for cultural icebergs. These are the new economics of broadcasting: open, not closed. Small discerning audiences, not large, captive audiences. More choice and more shelfspace opening up all the time, as a few fat books are replaced with many thin books.

Current market conditions are challenging old assumptions about how broadcasting policy works, and about the cultural dividends it pays. When our current Broadcasting Act was passed in 1991, the broadcasting value chain was essentially the same as when the previous Act was passed in 1968:

First, broadcasters aggregated audio-visual content, some of which was non-exclusive and paid for via copyright (music), some of which was exclusive, bought and paid for via 
licence fees (television programs), and some of which they produced and owned themselves.

Second, broadcasters arranged and branded that content into scheduled programming so it could compete with other broadcasters' content, and so it would accommodate commercial messages.

Third, broadcasters distributed that programming through a limited selection of distribution paths: through transmission towers they owned and operated, or through cable companies that picked up their signals and stuffed them down wires into houses in exchange for a monthly fee, a portion of which they remitted to the broadcaster. Cable allows signals to be easily directed to exact addresses, and is a closed system at both ends. This made it an easy system to regulate. In the mid-1990s, DTH satellite companies also began packaging broadcasters' signals into home distribution services, charging monthly fees, and remitting a portion of those back to the broadcaster. Because of its wide footprint, DTH was not as easily corralled through existing policy gates. It took an exceptional amount of lobbying and regulatory spadework to ensure DTH signals took the right path, through the right gates.

This traditional value chain runs straight through the fortress, facilitating precise rules for all who do business there. Ownership rules mean that only Canadians are allowed to participate directly in these transactions, with foreigners accepted into the gated policy space on a case-by-case basis. Access rules ensure that only licensed broadcasters are 
offered by cable and DTH companies, in predetermined combinations, and, in the case of specialty channels, that only one channel per 'genre' is licensed, protecting them from unlimited competition. Advertising rules ensure that the flow of advertising dollars goes primarily to Canadian companies. Content rules ensure that the programming that comes out the other side of the fortress contains as many Canadian elements as possible, although why this is desirable has never been clearly defined or expressed by the gatekeeper. 'Cultural sovereignty' is more about jurisdiction than identity, just as 'cultural nationalism' has more to do with nationalism than culture. Neither have anything to do with the new ways in which content is being produced, distributed and consumed.

Broadcasting vs. 'Broadbanding' (or, "see ya later, aggregator")

$63 \%$ of Canadians currently have access to a broadband network ${ }^{105}$ capable of transmitting a 90 minute, full motion video in under ten seconds. Internet speeds have now increased to the point where alternatives to traditional broadcasting value chains are financially viable. Broadband networks can deliver network television programming directly to a set-top-box without running through a branded channel, or without running through a licensed cable or DTH distributor. It can also deliver programming directly from the producer to the consumer, bypassing all other links in the value chain. And, of course, it permits the unlimited sharing of digital video and music files between individual users, regardless of where they were born, or where they live.

\footnotetext{
${ }^{105}$ Sources: CRTC Broadcast Policy Monitoring Report 2005: http://www.crtc.gc.ca/eng/publications/reports/PolicyMonitoring/2005/bpmr2005.htm
} 
$38 \%$ of Canadian homes have a compact disc burner, $16 \%$ a DVD burner. ${ }^{106}$ In other words, $54 \%$ of Canadian homes have the capability to produce hard cultural artefacts that convey, if the theory holds, cultural markers to other consumers. Licensed broadcasters are no longer the only program aggregators in the system, nor are licensed cable and satellite companies the only channel distributors.

The idea of television programming delivered across wireless broadband internet networks complicates the traditional value chain even further. Bell, Telus and Rogers all launched 'TV on mobile phones' services in late 2005. At the same time, Apple launched the video iPod, and began selling 99 cent commercial free episodes of primetime network programming on a per-episode basis.

Google, MSN and Yahoo all operate 'video stores', selling video content directly to consumers (including episodes of popular prime-time programs). Bloomberg reports that Google sold 3.04 million videos in December 2005, its first month of operation. That same month, MSN sold 9.4 million videos, while Yahoo sold 2.15 million. ${ }^{107}$

Sony and Sling Media each sell hardware that allows cable or DTH providers to access their set-top-box, and all of the channels it usually receives, anywhere there is wireless internet access, either on PCs or any number of pocket-sized devices. All of these

\footnotetext{
${ }^{106}$ Statistics Canada Daily Bulletin, December 12, 2005:

http://www.statcan.ca/Daily/English/051212/d051212a.htm

${ }^{107}$ Bloomberg News. Google Cites Flaws in its Video Store. January 26, 2006 : http://www.latimes.com/business/la-fi-google26jan26,1,521949.story?ctrack=1\&cset=true .
} 
examples have the potential to connect the program creator directly to the viewer, bypassing all other links in the chain. They also link the program creator to the person, not to the household.

These new aggregators circumvent traditional broadcasting policy approaches. They transform content from a 'public good' into a personal good, where a precise value can be assigned, based on the specific demand. Other recent developments also reflect the growing 'personalization' of broadcasting, similarly challenging the economic and cultural wisdom embodied in the traditional value chain.

\section{Video-on-demand (VOD)}

In 1994, the CRTC issued an exemption order for "persons carrying on programming undertakings for the purpose of conducting limited field trials or experiments to test and develop the technology for providing a VOD programming service and to determine the technical feasibility of that service." 108 The services proved feasible, so the CRTC moved to a full licensing framework in 1997, with attendant advertising, access and content rules. ${ }^{109}$

Since 2003, all Canadian digital cable subscribers have had the ability to order a variety of network programming and Hollywood movies 'on demand', as opposed to at a

108 Public Notice CRTC 1994-118, Exemption Order Respecting Experimental Video-on-Demand Programming Undertakings, September 16, 1994: http://www.crtc.gc.ca/archive/ENG/Notices/1994/PB94$\underline{118 . \text { HTM }}$

${ }^{109}$ See Public Notice CRTC 1997-83, Licensing of New Video-On-Demand Programming Undertakings Introduction to Decisions CRTC 97-283 to 97-287, July 2, 1997: http://www.crtc.gc.ca/archive/ENG/Notices/1997/PB97-83.HTM 
particular time of a broadcasters' choosing. In 2003, $12 \%$ of Canadian cable subscribers ordered on-demand programming. By 2005 , that number jumped to $35 \% .{ }^{110}$ In the United States, there were 177 million VOD transactions in 2004, and over a billion in 2005. ${ }^{111}$

VOD services are generally operated by distributors, who buy the 'on demand' rights to programming directly from the program creators, skipping the broadcaster's link in the value chain. Also in 2005, the CRTC permitted cable distributors, for the first time, to retain the advertising in any programming they offer on-demand, as long as it is the same as the advertising in the original program. ${ }^{112}$ Not surprisingly, VOD services in the United States are already far more commercialized. Cable companies sell two-minute advertising spots at the beginning of VOD programming, and are beginning to sell the right to place an advertiser's logo in place of the usual on-screen station 'bug' during VOD programs. Canadian cable companies have long complained that their American counterparts can sell advertising in the 'local avails' of cable channels. Once American VOD advertising reaches maturity, they are sure to clamour for the ability to replicate that in Canada too. Because set-top-boxes allow for the capturing of precise consumer viewing habits, they permit the specific targeting of products to consumers, based on viewing preference and its related economic profile. This will add to Canadian cable companies' urge to capitalize on that information by selling it to advertisers.

\footnotetext{
${ }^{110}$ Decima Research, 2005. The Digital Domain report.

${ }^{111}$ Cable and Telecommunications Association for Marketing, On-Demand Consortium Report, 2005. http://www.forrester.com/Research/Document/Excerpt/0,7211,35144,00.html

112 CRTC Broadcasting Decision 2005-497, Rogers on Demand-licence amendments, October 18, 2005 : http://www.crtc.gc.ca/archive/ENG/Decisions/2005/db2005-497.htm
} 
For example, Porsche might decide that a mass-market television buy is an ineffective way of reaching those few customers in the market for a six-figure sports car. But they might be very interested in reaching, directly, those few viewers whose economic profile exactly matches their target market. As more viewing moves to an on-demand platform, allowing for the collection of ever-more precise viewing data, the urge for cable companies to take advantage of their direct relationship with consumers in the form of VOD advertising will become irresistible. Even the smallest audiences will be valuable, provided they fit the right profile. The high return on investment will justify the cost of doing that kind of personalized advertising. This will threaten the central bargain between broadcasters and the regulator. That bargain now says that advertising is reserved for broadcasters, in exchange for programming commitments.

As currently regulated in Canada, VOD underlines the selective and inconsistent nature of the current policy framework. Distributors can apply for a VOD licence, then populate the menu with virtually any type of programming, absent any detailed regulatory oversight.

For example, a cable company could offer an 'Animation On Demand' category, on which viewers could choose from a menu of hundreds of animated programs. If the same cable company applied for a Category 2 digital licence to operate a digital 'Animation Channel', it would be rejected, on the basis that the new channel would offend the CRTC's 'one per genre' policy, as there is already an analog channel dedicated to 
animated programming. The effect, however, is the same - the incumbent channel now faces competition for viewers and programming rights for animated content- - but the CRTC maintains that its 'one per genre' policy is necessary to preserve a diversity of formats in the limited amount of spectrum available for broadcasting. There are multiple sports channels, drama channels, cartoon channels, kids channels, old-show channels and movie channels, but the CRTC maintains the fiction that each of these fills a slightly different niche, for example, that NHL games on a regional sports network are only of interest to viewers in that region, while NHL games on national sports networks are of interest to everyone.

Despite the fact that available spectrum now supports exponentially more channels than when the 'one per genre' policy was created in the $1980 \mathrm{~s}$, or that its effect is completely undercut by the licensing framework for on-demand services and by the sheer proliferation of channels (there are only so many truly distinct 'genres' of programming) the CRTC maintains the original rule, applying it every time anyone applies for a licence to operate a new specialty channel, or for approval to distribute a foreign channel. The use of personalized scheduling is growing, and the supply of specialized programming for any and all tastes is multiplying rapidly, but the regulatory system is still predicated on closed channels and narrowly-defined niches.

\section{High-definition television}

The CRTC has stated that it considers digital television to be a "replacement technology" to analog television, and has launched several proceedings and initiatives to entice 
broadcasters to switch to high-definition broadcasting as fast as possible. ${ }^{113}$ These may appear to be complementary initiatives, but in fact, their assumed benefits cancel each other out.

As noted, each 'hard cover' analog channel takes up 10 to 12 times the shelf-space as the digital 'paperback' version of the same channel. This allows a great deal of spectrum to be freed up for new channels, or for other uses, such as broadband internet or digital phone service. Digital channels are a far more efficient use of shelf space than analog channels.

At the same time, the CRTC is encouraging broadcasters to launch large, high-definition art-book versions of their channels, soaking up all the extra space with glossier versions of traditional channels. When it refers to "the digital transition," the CRTC is in fact jumbling three separate transitions from analog to digital broadcasting.

First came the deployment of digital cable and satellite, a transition which is nearly complete (few areas are not served by at least one digital distributor). Second is the transition from analog to digital conventional and specialty broadcasting. The comparison is often made to the transition from black and white to colour broadcasting, but this is a false analogy: broadcasters were not required to build new transmitters, and customers with black and white televisions could still watch colour signals. Conventional stations who transition to digital face massive system upgrades and

${ }^{113}$ For example, see Public Notice CRTC 2003-61, The regulatory framework for the distribution of digital television signals, October 20, 2003: http://www.crtc.gc.ca/archive/ENG/Notices/2003/pb2003-61.htm 
retooling. For analog specialty channels, the transition to digital is not as costly, but does represent a very real overhead in terms of equipment and satellite uplink costs. The third transition is from standard to high definition broadcasting. Some stations are better suited to a HD format than others, and could be expected to make that transition in accordance with audience demand. For other channels, there is simply no HD programming available in their format (e.g. 'vintage' programming channels), or no dramatic improvement in quality that would justify the cost of the transition (e.g. news, weather channels).

The government has yet to explain why prettier HD pictures are a valid public policy objective, except to note, predictably, their concern that " $80 \%$ of Canadians who live near the border will start disconnecting their Canadian cable to watch American high def programming over the air." 114 There is no doubt that the HD version of some programming is better to look at, and that as more people buy HDTV sets, they will expect there to be the highest-quality programming available. But this should obviate the need for a regulated deadline, not reinforce it. Along these lines, the CRTC has so far signalled that it would permit a "market-based" transition (which, it could be argued, means that it is not really that important if it is confused the various, separate, transitions that fall under the heading of 'digital transition').

\footnotetext{
${ }^{114}$ Michael Binder, Assistant Deputy Minister, Spectrum Information Technologies and Telecommunications, Industry Canada. Remarks made during a panel discussion "High Definition Television: There is no looking back," at the International Institute of Communications annual conference, Ottawa, December 12, 2005.
} 
Moreover, requiring the full duplication of every channel in digital/HD is not an efficient use of spectrum. In an increasingly 'take it with you' communications environment, HD is a fixed platform, the province of the home, not the individual, reflecting yesterday's priorities in today's marketplace. Lippmann makes the case that instead of requiring bandwidth to be dedicated to new 50 megawatt digital broadcast towers (to send out a single stream of signals nobody asked for) we should instead be allocating that spectrum in smaller packages, allowing individuals to send and receive addressable signals through mobile devices, using the liberated spectrum to empower the audience by making it available for more personalized use. ${ }^{115}$

Again, forging ahead with spectrum-hogging high-definition versions of traditional massmarket channels, at a time when consumers are turning in greater numbers to nontraditional personalized platforms, highlights the general and growing gap between the ambition of our broadcasting policy and the capacity of the marketplace.

\section{Advertising}

Traditionally, a broadcaster beamed a signal into a neighbourhood, and used household diaries and set-top meters to record, after the fact, how many homes tuned in. The growing importance of the internet as a competitor to traditional value chains can be seen in the move of major advertisers away from television and radio, and into online

${ }^{115}$ Ibid. 
advertising. ${ }^{116}$ The appeal to the advertiser is in the specificity of broadband consumption.

Previous economic wisdom dictated that because it was impossible to determine with any precise degree of accuracy how many people were watching, advertisers were drawn to the widest possible platforms in the hope of reaching as many eyeballs as possible. This in turn had an impact on programming strategies and the operation of rights markets. A popular sitcom would run first in the busiest possible timeslot, to attract the largest possible number of viewers to sell to advertisers (its first window). It might be aired later on the original network as a repeat (or in today's lingo, an 'encore'), for which advertisers were charged less, on the assumption that it would attract fewer viewers to its 'second window'. It might later be licensed to a specialty channel, who would run it as a syndicated rerun, charging advertisers even less, because a third-window audience was presumed to be naturally smaller than the second, and so on.

That economic model and the theory behind it has been turned on its head as the delivery of signals has ecome more personalized, as specialty channels draw audiences on par with conventional networks, as digital video-recorders allow viewers to skip commercials altogether, and as new devices create successive and overlapping rights windows (think of next-day iPod downloads of that sitcom as a simultaneous second window). Not

116 PricewaterhouseCoopers estimates that internet advertising will grow at a $10.5 \%$ annual rate through the end of the decade. See http://www.hollywoodreporter.com/thr/pwc/talking_display.jsp?vnu_content id=1001096432. 
surprisingly, advertising and audience measurement are also moving towards a more addressable model.

Audience measurement companies are rolling out ominous sounding "personal people meters" (PPMs) across the United States and Canada. ${ }^{17}$ These are pager-sized gadgets that clip to a belt. The broadcaster buries a unique, repeating, inaudible digital code in the audio tracks of every radio or television channel in the country, and the PPM recognizes that code. It also captures exposure to broadcasting signals in passing, whether in an elevator, taxi, waiting room etc. The exact amount of time, down to the second, that any given individual is exposed to any given bit of content is recorded and reported. As programming moves from the living room to the pocket, so does the measurement.

Back in the living room, digital video recorders that can be set to automatically skip commercials are also enticing broadcasters and advertisers to find new ways to reach audiences. The most common technique is 'product placement', placing a recognizable product in a camera shot. An emerging and more specialized variation to this idea is 'dusting in' a product: the producer shoots the scene with a brown food delivery bag on the kitchen table. Each broadcaster in each market 'dusts in' the logo and phone number of a local take-out restaurant. This is a more addressable, less random, variation on product placement that reflects the increasingly precise delivery and measurement of programming signals.

${ }^{117}$ See http://www.engadget.com/entry/1234000577039635/ 
Predictably, the old habits die hard. As personalized measurement and advanced product placement techniques take hold, Kate Taylor has urged regulators to impose conventional advertising regulations on these new practices. ${ }^{118}$ Citing Neilsen numbers that point to an almost 50\% increase in product placements on NBC between 2004 and 2005, she recommends that every second a product appears on the screen be counted towards the 12 minutes of advertising permitted in any televised hour of programming. How this would work in practice is, of course, not explained -presumably armies of bureaucrats with stopwatches and zoom lenses would monitor and clock every program that airs. More to the point, however, is how this recommendation reflects the lingering preference for outdated regulatory impulses in the face of new practices made possible by new technologies.

\section{Broadcaster/distributor integration}

Just as programmers and advertisers are clamouring for a better understanding of the television audience, a wave of new consumer products has made it increasingly difficult to satisfy them. Most of these are the offspring of companies who have moved out of their traditional place in the value chain, and now occupy several overlapping links.

Increasingly, the lines are blurring between creator, aggregator and distributor. Facilitating this is the amount of bandwidth being made available for the transmission of personalized content to 'personal media devices', such as mobile phones and iPods. The

118 Taylor, K. "I turn on Corner Gas, I get the Sears wishbook?" Globe and Mail. November 19, 2005. R2. 
exact scope and impact of this industry restructuring could be the subject of a separate and much longer study, but it is possible to see in its broad lines the effect it is having on conventional schools of regulatory thought.

We are moving to a value chain with three links (producer-distributor-audience) instead of four (producer-broadcaster-distributor-audience). In this shortened value chain, distributors gain direct access to audiences, and the attendant share of advertising and subscription revenues. This impacts regulatory assumptions about the traditional roles played by programmers and distributors in the broadcasting system. It is also increasing the number of programming rights windows, and collapsing them onto each other, further undermining regulatory thinking about who does what in the system.

John Durham Peters writes that "the contrast between broadcasting and common carriage became a cornerstone of United States broadcasting policy" in its formative years. (1999, 210) He explains that common carriers operate point-to-point systems, delivering their goods to exact addresses, and is characterized by the separation of content and the channel used to deliver it. "Thus, if you shout obscenities into a phone, the phone company is exempt from prosecution; if you do so into a radio microphone, the station may have to answer to the FCC." $(1999,210)$ Traditionally, broadcasters delivered content, while carriers carried communications. This distinction is currently reflected in our separate Broadcasting and Telecommunications Acts. 
However, these distinctions are rapidly disappearing. Cable and DTH companies are regulated as distribution undertakings, despite the fact that they share characteristics with broadcasters (as aggregators and, in the case of cable community channels, originators of programming), and with telephone companies (in provision of voice-over-internet services). Similarly, telephone companies are offering television service over phone lines and/or over wireless networks. The regulatory definitions of 'broadcaster', 'distributor' and 'common carrier' are throwbacks to a previous set of circumstances, yet continue to be reflected in how we regulate content.

\section{The long tail}

The regulatory assumptions behind current access, distribution and linkage rules are based on notions of poor supply-and-demand matching: a response to inefficient distribution that no longer applies in an age when the lifespan of any given bit of programming is stretched across windows that are simultaneously multiplying and collapsing.

Chris Anderson argues that most of current marketing theory has been bypassed by developments in the marketplace. ${ }^{119}$ "The main problem," he claims, "is that we live in a physical world, and, until recently, most of our entertainment did, too." He finds that this

\footnotetext{
${ }^{119}$ Anderson, C. "The Long Tail." Wired Magazine online, December 10, 2004: http://www.wired.com/wired/archive/12.10/tail.html
} 
world puts "two dramatic limitations on our entertainment." And, I would add, on our approach to regulating the broadcasting system.

The first is the need to generate sufficient sales to justify the shelfspace. This descends from notions of economies-of-scale: the first window for any program, movie, book, videogame, should cover the cost of its production. Subsequent windows are the profit. This is what drives the fear that American content, if left unchecked, will wash away our Canadian content: once its production costs are covered in the American market, it will be 'dumped' into the Canadian market, at rates that undercut our own ability to produce and distribute culturally-relevant content. This in turn relies on notions of mass audiences: as Anderson states, "in the tyranny of physical space, a thin audience is the same as no audience at all."

The second limitation is physics. Anderson notes that:

The radio spectrum can only carry so many stations, and a coaxial cable so many TV channels. And, of course, there are only 24 hours a day of programming. The curse of broadcast technologies is that they are profligate users of limited resources. The result is yet another instance of having to aggregate large audiences in one geographic area -another high bar, above which only a fraction of potential content rises.... Hit-driven economics is a creation of an age without enough room to carry everything for everybody ... This is world of scarcity ... we are entering a world of abundance.

His bottom line is that the entertainment marketing machine is a captive of "hit driven economics," and these are, in turn, "a creation of an age without enough room to carry everything for everybody." The old assumption is two-fold: that only $20 \%$ of programs 
or songs will be hits, and that the vast majority of consumption takes place in the first window, dropping off rapidly in subsequent windows.

In a world of virtually unlimited bandwidth, there is room for a vast amount of choice. This shatters the idea that there is not enough room for everybody, and that as a result, we have to carve out sections of our broadcasting shelfspace to privilege certain content. It belies the notion that 'important' content will be squeezed off the shelf by imported content, dumped into our market once it has made its money back at home.

Moreover, the proliferation of personalized media devices has greatly expanded the lifespan of any given program or song. Previously, a program aired in prime-time once, possibly twice, was repeated ad nauseam in syndication, then maybe got another lease on life in video sales: three, maybe four windows, each following on the other. A song earned its creator royalties from radio play, and if enough people liked it, from album sales: two windows, with some overlap.

Today, an episode airs in prime-time, is available for downloading to an iPod the next day, appears on-demand the following week, is released on DVD at the end of the season, re-runs on prime-time, and on a specialty channel, all within its first year. And these are just the licensed channels; unlicensed downloads add a parallel lifespan to any given bit of content. 
Today, an artist records a song, makes it available for downloading, hoping that it generates enough reaction to lead to paid downloads, and retail distribution, and then, maybe, commercial radio play, or satellite radio play, or perhaps a place in any of the millions of popular 'podcasts' that allow individual users to assemble songs into 'programs' and make them available for downloading. The windows for recorded music are growing, overlapping, and creating new, simultaneous revenue streams.

By the same token, rather than a front-loaded model, where most consumption happens in the first window, then tails off rapidly over the course two or three subsequent windows, today that curve is both flatter and longer: hence, 'the long tail.'

This marketing phenomenon undercuts many of the long-standing assumptions of a broadcasting policy that privileges certain windows over others. We maintain more restrictive or permissive rules, depending on whether they target conventional 'first window' television, or specialty 'second window' channels. We assume top 40 hits will gravitate to FM radio, so we restrict the number of 'hits', variously defined, that AM radio can play. ${ }^{120}$ Consumers simply do not react in the same way to content as they did in an era of scarce spectrum and limited choices. Even where the framework has changed to accommodate these factors, we hear repeated calls for a return to way things used to be.

\footnotetext{
${ }^{120}$ See Public Notice CRTC 1998-41, Commercial Radio Policy April 30, 1998: http://www.crtc.gc.ca/archive/ENG/Notices/1998/PB98-41.HTM
} 
Consider the seven-year campaign waged by various unions and guilds for the return of rules that went by the wayside in the CRTC's 1999 Television Policy. ${ }^{121}$ According to the supporters of this campaign, the CRTC erred when it removed the requirement that conventional broadcasters spend certain amounts of their revenues on the kind of massively expensive, distinctively Canadian drama that depends on a short-tail return, i.e, large audiences to the first window, if it is to be economical.

These calls for a return to more restrictive programming practices and narrower spending patterns are based on outdated notions about the ability of 'short tail' programming to generate prime-time audiences. It suggests a disregard, even a disdain, for current market trends. It suggests that the system should be forced to supply more of the content that audiences do not gravitate to naturally (if they did, there would be no need for rules to ensure that supply).

Not surprisingly, this campaign's loudest advocates claim that "it is through television drama that most Canadians participate in their national culture and share in the evolution of social values and stories of human passion..."122 This statements has several implications.

\footnotetext{
${ }^{121}$ See http://www.actra.ca/actra/control/feature 12

${ }^{122}$ See Submission of the Coalition of Canadian Audio-visual Unions (CCAU) to the CRTC re Public Notice CRTC 2003-54: Support for Canadian Television Drama. Novem,ber 28, 2003: http://www.actra.ca/actra/images/03dec/CCAU-DRAMA\%20BRIEF.pdf
} 
First, it is completely illogical. If the problem they are trying to address is the lack of Canadian drama, then how is it possible for "most Canadians to participate in their national culture and share in the evolution of social values" through Canadian drama? Our national culture must be pretty weak and our social values remarkably unevolved if most Canadians connect to it through a medium that, even its staunchest supporters admit, scarcely exists. Moreover, if most Canadians participate in their "national culture" and "human passion" by watching sitcoms and soap operas, we need to get out more. Second, this statement speaks to the resilience of the indefensible idea that television programs somehow automatically embody the "social values" of a majority of the citizens in the producer's birthplace.

Surely, in an age of unlimited programming choices, from an unrestricted range of creators, on an endless array of devices, it is time to put this notion to rest, once and for all. Primetime television and top 40 radio make no lesser or greater a contribution to the 'national culture' than the internet, video-on-demand, podcasts, or video-enabled mobile phones. Canadian-owned broadcasters and distributors add no additional cultural residue to the channels they deliver. Canadian creators do not automatically produce content that reflects the ideals and opinions of all Canadians.

James Carey submits that technology "is thoroughly cultural from the outset: an expression and creation of the very outlooks and aspirations we pretend it merely demonstrates." $(1988,155)$ Our entertainment choices may reflect, but do not embody our culture; and even if they did, the current open communications environment suggests 
a Canadian 'culture' that has long ago surpassed our gated broadcast policy, with its narrow economic assumptions and problematic cultural prescriptions. Clearly, it is time for a broadcasting policy that reflects the way content is produced, distributed, and consumed in today's marketplace, and that is not predicated on parochial notions of cultural superiority. 


\section{Chapter 6: conclusion}

And now, we've broken down the walls that kept TV immobile and find our tried-and-true business models being put to the test while new content delivery methods and new players emerge at a frenetic pace. And we need to re-evaluate our regulatory policies in light of the alternative distribution channels that are emerging.

$$
\text { Allan Sawyer, } 2006^{123}
$$

A Canadian broadcasting industry, we are reminded, often, is crucial to the development and maintenance of Canada's national or cultural identity. But because of the peculiar economics of broadcasting, rules and regulations are required to ensure Canadian broadcasters can compete with American broadcasters. If they cannot -the argument runs-American content will dominate the airwaves, and our 'cultural sovereignty' will be weakened.

The assumption behind much of Canadian broadcasting policy is that, if left to the open market, the Canadian broadcasting system will produce an insufficient amount of Canadian programming for Canada to remain culturally distinct from the United States. This assumption relies, in turn, on highly subjective notions about the influence of television programs and popular music on cultural identity, and about the influence of individual creators on the 'nationality' of broadcasting content.

If the current regulatory framework stems from a particular set of cultural and economic assumptions, the definition of 'Canadian culture' it supports is inherently dependent,

\footnotetext{
${ }^{123}$ From The end of Television as we know it: a Canadian perspective, a draft report for IBM Business Consulting Services, 4
} 
parochial, and pessimistic. It supposes that Canadian ideals and opinions are distinctive simply because they are not American, and that they are preferable, or superior, to American ideals and opinions. This is hardly an affirmative, constructive view of cultural identity.

Moreover, Canadian content regulations enshrine our cultural interdependence on the United States, rather than our cultural sovereignty. Broadly stated, the main cultural objective behind Canadian content regulations is a Canadian market in which Canadian consumers have the option of viewing or listening to Canadian content. The main economic objective is a Canadian industry to produce and deliver that content. Achieving the former requires a cross-subsidy approach to secure the later: Canadian broadcasters attract large Canadian audiences to profitable American programming. This allows them to offset the losses they incur in providing the required, unprofitable Canadian programming to small Canadian audiences. In other words, without American ideals and opinions, we could not sustain our own. This is a far cry from a free, sovereign Canadian broadcasting market.

Acheson and Maule submit that cultural nationalism is based on several myths: that "commercial cultural products made by Canadians differ significantly from those made by foreigners," $(2001,15)$ that "state support is necessary because the costs of Canadian cultural products exceed their value in the marketplace," $(2001,15)$ and that "ensuring access (by Canadians to Canadian cultural products) requires that the means of distribution be Canadian owned." $(2001,17)$ They conclude that the notion that only 
Canadians can tell Canadian stories is an "emotional wrapping for an industrial policy," $(2001,19)$, ensuring only that stories get told by Canadians, not that Canadian stories get told.

As far as industrial objectives go, it is easy to demonstrate that Canadian broadcasting regulation has had some measure of success: In 2004, Canadian broadcasters earned over $\$ 4$ billion in revenue. The average profit margin for a Canadian broadcaster is in the range of $30-40 \% .^{124}$ However, production and distribution of Canadian content far exceeds actual demand. This can be partially explained in part by Paul Attallah's observation that "Canadian content quotas ... restrict the supply of programming Canadians most enjoy and increase the supply of programming they least enjoy." (1996, 221) If Canadians enjoyed Canadian and American programming to an equal degree, there would be no need of specific spending and exhibition quotas. Although, to be fair, there is likely some truth to the argument that American programs do better than Canadian programs with Canadian audiences because of economies of scale that allow for greater production and marketing budgets.

The economics of scale assume that American programming outperforms Canadian programming because American producers enjoy natural advantages that result in a more attractive product. However, as technology continually reduces the production and distribution costs of broadcasting content, and creates new platforms and new windows

\footnotetext{
${ }^{124}$ CRTC Broadcast Policy Monitoring Report, 2004: http://www.crtc.gc.ca/eng/publications/reports/PolicyMonitoring/2004/gic2004.htm
} 
for distribution, that content is becoming increasingly resistant to national borders anyhow, and to the protectionist policies that police them.

This is not to suggest that these cultural assumptions could never be quantified. It could conceivably be demonstrated that Canadians are more familiar with some aspects of American history than Canadian history, or with some aspects of American law than Canadian law, because of the prevalence of American broadcasting content in Canada.

However, such a study would be both an endorsement and indictment of our gated policy space. On one hand, there would be evidence that Canadians are more familiar with American ideals and opinions than their own because of exposure to American programming. On the other hand, there would be evidence that 80 years of cultural protection have failed to ensure that Canadian ideas and opinions are noticeably different from American ideals and opinions.

Acheson and Maule allow that "what we listen to, or watch, matters," but insist that that "does not justify policies that prohibit or make more expensive content based on criteria that do not relate to the content itself." $(2001,335)^{125}$ The popular argument that content

\footnotetext{
${ }^{125}$ Their 'concession' that content "matters" raises some interesting questions. Why does Canadian content matter? How does it affect us differently than American content? Examining the social effects of broadcasting is a well established field of study, but one that rarely, if ever, features into our broadcasting policy.

It is generally accepted that broadcasting content helps shape social tastes and preferences, if for no other reason (and there may well be others) that it provides common frames of references But does this mean that all official Canadian content conveys Canadian values to all Canadians who happen to be exposed to it?
} 
quotas are about ensuring a choice of Canadian content that the open market would not otherwise provide bears with it assumptions that Canadian content benefits Canadians in ways that American content does not. If not, then what is the problem if Canadian broadcasters cannot compete on an equal footing with American broadcasters?

Even if we accept the premise, it begs questions about why content quotas are limited to broadcasting. Surely American magazine and book publishers enjoy similar economies of scale. Picking up on this theme, the Globe and Mail asks:

what if Ottawa announced tomorrow that it was creating a new agency, the Canadian Periodicals Commission, to determine which newspapers and magazines should be allowed to publish in this country? To get a publishing licence, you would have to approach the Commission and make your case, fulfilling all the requirements for decency, quality, and of course, Canadian content. If the Commission decided that there were too many, say, fishing magazines on Canadian newsstands, it would turn thumbs down on any new entries into the market. ${ }^{126}$

Few would argue that broadcast programming has no impact on its audience. But this is not the same thing as accepting that it conveys the 'national values' of its creator. If I get into a taxi whose radio is tuned to an Avril Lavigne song, am I more Canadian than when I got in? Or does it take repeated exposure before it begins to matter to me at a national level? And what of the Michael Bublé song that follows it? As a Canadian artist, he scores an 'A' on the MAPL scale, but because his lyrics, music and production originate from foreign sources, his music does not qualify as official Cancon. Do the 'foreign' values in his song cancel out the 'Canadian' values in Lavigne's song?

This is, of course, to reduce questions of broadcasting policy and media effects to the level of specific examples, a process that invariably produces absurd results. But that fact should be troubling in and of itself: if our broadcasting policy does not hold together at the level of personal consumption, how can it hold together at the level of national consumption? If it does not work in practice, how can it work in theory?

It is entirely possible for content to "matter" to its audience without it holding some deeper patriotic meaning. And even if it could be demonstrated that all Canadian content conveys Canadian values, why do we limit content quotas to broadcasting?

${ }^{126}$ Editorial, Globe and Mail, June 17, 2005, A12. 
I would argue that broadcasting content suffers no more or less a 'cultural discount' than other media when crossing the border, and that broadcasting does not play any greater role in the formation of ideals and opinions than newspapers, magazines, books, or the internet -and yet the very suggestion of state intervention in the content of any of those media is absurd. If the "state has no business in the newsrooms of the nation,",127 apparently it is perfectly comfortable in the production studios and editing suites of the nation. Even so, as Andrew Coyne notes, they cannot make us consume Canadian content, but at least they can pretend to. ${ }^{128}$

So how to get past these inconsistencies, illogicalities, and parochial notions of Canadian identity?

I have argued that technology is fragmenting audiences and eroding borders in ways that challenge the most deep-seeded totems of Canadian broadcasting policy. The fact that we rely on American programming to subsidize Canadian programming suggests we already operate in a North American media marketplace. A more affirmative and effective broadcasting policy for Canada would be one that recognizes that the popularity of American programming in Canada is an indication of our similarities, not a sign that we have failed to properly enshrine our differences.

\footnotetext{
${ }^{127}$ Senator Joan Fraser, quoted in Spencer, C. "Let consumer choice 'save' our media." Toronto Star. May 12, 2003. A19.

${ }^{128}$ Coyne, A. "The con we call Cancon." National Post, June 18, 2005, A16.
} 
Recently, the Chair of the CRTC suggested that late 2007 might be a good time to study how the regulated parts of the industry are coming under strain from the increasing amount of unregulated programming available to Canadians. However, it appears as if this examination is already saddled with the weight of outdated expectations. Despite the fact that viewing patterns have shifted drastically since the 1999 Television Policy was issued, "the question remains the same, (even if) the answers differ," insists the Chair. "How do we, in this universe of choice ... ensure we have a means of communicating with each other ... our stories, news, sports, and ensure that Canadians are going to find it interesting and worthwhile to tune into?",129

I would suggest that the questions themselves have to change, or we will keep getting the same unsatisfying answers. If the CRTC is indeed serious about a top-to-bottom review of our broadcasting policy, it will need to go back to the kind of first principle question that was never satisfactorily addressed in the Lincoln Report, the last major government foray into Canadian broadcasting; it will need to review why we regulate broadcasting, not just how.

Instead of assuming Canadian content somehow pays cultural dividends, and then examining how best to ensure its supply meets (or exceeds) demand, any future policy review needs to start with an examination of the principles behind the regulation, not just the impact of the rules themselves. The following are several principles and propositions that I suggest should guide such a proceeding.

${ }^{129}$ McLean, C. "Television's penetration my force policy review." Globe and Mail, January 18, 2006, B3 Emphasis added. 
As a general note, I would suggest, in each case, that we need better and more frequent measures for determining if the regulations actually meet their stated objectives. If we are to have cultural objectives, there must be more than industrial measures to determine if they work. If we are to have an industrial policy, we need to stop dressing it up in cultural rhetoric.

\section{We need a new Communications Act}

Cable and telephone companies each compete on each other's traditional turf. Increasingly, broadcasting policy will need to be contemplated in the telecom space, and vice versa. Broadcasting and telecom companies all fall to some degree under the Broadcasting Act, the Telecommunications Act, the Radiocommunications Act, the Elections Act, the Copyright Act, and the Income Tax Act. There is nothing in any of these Acts requiring their provisions to be considered in the context of any of the others. At the same time, regulatory tools and approaches from one sector have begun to creep into others. For example, the CRTC in 2004 announced a policy to increase Canadian content obligations of specialty channels in brackets based on profit margins, an approach borrowed from 'rate of return' telecom regulation. ${ }^{130}$

Within the past few years, the United States, the United Kingdom and other countries have developed updated legislation to specifically address the modern communications

\footnotetext{
${ }^{130}$ See Public Notice 2004-2 Introduction to Broadcasting Decisions CRTC 2004-6 to 2004-47, renewing the licenses of 22 specialty services, January 21, 2004.

http://www.crtc.gc.ca/archive/ENG/Notices/2004/pb2004-2.htm
} 
marketplace. In some cases, these new laws stitch together various existing legislation and agencies. In other cases, they completely replace the old framework. By contrast, every piece of legislation that applies to Canada's communications field predates the internet (although, to be fair, in 2002, the Copyright Act was amended to clarify that the Compulsory Retransmission tariff does not apply to live streaming of broadcasting signals over internet). ${ }^{131}$

If history is a guide, another review of broadcasting policy by the CRTC will inevitably be dominated by a review of policy within the gated space, rather than a full discussion of what is happening outside of it, if for no other reason than regulatory self-preservation. Like the 2003 Lincoln Report (which is as much about preserving the ability of legislators to legislate broadcasting as it is about how broadcasting should be legislated), another regulatory framework review is unlikely to come to the conclusion that drastic reductions in regulation are in order. And they may well be. But to get to that point, we need a much higher-level look at the entire communications field, and whether we should have one set of laws governing all traffic and commerce that occupies it.

\section{The new framework should be open, not closed}

Other features of the communications field are moving toward more open administration and consumption, and content consumption is following suit. Our regulatory framework has to acknowledge this fact.

${ }^{131}$ The Act to amend the Copyright Act (Bill C-48) received Royal Assent on December 13, 2002. 
Linux, for example, is an open-source web browser, meaning that anyone can contribute to its code, adding new features or altering existing ones. Wikipedia is an open-form online encyclopedia, to which anyone can add, subtract, or alter any entry. Blogs and podcasts are open-communication models, turning anyone with an internet connection into a publisher or broadcaster. These are also prime examples of the type of personalized, unregulated media that compete for audiences with linear, mass-market media, and that at some point, will win that battle.

If a centralized broadcasting system is to have any relevance in the communications field, It has to move away from command-and-control, gatekeeping-style, regulation that assumes a one-way flow of information. Content that only exists in one format, or that cannot be tailored to individual tastes, will be orphaned in this landscape.

For this reason, the main regulatory and business challenge is how to ensure the people who created the content are paid for it, and how much. 'Digital rights management' (DRM) will need to feature prominently in any future discussion of the communications field. At the same time, it has to be remembered that 'managing' rights is not the same thing as 'protecting' each and every existing copyright. Rights holders also need to be cognizant of the open environment in which they operate, and adjust their operations and expectations accordingly. Audiences expect to pay for a program or song once, and then to have the freedom to do what they like with it. The long-tail model must be married to a more realistic rights-management model: if programming is going to generate revenues 
across a wider array of platforms, technological 'fixes' that limit the portability of content will ultimately be self-defeating.

For example, the Federal Communications Commission (FCC) in the United States had adopted a regulation requiring digital television tuners to include "content protection" (DRM) technologies. This software would look for 'broadcast flags' embedded in each program by the copyright holders. Programming that contained the flag could be viewed once, and perhaps copied onto a DVR for viewing once, but could not be transferred to another device. Some windows, such as VOD or pay-per-view, could be viewed once but not reproduced, even for personal use. As long as a bit of programming had the flag, and a device has the capability to read it, unauthorized distribution of content would require complicated technological work-arounds. The objective was to discourage casual piracy, but the effect was to seriously limit personal use of paid media. Because it was required to be included in all new DTV sets, it would have increased the cost of that sets, while reducing their utility to the buyer.

In May 2006, the District of Columbia Court of Appeals overturned the FCC's decision, but the example is still instructive: the broadcast flag was an attempt to curb the functionality of digital content, rather than truly responding to it. The regulatory impulse, as usual, was to use the new technology to reinforce the gated policy space. The 'reproducibility' of digital content was something to be curbed, not harnessed. To protect "free" over-the-air digital signals, the FCC tried to limit their ability to be freely consumed. 
Even amid recent announcements by more free-form participants in the audio-visual field, the default approach is still to erect gates and barriers. When Google officially launched its video store, its CEO and co-founder used the occasion to issue a heartfelt call for greater interoperability between content creators and personal media devices, before unveiling a system that uses a proprietary DRM standard (meaning that videos purchased from Google will be restricted in terms of what can be done with them, and for how long). Why the discrepancy? "We have our own DRM that we are using ... creating our own just seemed easier" he explained. ${ }^{132}$ This example suggests that even those that are ostensibly committed to more openness are prone to gated behaviour to meet commercial and regulatory expectations: it is simply easier to do so in the current climate, even if it reflects outdated business models, based on old frameworks.

Likewise, the owners of the broadband networks have shown themselves prone to erecting gates and barriers between the creator and the consumer. Shaw now offers a premium voice-over-internet-protocol (VoIP) service that, for a fee, privileges its own internet voice traffic over that of others. Users of competing VoIP services will require an additional fee to use them on Shaw's broadband network. Videotron has referred to competing VoIP services as "parasitic," suggesting that it greatly resents having to carry competing services on its own network. An American ISP actually kicked traffic from a competing VoIP provider off of its network, until the FCC intervened. Telus recently

\footnotetext{
${ }^{132}$ Rosmarin, R. "Google goes gaga for video." Forbes.com, January 12, 2006: http://www.forbes.com/digitalentertainment/2006/01/11/google-video-rights-cx rr_0112googlevid.html
} 
prevented its users from accessing a union website while in negotiation with its workers. ${ }^{133}$

These examples demonstrate that the impulse to channel unregulated communications through one gate or another is not limited to the regulator. Companies that are licensed and regulated on along gated lines tend to revert to gatekeeping impulses in their business practices. They also show the value of regulation: it allows us to control the behaviour of individuals and only appears to control the behaviour of the industry. Or, put another way, beyond industry control, the indirect target of regulation is individual behaviour. Any future framework will need to address the 'neutrality' of standards and networks, if we do not want our big walled fortress to be replaced by many little walled fortresses.

The new framework should put the audience at the centre of the model, not off to one side Business models, value chains, regulatory frameworks: these all refer to who pays who to do what, and who has to pay what to whom. In these constructions, the audience is only considered in passing, if at all, with various rules and regulations requiring it to buy various rate-regulated services in various rate-regulated bundles. Allan Sawyer argues that "today's consumer clearly has choices on how they acquire their content and the number of choices will increase in the near term."134

New audio and visual technologies are shifting that locus of control. Creation, aggregation, distribution, and consumption are becoming the domain of the customer, not

${ }^{133}$ Geist, M. "Keep Networks Neutral." Ottawa Citizen. December 22, 2005. E4.

${ }^{134}$ Ibid. 
the centralized firm. Already, much of the content that crosses centralized networks, through the policy gates, can be 'time-shifted' -content that was previously available in regimented schedules only can now be consumed anytime. Portable media devices mean that 'space-shifting' is also possible -content that was previously limited to the livingroom space can now be easily transported anywhere. This means that any rule or regulation predicated on being able to limit a signal to one device, location or timeframe will become decreasingly effective as the adoption of these new personalized consumption habits picks up speed.

Already, some steps have been taken by regulators to re-focus the transaction on the consumer -wireless number portability, for example. However, the liberating potential of this measure will be greatly dampened by the non-negotiable, three-year binding contracts that are the take-it-or-leave it bargain between wireless phone companies and their customers (portable numbers are of little use to someone contractually unable to switch phone companies without being hit with expensive penalties). Again, any examination of any particular link in the value chain, or any aspect of the business model, must take into account all other links and aspects. We live in an integrated communications field, so to be credible, the regulatory framework that applies to it has to be just as integrated.

Above all, any new policy must take into account the ability of audiences to find the content they want, at the price they want, on the device they want. The impact of any rule or regulation on consumers has to take greater prominence in regulatory proceedings. 
To that end, it is worth noting that in the current CRTC proceedings on digital migration, high definition, and broadcasting to mobile phones, not one consumer group has intervened -an indication that the 'dialogue' has become overly internalized by virtue of the highly-technical nature of our micro-regulatory approach to broadcasting. What does it say about the level of 'public interest' in the regulatory framework when the public is unable to participate in the regulatory process?

\section{It should be affirmative, not protectionist}

Any future framework has to separate the unrelated arguments about economies of scale, and Canadian content. While it is true that American producers enjoy certain advantages over Canadian producers by virtue of their immense domestic market, this holds true independently of the idea that exposure to their work is somehow harmful for Canadians. Economies of scale certainly privilege American producers, who can amortize the cost of their work across a much larger domestic market. But this advantage holds true in many sectors of the economy, not just in broadcasting. Moreover, those advantages bear no relation to the values being conveyed in their work: Canadian producers working in Hollywood, and American producers working in Canada, are still subject to these economies of scale. But we do not count most of their work, in either case, as Canadian.

The argument that Canadian content benefits us in ways that foreign content does not is often conflated with the argument that there are natural advantages to producing broadcast programming in the United States. But in fact, these two arguments are unrelated articles: those economic advantages would still be there even if Hollywood 
produced nothing but Canadian content. The supposed benefits of Canadian content bear no relation to the cost of the work itself: either it is beneficial, or it is not. But whenever the question is asked "why do we need Canadian content quotas," the answer invariably comes back "to counteract the natural advantages of American producers." The industrial objective passes for a cultural one.

The effect is to reduce 'Canadian culture' to a low-budget version of American culture, our 'values' dependent on programming that, for the most part, looks and feels just like American programming, but on a smaller budget. Transposing popular American formats into Canadian settings, and filling up the script with topical Canadian references, suggests that Canadian values are simply American values in Canadian clothing. This is hardly a satisfying picture of what it means to be Canadian.

For any future framework to be credible, it has to shed our current protectionist impulses. The idea of a centralized authority controlling a one-way flow of broadcasting traffic, instilling a uniform Canadian identity on the audience, is completely out of touch with how content is produced, distributed, and consumed. The official view of Canada envisioned by our broadcasting policy is of a country that it is the product of the institution, rather than of its citizens' creativity. This is not an affirmative view of Canadian culture.

It has never been reasonably demonstrated that the nationality of a creator or financier has any cultural bearing on the messages contained in the programming they produce. 
This is not the same thing as saying that a Canadian marketplace devoid of programming created by Canadians is a desirable thing. But examples abound of Canadian creators who work outside of the walled policy space, and who do very well. ${ }^{135}$

Canadians producers may be helped to market by our broadcasting policy, but it is obvious that Canadian content gets produced outside of the official policy confines as well. To suggest otherwise is again to place the institution at the centre of the equation, rather than creators or their audience - this is a highly patronizing model.

It is likely that purchasing or renting the geographic rights to programs, arranging them into a schedule, draping a brand over the whole thing, and selling it, through a distributor, to a customer, will soon no longer be a good business to be in. Content producers will have many ways to reach their audience directly, channels that do not require businesscontrolled or government-mandated packaging. Our current broadcasting policy, which is predicated on that packaging, will likewise be unsustainable.

In short, as more and more content gets past the walls, it is time we got past the official need to maintain them. The communications field has never been more open, yet our broadcasting policy has never been more removed from the ways in which people actually communicate.

\footnotetext{
${ }^{135}$ To cite one current example, Montreal band The Arcade Fire was nominated for a 2006 Grammy Award for Best Alternative Album. Meanwhile, no songs from The Arcade Fire currently appear among the top 100 songs getting radio airplay in Canada for 2005 , meaning that they received no benefit or assistance from Canadian content quotas. Nielsen Broadcast Data Systems. See: http://jam.canoe.ca/Music/Charts/BDS 1.html
} 


\section{Bibliography}

Acheson, K. and Maule, C. (2001). Much Ado about Culture: North American Free Trade Disputes. Ann Arbor: University of Michigan Press

Adamson, R. "Will we benefit from UN pact on cultural diversity?" Toronto Star, October 30, 2005. A16.

Anderson, B. (1983) Imagined Communities: Reflections on the Origin and Spread of Nationalism. London: Verso.

Anderson, C. "The Long Tail." Wired Magazine online. December 10, 2004: http://www.wired.com/wired/archive/12.10/tail.html

Attallah. and Foster, D. (2002) "Television in Canada. In Mediascapes: New Patterns in Canadian communication. Toronto: Nelson Canada. (216-234).

Beale, A. (1993) Harold Innis and Canadian Cultural Policy in the 1940s. The Australian Journal of Media \& Culture, Vol,7 No 1.

Binder, M. Remarks made during a panel discussion "High Definition Television: There is no looking back" International Institute of Communications annual conference, Ottawa, December 12, 2005.

Bird, Roger ed. (1988) Documents of Canadian Broadcasting. Ottawa: Carleton University Press.

Bloomberg News. "Google Cites Flaws in its Video Store." January 26, 2006:

http://www.latimes.com/business/la-figoogle26jan26,1,521949. story?ctrack $=1$ \&cset $=$ true .

Bristow, J. (2003) Canada and the Cultural Trade Quandary: Rethinking National Identity, Economic Liberalization and Policy Capacity. Doctoral dissertation, Carleton University.

Brooker, Peter. (2003) A Glossary of Cultural Theory, second edition. New York: Oxford University Press Inc.

Carey, J. W. (1988) Communication and Culture: Essays on Media and Society. New York: Routledge.

Cable and Telecommunications Association for Marketing. On-Demand Consortium Report. May 5, 2005.

http://www.forrester.com/Research/Document/Excerpt/0,7211,35144,00.html 
Canadian Association of Broadcasters. Reply to Public Notice CRTC 2004-47 and Public Notice CRTC 2004-48 (PN 2004-48): Proposal by the Canadian Cable Television Association and Application No. 2003-1177-0 by Vidéotron ltée, respecting the use of the local availabilities of non-Canadian satellite services, October 7, 2004:

http://www.cabacr.ca/english/research/04/sub_oct0704.pdf

Canadian Film and Television Producers Association Profile 2005: http://www.cftpa.ca/newsroom/pdf_profile/profile2005-english.pdf

Canadian Press. "Companies bid to import top US channels to boost revenues." June 23, 2003.

Canadian Radio-television and Telecommunications Commission. CRTC Broadcast Policy Monitoring Report 2004:

http://www.crtc.gc.ca/eng/publications/reports/PolicyMonitoring/2004/gic2004.htm

Canadian Radio-television and Telecommunications Commission. CRTC Broadcast Policy Monitoring Report 2005:

http://www.crtc.gc.ca/eng/publications/reports/PolicyMonitoring/2005/bpmr2005.htm

Canadian Radio-television and Telecommunications Commission. CRTC Letter to CCTA. November 7, 2003: http://www.crtc.gc.ca/archive/ENG/Letters/2003/lb031107.htm).

Canadian Radio-television and Telecommunications Commission. Individual financial date for specialty and pay services 1999-2003:

http://www.crtc.gc.ca/eng/publications/reports/BrAnalysis/p\&sp2003/individual/Cover.ht $\underline{\mathrm{m}}$

Canadian Radio-television and Telecommunications Commission. Policies Respecting Broadcasting Receiving Undertakings (Cable Television) December 16, 1975.

Coalition of Canadian Audio-visual Unions, submission to the CRTC re Public Notice CRTC 2003-54: Support for Canadian Television Drama. November 28, 2003 : http://www.actra.ca/actra/images/03dec/CCAU-DRAMA\%20BRIEF.pdf

Copyright Board of Canada. Reasons for the decision certifying the tariffs in respect of commercial radio for the years 2003 to 2007, October 14, 2005: http://www.cbcda.gc.ca/decisions/m14102005-b.pdf

Coyne, A. “Against Art Subsidies." Next City Magazine, Fall 1996:

http://www.andrewcoyne.com/Essays/Magazines/Next $\% 20 \mathrm{City} /$ Against $\% 20 \mathrm{arts} \% 20$ subs idies.rtfd/TXT.html

Coyne, A. "Let the viewers decide." National Post. September 24, 2005, A15.

Coyne, A. "The Con we call Cancon." National Post, June 18, 2005, A16. 
Cowen, T. (2002). Creative Destruction: How Globalization is Changing the World's Cultures. Princeton: Princeton University Press.

Cowen, T. (2000). Culture and the Global Economy: The 2000 Hans L. Zetterberg Lecture. Stockholm: City University Press.

Currie, D. Hooper, R. Carter, S. OFCOM review of public service television broadcasting: phase 1-Is television special? March 21, 2004.

Davidson, S. "They have seen the future. Or not. No easy answers as CAB looks at new technologies." Playback Magazine, November 7, 2005, 7

Davidson, S. "Mobile biz gets moving." Playback Magazine, January 23, 2006, 1.

Dalfen, C. Address to the Canadian Association of Broadcasters annual convention, Ottawa, November 29, 2004.

Dalfen, C. Address to the Broadcast Executives Society, Toronto, April 12, 2005.

Decima Research. The Digital Domain: Tracking the Growth and Development of the Canadian Digital TV Distribution Market. September 1, 2005.

Decision CRTC 96-259 StarChoice Television Network Inc. August 27, 1996: http://www.crtc.gc.ca/archive/eng/Decisions/1996/DB96-529.htm)

Decision CRTC 97-87 Application for a new direct-to-home satellite distribution undertaking -approved. February 27, 1997:

http://www.crtc.gc.ca/archive/ENG/Decisions/1997/DB97-87.HTM

Decision CRTC 97-38 Shaw Communications, on behalf of an company to be incorporated (Homestar). January 31, 1997:

http://www.crtc.gc.ca/archive/eng/Decisions/1997/DB97-38.htm

Decision CRTC 2004-271 CHOI-FM: non-renewal of Licence, July 14, 2004:

http://www.crtc.gc.ca/archive/ENG/Decisions/2004/db2004-271.htm

Decision CRTC 2005-49 Rogers on Demand-Licence Amendments. October 18, 2005: http://www.crtc.gc.ca/archive/ENG/Decisions/2005/db2005-497.htm

Decision CRTC 2005-246. Canadian Satellite Radio Inc, June 16, 2005 :

http://www.crtc.gc.ca/archive/ENG/Decisions/2005/db2005-246.htm

Decision CRTC 2005-247. Sirius Canada Inc, June 16, 2005:

http://www.crtc.gc.ca/archive/ENG/Decisions/2005/db2005-247.htm 
Decision CRTC 2005-248. Chum Ltd, on behalf of a corporation to be incorporared, June 16, 2005: http://www.crtc.gc.ca/archive/ENG/Decisions/2005/db2005-248.htm

Dick, T. "What is the Frequency Cancon?" This Magazine, September-October 2005, 13.

Dorland, M. (1991) The War Machine: American Culture, Canadian Cultural Sovereignty, and Film Policy. Canadian Journal of Film Studies. V.1 no. 2, 1991, 35-48.

Dorland, M. (Ed.) (1996) The Cultural Industries in Canada: Problems, Policies, and Prospects. Toronto: James Lorimer \& Co.

Fellows, C.M., Flanagan, G. and Shedd, S. (1997) Economic Issues: a Canadian perspective. Toronto: McGraw Hill.

Fortier, J. "Do we still need the CBC? No." Toronto Star, August 29, 2005, A19.

Fraser, J. "Let consumer choice save our media." Toronto Star. May 12, 2003, A19.

Fraser, M. (1999) Free for All the struggle for dominance on the digital frontier. Toronto: Stoddart Publishing.

Fraser, M. (2002) "It is time for the CBC to get out of advertising." National Post, March 18 2002, F3.

Fraser, M. (2003) "Canadian pop music does not need the CRTC." National Post, April 7, 2003, F3.

Frulla, L. "How Culture Defines Who we Are." Speaking notes for an address to the Canadian Club of Toronto, May 9, 2005: http://www.pch.gc.ca/pc-ch/min/discoursspeech/2005-05-09_e.cfm

Galloway, G. "Broadcasters offered ads for home-grown drama." Globe and Mail, November 30, 2004, B7.

Geist, M. (2005a) "Cancon in the internet age: CRTC's pay-radio decision benefits both musicians and listeners." Ottawa Citizen, June 23, 2005, F6.

Geist, M. (2005b) "Keep Networks Neutral." Ottawa Citizen. December 22, 2005, E4.

Giroux, R. "Coderre sonne la charge contre le CRTC." Le Soleil, September 16, 2005, A10.

Globe and Mail. Editorial, no title. June 17, 2005, A12.

Globe and Mail. Editorial, "Beyond the network mindset." April 13, 1995, C1. 
Globe and Mail. Editorial "Canada's outmoded broadcast regulator." June 17, 2005, A12.

Globe and Mail. "Explain Canada, Boyle tells broadcasters." April 19, 1977.

Goldstein, K. "What works: Some practical considerations for the role of the state in broadcasting." Paper presented to the International Seminar on the Role of the State in Broadcasting. McGill University, Montreal. January 25, 2005.

Grant, Keenelyside, A., Buchanan, G. The 2004 Canadian Broadcasting Regulatory Handbook, and the Regulatory Guide to Canadian Television Services. (Toronto): McCarthy Tétrault, 2004.

Grant, and Wood, C. (2004). Blockbusters and Trade Wars: Popular Culture in a Globalized World. Toronto: Douglas and McIntyre.

Grimes, C. "Play it again -Napster proved there was a demand for online music." The Financial Times. August 29, 2001.

Hampson, S. "Good at the talking part." Globe and Mail. February 19, 2005, R3.

Industry Canada: Satellite-Use Policy to accommodate Broadcasting Services to the Canadian Public, September 26, 2005: http://strategis.ic.gc.ca/epic/internet/insmtgst.nsf/en/sf08453e.html

Innis, H. A. (2003) The Bias of Communication, 11th edition. Toronto: University of Toronto Press.

Innis, H. A. (1986) Empire and Communication. Toronto: Press Porcépic.

Jeffrey, L. (1996) Private Television and Cable. In Michael Dorland (Ed.) The Cultural Industries in Canada: Problems, Policies, and Prospects. (p 253-256) Toronto: James Lorimer \& Co.

Kedorsky, "Irrelevant CRTC tithes satellite radio." National Post. Jnune 18, 2005, FP17.

Lippman, A. Keynote address to the Canadian Association of Broadcasters' annual convention. November 7, 2005. Winnipeg.

Martin, D. "2005: A space odyssey for a nation of music lovers." Ottawa Citizen, June $17,2005, \mathrm{E} 4$.

McArthur, K. and Robertson, G. "CRTC ponders impact of product placement." Globe and Mail, November 21, 2005, B1. 
McFayden, Hoskins and Finn. (2000) Cultural Industries from an Economic/Business Research Perspective. Canadian Journal of Communications online, Vol 25. No 1. http://www.cjc-online.ca/viewarticle.php?id=569\&layout $=h t m l$

McLean, C. "Television's penetration my force policy review." Globe and Mail. January $18,2006, \mathrm{~B} 3$.

McQuiag, L. "Will we benefit from U.N. pact on cultural diversity?" Toronto Star, October 30, 2005, A16.

Montreal Gazette, "Prove you're Canadian: Feds to Berton." December 21, 2001.

Morrison, I. "Pay radio ruling favours Americans." Toronto Star. June 28, 2005, A15.

Murphy, R. "Locked out, tuned out, treasured." Globe and Mail. September 3, 2005, A19.

Nimijean, R. "Do we still need the CBC? Yes." Toronto Star. August 29, 2005, A19.

Olsen, S. "Record Labels Sue Napster." CNET News.com ,April 22, 2003

http://news.com.com/2100-1027-997860.html

Our Cultural Sovereignty: the second century of Canadian broadcasting. Report of the Standing Committee on Canadian Heritage, 2003.

http://www.parl.gc.ca/InfoComDoc/37/2/HERI/Studies/Reports/herirp02-e.htm

Peers, F.W. (1979) Television and the Politics of Canadian Broadcasting 1952-1968. Toronto: University of Toronto Press.

Peters, J.D. (1999) Speaking into the Air: a history of the idea of Communication. Chicago: University of Chicago Press.

Posner, M. "TV producers blast fund's 'parochial' Canadian-content rules." Globe and Mail, February 14, 2005, R7.

Proceedings of the Senate Standing Committee on Banking, Trade and Commerce, Senate of Canada, Issue No. 93, June 16, 1976

Proudfoot, S. "With a Canadian location, director and crew, acclaimed film still too 'foreign' for Genie nod." Ottawa Citizen. January 27, 2006, A1.

Public Notice CRTC 1993-74, Structural Public Hearing, June 3, 1993: http://www.crtc.gc.ca/archive/ENG/Notices/1993/PB93-74.HTM 
Public Notice CRTC 1994-118, Exemption Order Respecting Experimental Video-onDemand Programming Undertakings, September 16, 1994:

http://www.crtc.gc.ca/archive/ENG/Notices/1994/PB94-118.HTM

Public Notice CRTC 1995-217 Introductory Statement-licensing of new direct-to-home (DTH) satellite distribution undertakings, and new DTH pay-per-view (PPV)television programming undertakings, December 20, 1995:

http://www.crtc.gc.ca/archive/ENG/Notices/1995/PB95-217.htm)

Public Notice CRTC 1997-25, New regulatory framework for broadcasting distribution undertakings, March 11, 1997: http://www.crtc.gc.ca/archive/ENG/Notices/1997/PB9725.HTM

Public Notice CRTC 1997-83, Licensing of New Video-On-Demand Programming Undertakings - Introduction to Decisions CRTC 97-283 to 97-287, July 2, 1997: http://www.crtc.gc.ca/archive/ENG/Notices/1997/PB97-83.HTM

Public Notice CRTC 1997-96, Revised list of eligible satellite services, July 22 1997: http://www.crtc.gc.ca/archive/ENG/Notices/1997/PB97-96.HTM

Public Notice CRTC 1997-150, Broadcasting Distribution Regulations, December 22, 1997: http://www.crtc.gc.ca/archive/ENG/Notices/1997/PB97-150.HTM

Public Notice CRTC 1998-41, Commercial Radio Policy, April 30, 1998 :

http://www.crtc.gc.ca/archive/ENG/Notices/1998/PB98-41.HTM

Public Notice CRTC 1999-84, New Media May 17, 1999 :

http://www.crtc.gc.ca/archive/ENG/Notices/1999/PB99-84.htm

Public Notice CRTC 1999-97, Building on Success, a policy framework for Canadian television, June 11, 1999: http://www.crtc.gc.ca/archive/ENG/Notices/1999/PB9997.HTM

Public Notice CRTC 1999-197, exemption Order for New Media Undertakings, 17 December 1999: http://www.crtc.gc.ca/archive/ENG/Notices/1999/PB99-197.HTM

Public Notice CRTC 2000-6, Licensing framework policy for new digital pay and specialty services, January 13, 2000:

http://www.crtc.gc.ca/archive/ENG/Notices/2000/PB2000-6.htm

Public Notice CRTC 2001-62, Call for comments on a proposed policy to oversee the transition from analog to digital over-the-air television broadcasting, 5 June 2001: http://www.crtc.gc.ca/archive/ENG/Notices/2001/PB2001-62.htm 
Public Notice CRTC 2002-31, A licensing policy to oversee the transition from analog to digital, over-the-air television broadcasting, 12 June 2002:

http://www.crtc.gc.ca/archive/ENG/Notices/2002/pb2002-31.htm

Public Notice 2003-61, The regulatory framework for the distribution of digital television signals, October 30, 2003: http://www.crtc.gc.ca/archive/ENG/Notices/2003/pb200361.htm.

Public Notice 2004-2 Introduction to Broadcasting Decisions CRTC 2004-6 to 2004-47, renewing the licenses of 22 specialty services, January 21, 2004.

http://www.crtc.gc.ca/archive/ENG/Notices/2004/pb2004-2.htm

Public Notice CRTC 2004-50 Requests to add non-Canadian Third-language Services to the lists of eligible satellite services for distribution on a digital basis, July 15, 2004: http://www.crtc.gc.ca/archive/ENG/Notices/2004/pb2004-50.htm

Public Notice CRTC 2004-18, Amendments to the Broadcasting Distribution Regulations-implementation of the policy framework for community based media, March 30, 2004: http://www.crtc.gc.ca/archive/ENG/Notices/2004/pb2004-18.htm

Public Notice CRTC 2004-50 Requests to add non-Canadian third-language services to the list of satellite services eligible for distribution on a digital basis, July 15, 2004: http://www.crtc.gc.ca/archive/ENG/Notices/2004/pb2004-50.htm

Public Notice CRTC 2004-93, Incentives for English-language Canadian Television Drama, November 29, 2004: http://www.crtc.gc.ca/archive/ENG/Notices/2004/pb200493.htm

Public Notice CRTC 2004-96 Improving the diversity of third-language television services - A revised approach to assessing requests to add non-Canadian third-language television services to the lists of eligible satellite services for distribution on a digital basis, December 16, 2004: http://www.crtc.gc.ca/archive/ENG/Notices/2004/pb200496.htm

Public Notice CRTC 2005-9 Distribution of Spike by Broadcasting Distribution Undertakings, January 27, 2005:

http://www.crtc.gc.ca/archive/ENG/Notices/2005/pb2005-9.htm

Public Notice CRTC 2005-24 Commission's response to the report of Task Force for Cultural Diversity on Television. 21 March 2005: http://www.crtc.gc.ca/archive/ENG/Notices/2005/pb2005-24.htm

Public Notice CRTC 2005-61, Introduction to Broadcasting Decisions CRTC 2005-246 to 2005-248: Licensing of new satellite and terrestrial subscription radio undertakings, June 16 2005: http://www.crtc.gc.ca/archive/ENG/Notices/2005/pb2005-61.htm 
Public Notice CRTC 2005-82, Call for comments on a regulatory framework for mobile broadcasting services, September 12, 2005:

http:/www.crtc.gc.ca/archive/ENG/Notices/2005/pb2005-82.htm

Public Notice CRTC 2005-98, Distribution and Linkage Rules for Class and Class 2 Licensees, October 27, 2005: http://www.crtc.gc.ca/archive/ENG/Notices/2005/pb200598.htm

Public Notice CRTC 2006-9 Revised list of eligible satellite services, January 6, 2006: http://www.crtc.gc.ca/archive/ENG/Notices/2006/pb2006-9.htm

Raboy, M. (1990) Missed opportunities, the story of Canada's broadcasting policy. Montreal: McGill-Queen's University Press.

Raboy, M. (1996) "Rhetorics of the Divided Voice." Journal of Canadian Studies. Winter 1996/1997:

http://www.findarticles.com/p/articles/mi qa3683/is_199601/ai n8750441

Report of the Auditor General of Canada: Support to cultural industries. November 5, 2005 http://www.oag-bvg.gc.ca/domino/reports.nsf/html/20051105ce.html

Report of the Deputy Minister of Public Works, Sessional Papers No. 19 (1st session, 9th Parliament), December 24, 1900.

Roche, M. (1992) Rethinking Citizenship: Welfare Ideology and Change in Modern Society. Cambridge: Polity Press.

Rosenberg, S. "As you kiss your tired old CDs goodbye, imagine a broadband future that is not like the Broadcast Past." Salon.com, February 4, 2000:

http://www.salon.com/tech/col/rose/2000/02/04/napster_swap/

Rosmarin, R. "Google goes gaga for video." Forbes.com, January 12, 2006: http://www.forbes.com/digitalentertainment/2006/01/11/google-video-rightscx_r_ 0112googlevid.html

Sawyer, A. (2006) The end of television as we know it: a Canadian perspective. Draft report prepared for IBM Business Consulting Services.

Schiller, H.I. (1989) Culture Inc, The Corporate Takeover of Public Expression, New York: Oxford University Press.

Statistics Canada. Daily Bulletin. December 12, 2005:

http://www.statcan.ca/Daily/English/051212/d051212a.htm

Smith, M. "Miles of Tape, Reams of Paper." Globe and Mail. May 1, 1971. 
Smythe, D. W. (1981) Dependency Road: Communications, Capitalism, Consciousness and Canada. Norwood: Ablex Publishing Corp.

Taylor, K. "I turn on Corner Gas, I get the Sears wishbook?" Globe and Mail. November 19, 2005, R2.

The end of Television as we know it, report from IBM Business Consulting Services. January 27, 2006: http://www-

1. ibm.com/services/us/index.wss/ibvstudy/imc/a1023172?cntxt=a1000062

The Uncertain Mirror: Report of the Special Senate Committee on Mass Media, 1970. Ottawa: Queen's Printer for Canada.

Toronto Star. Editorial. "Your show of shows." March 23, 1979.

Trudeau, P. E. "Trudeau Speaks Out” Maclean's, September 28, 1992. Vol. 105, No. 39, 22-26.

Viera, "CanWest seeks to reform cable fee 'imbalance'." National Post, December 1, 2004.

Walsh, D. "Heineken calls last orders on TV ads after 30 years." London Times, October 21, 2005: http://business.timesonline.co.uk/article/0,9071-1836183,00.html

Williams, R. (1981) Culture. London: Collins.

Williams, R. (1974) Television, Technology and Cultural Form. London: Collins.

Winter J. and Goldman, I. (1995) In Singer, B. (Ed.) Mass Media and Canadian Identity. In Communications and Canadian Society, 4th edition. Scarborough: Nelson Canada. $\mathrm{p}$ 201-220.

Vogel, H.L. (2001) Entertainment Industry Economics: a guide for financial analysis5th edition. Cambridge: Cambridge University Press. 